Portland State University

PDXScholar

Fall 12-5-2017

\title{
Non-Native Mangroves (Rhizophora mangle) of Moloka'i, Hawai'i: a Socio-Ecological Analysis
}

Casey Lynette Lewis

Portland State University

Follow this and additional works at: https://pdxscholar.library.pdx.edu/open_access_etds

Part of the Environmental Sciences Commons

Let us know how access to this document benefits you.

\section{Recommended Citation}

Lewis, Casey Lynette, "Non-Native Mangroves (Rhizophora mangle) of Moloka'i, Hawai'i: a SocioEcological Analysis" (2017). Dissertations and Theses. Paper 4074.

https://doi.org/10.15760/etd.5958

This Thesis is brought to you for free and open access. It has been accepted for inclusion in Dissertations and Theses by an authorized administrator of PDXScholar. Please contact us if we can make this document more accessible: pdxscholar@pdx.edu. 
Non-Native Mangroves (Rhizophora mangle) of Moloka'i, Hawai'i:

A Socio-Ecological Analysis

by

Casey Lynette Lewis

A thesis submitted in partial fulfillment of the requirements for the degree of

\author{
Master of Science \\ in \\ Environmental Science and Management
}

Thesis Committee:

Elise F. Granek, Chair

Angela L. Strecker

Max Nielsen-Pincus

Portland State University

2017 
(C) 2017 Casey Lynette Lewis 


\begin{abstract}
The formation of novel ecosystems by non-native species poses management challenges that are both socially and ecologically complex. This complexity necessitates consideration of both ecological dynamics and social attitudes and perceptions. Red mangrove propagules were introduced to Moloka'i, Hawaii in 1902 to mitigate the effects of soil erosion and they have since spread along the coast and to adjacent islands creating novel habitat. Non-native mangroves in Hawai'i present a unique case study to examine diverse social attitudes and perceptions resulting from a long history of land cover transformations on the Hawaiian Islands, socio-cultural diversity of involved stakeholders, and the potential array of ecosystem services they may provide under changing land use and climatic conditions.

Ecological dynamics were examined to (1) determine whether novel mangrove habitat affects zooplankton diversity and richness, (2) test the hypothesis that zooplankton community composition differs significantly among established mangrove and coastal non-mangrove habitat, and (3) assess other factors driving differences in zooplankton community assemblages. This study found no significant differences found between sites with and without mangroves in terms of richness, diversity, or community composition. However, lunar cycles and site dynamics, including fishpond structure, mangrove and open shoreline length, percentage of mangrove shoreline length, total percentage of carbon in mangrove leaves, and disturbance in the upstream watershed influenced zooplankton community composition. These findings suggest that non-native mangroves support community composition, richness, and diversity similar to non-
\end{abstract}


mangrove areas, though some widespread taxa have lower abundances in mangrove habitat. My research suggests that in the face of declining fisheries, threatened reef habitat, and changing climate and ocean conditions, mangroves may provide zooplankton habitat in novel locations similar to that provided by native habitat, such that habitat availability for zooplankton is not hindered by non-native mangroves.

To understand social dynamics 204 residents of Moloka'i, Hawaii were surveyed to evaluate: 1) attitudes and perceptions about this non-native species, 2) what factors influence these attitudes, and 3) how attitudes influence perceptions about management. A belief that mangroves should be removed, concern about threats to Moloka'i's coast, and not relying on mangroves for benefit were the primary drivers of negative attitudes towards non-native mangroves. Support for management actions was predicted by attitudes towards mangroves, perception and concern about threats to Moloka'i's coast, and experiences involving mangroves. I propose a framework for assessing and incorporating diverse perceptions and attitudes into decision-making around non-native species that have created novel ecosystems.

An active management approach allowing mangroves to thrive in certain locations and to provide services such as habitat and crabbing access while in other locations limiting their extent to protect native bird habitat and cater for human needs, including safe beach and ocean access, may ultimately offer the greatest benefits to both the ecosystem and society. As environmental issues, such as species introductions, become increasingly complicated in the age of the Anthropocene, with intricate relationships made more difficult in the face of climate change, integrated research in socio-ecological 
systems may provide a comprehensive approach to better evaluate and understand our changing world. 


\section{ACKNOWLEDGEMENTS}

Thank you to those who provided me with guidance and funding on this research; this project would not have been possible without this support. I would like to thank Portland State University for funding Dr. Elise Granek with a Faculty Enhancement Grant that made it possible to travel to Moloka'i and conduct research there.

Additionally, I would like to recognize the Edward D. and Olive C. Bushby Scholarship, which provided the funding necessary to conduct nutrient analysis.

To my adviser, Dr. Elise Granek, and my thesis committee members, Dr. Max Nielsen-Pincus and Dr. Angela Strecker, thank you for your expertise and guidance in all aspects of the project. I appreciate the perspective and always challenging me to push myself.

Working on Moloka'i provided me with the opportunity to work with many wonderful individuals and groups on the island. Thank you to Colette Machado for providing a warm island welcome and supplying introductions to key personnel. Raymond Leimana Naki was instantly welcoming and contributed instrumental assistance with field site determination, access, and assistance. Both Ka Honua Momona and their outstanding employees and Keawanui Fishpond provided assistance in the field and helped with finding survey participants. Thank you to the owners of the fishponds on Moloka'i for allowing me to access these historical sites.

Thank you, Joey Peters, for invaluable help in the field. Without your contribution, this project wouldn't have been as successful. For providing much needed logistical support prior to field work, thank you to Cordell and Jay Johnston. 
A very special thank you goes to the 204 respondents who took the time to fill out my survey and provide comments. This project would not have been possible without you.

To all of those that helped me with lab work, thank you for providing your time, knowledge, and entertainment. In particular, I would like to recognize, Andy Daws, Kim Hack, Steve Wells, and Bruce Mundy. Dr. Meredith Holgerson, thank you for your assistance with stable isotope analysis in addition to the numerous times we discussed research.

To my lab mates and peers, this experience would have been completely different without all your support; it has been a true pleasure working alongside all of you. A special acknowledgement to my lab mates, Amy Ehrhart, Jaclyn Teixeira, Britta Baechler, Bryn Hudson, Kaegan Scully-Engelmeyer, and Sabra Comet for their constant feedback and encouragement. Thank you to my family and friends for encouraging me throughout my master's work. And last but not least, thank you to the ESM office staff for their irreplaceable assistance and administrative support. 


\section{TABLE OF CONTENTS}

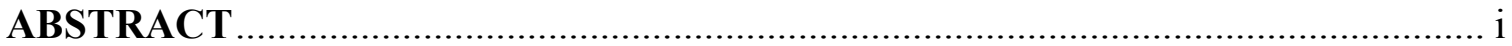

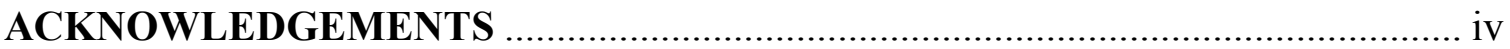

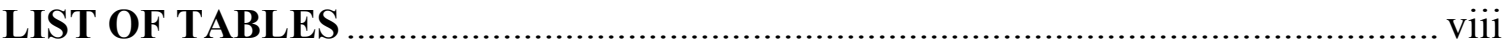

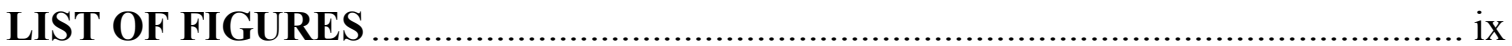

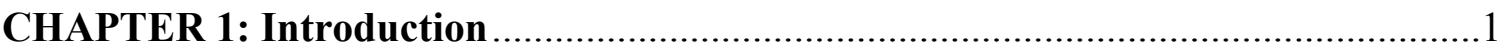

1.1 A history of human impacts and land-use changes on Moloka'i, Hawai'i ...............1

1.2 Brief history of invasive and non-native species ..............................................

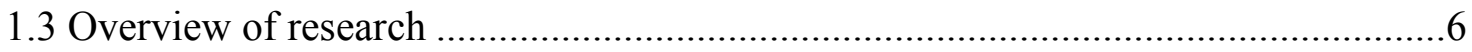

CHAPTER 2: Drivers of zooplankton community composition in a novel ecosystem 7

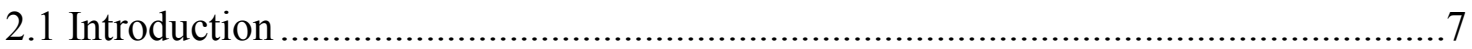

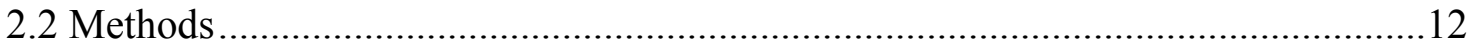

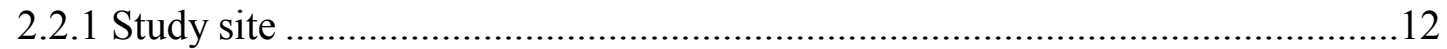

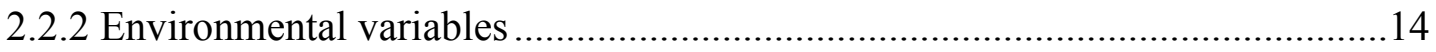

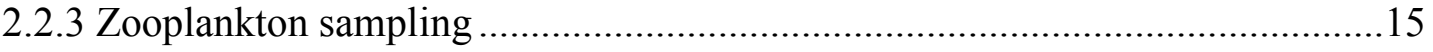

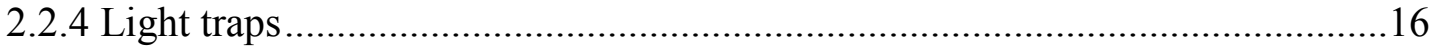

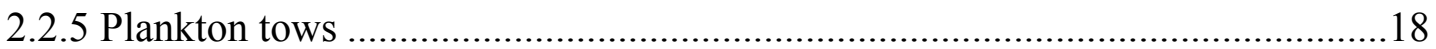

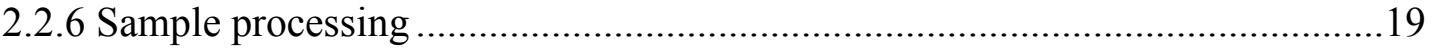

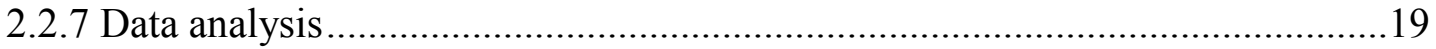

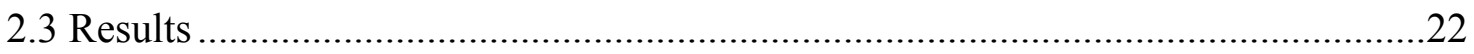

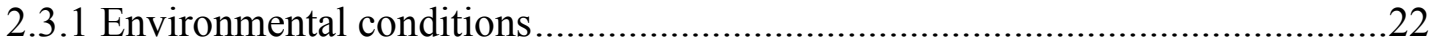

2.3.2 Variation in zooplankton assemblages among habitats ...............................25

2.3.3 Temporal variation in zooplankton assemblages.......................................44

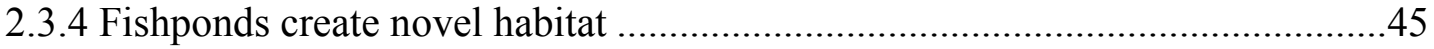

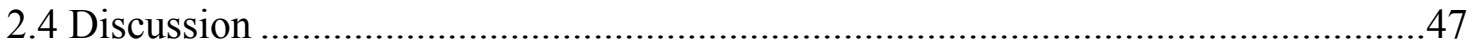

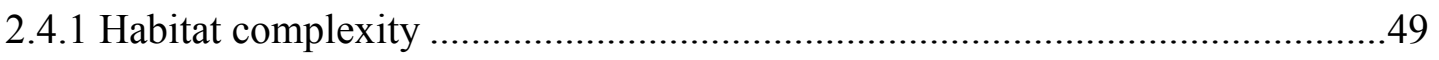

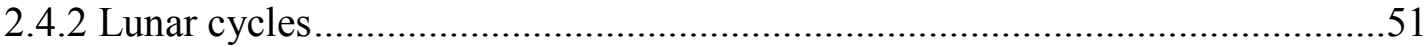

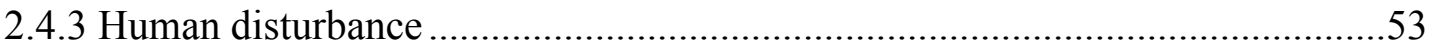

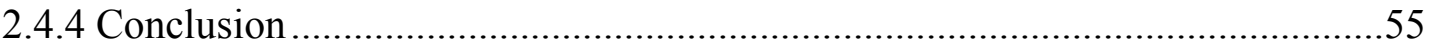


CHAPTER 3: Assessing local attitudes and perceptions of non-native species to

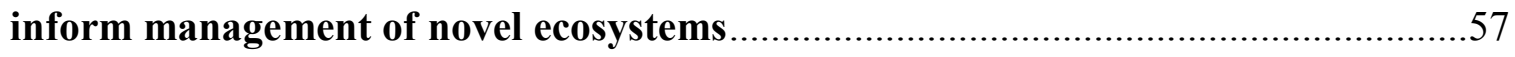

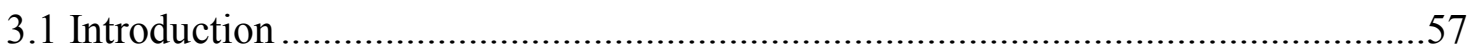

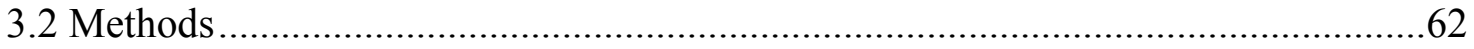

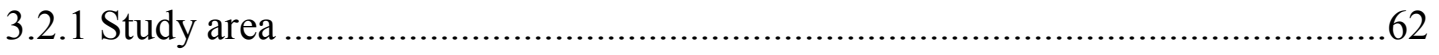

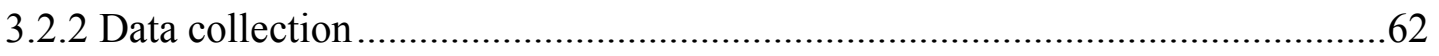

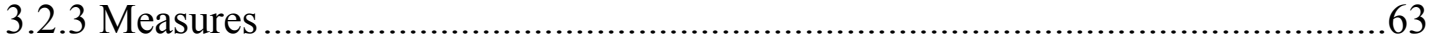

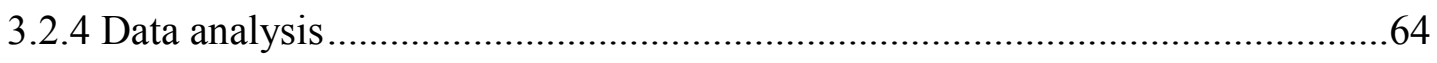

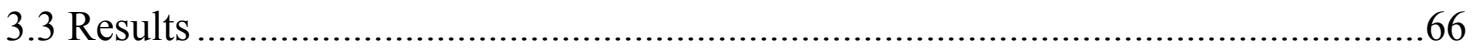

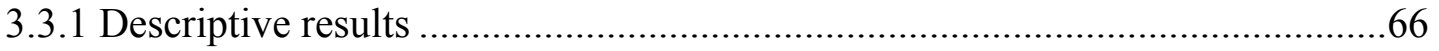

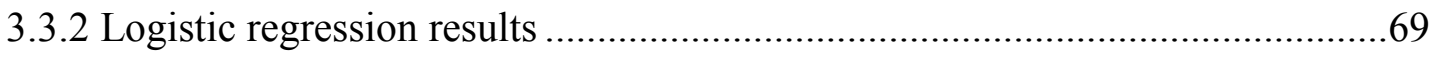

3.3.3 Ordinary least squares regression results............................................... 70

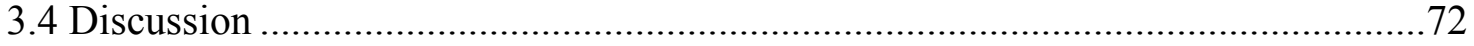

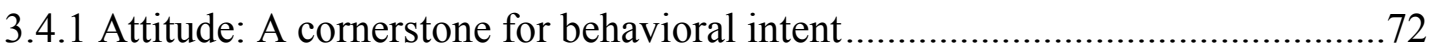

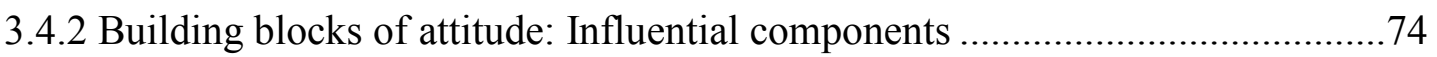

3.4.3 Attitudes and management: Assessing levels of management support .............76

3.4.4 Next steps: Education and management ................................................ 78

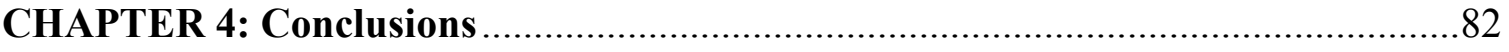

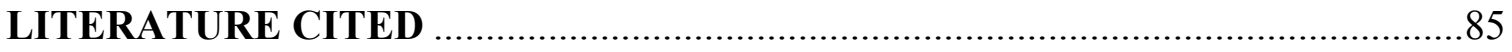

APPENDIX A. Zooplankton community composition supporting data.................110

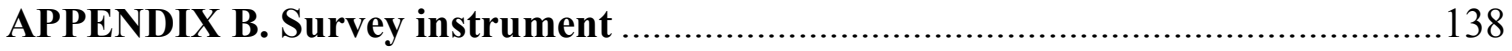

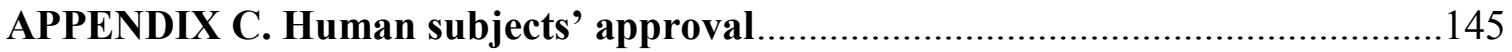

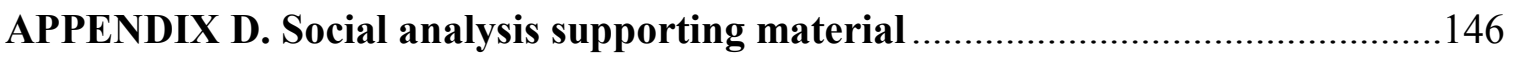




\section{LIST OF TABLES}

Table 2.1. Key environmental and watershed variables by site type

Table 2.2. Paired t-tests comparing richness and diversity of all mangrove and open coast sites, fishpond mangroves to fishpond open coast, and open coast mangrove to open coast non-mangrove for both sampling methods

Table 2.3. Envfit analysis of NMDS (excluding rare taxa) showing environmental variables co-varying with zooplankton community composition

Table 2.4. Envfit analysis of NMDS showing environmental variables co-varying with zooplankton community composition.

Table 2.5. Spearman correlation (positive $(+)$ and negative $(-)$ ) between taxon abundance and mangrove and open shoreline length. Bold indicates significant values; bold italics represent marginally significant values. $\mathrm{RA}=$ mean relative abundance

Table 2.6. Spearman correlation (positive $(+)$ and negative $(-)$ ) between taxon abundance and percentage of mature forest in the watershed. Bold indicates significant values; bold italics represent marginally significant values. $\mathrm{RA}=$ mean relative abundance 43

Table 3.1. Summary of demographic and place connection variables used in regression.66

Table 3.2. Summary of variables used in regressions. Some items were indexed using the average of items with conceptual consistency and high correlations; Cronbach's alpha $(\alpha)$ is reported as a measure of internal validity of indexed items.

Table 3.3. Logistic regression predicting differences between positive/neutral (0) and negative (1) attitudes towards non-native mangroves (coefficients are standardized). $\mathrm{N}=146$ (74 negative, 72 positive/neutral). McFadden $\mathrm{R}^{2}=0.47$, Nagelkerke $\mathrm{R}^{2}=0.64 . \mathrm{Chi}^{2}$ $\mathrm{p}=0.98$

Table 3.4. Ordinary least squares regression results predicting extent of support for mangrove management. Standardized coefficients are presented. ANOVA revealed no significant difference between the full and reduced models. 


\section{LIST OF FIGURES}

Figure 2.1. a) The island of Moloka' $i$ and its location in the Hawaiian Islands. b) Southeast Moloka'i with site locations. An example c) of a paired site within a fishpond and d) a paired site outside a fishpond. Blue arrows represent approximate sampling locations. Green pins indicate paired sites within fishponds and pink pins indicate paired sites outside of fishponds. ( $M$ open coast mangrove, $O$ open coast non-mangrove, $P M$ fishpond mangrove, $P O$ fishpond non-mangrove) .....

Figure 2.2. Diagram of zooplankton light trap design (from Granek and Frasier 2007; not to scale). .18

Figure 2.3. Comparison of proportional abundance values of major zooplankton groups among habitat type. a) Light trap sampling b) Plankton tow sampling ( $M$ open coast mangrove, $O$ open coast non-mangrove, $P M$ fishpond mangrove, $P O$ fishpond nonmangrove)

Figure 2.4. Boxplots of richness $(a, b)$ and Shannon diversity $(c, d)$ between habitat types and sampling method ( $M$ open coast mangrove $(\mathrm{n}=3), O$ open coast non-mangrove $(\mathrm{n}=$ 3), $P M$ fishpond mangrove $(\mathrm{n}=7), P O$ fishpond non-mangrove $(\mathrm{n}=7))$.

Figure 2.5. Nonmetric multidimensional scaling (NMDS) comparing zooplankton assemblages collected in light trap samples across site locations and habitat types. a. NMDS plot of study sites and types including environmental vectors driving community assemblages. ( $\mathbf{\Delta}$ = fishpond mangrove, $\Delta$ = fishpond non-mangrove, $\boldsymbol{O}$ = open coast mangrove, $\mathrm{O}=$ open coast non-mangrove, dark thick line $-\mathrm{p}=0-0.0001$, thin line $\mathrm{p}=0.001-0.01$, light dotted line $-\mathrm{p}=0.01-0.05) \mathrm{b}$. NMDS with taxa orientation. The number in parentheses following rare taxa $(<1 \%$ mean relative abundance) indicates the number of sites where the species was present. (Copepod $=\mathrm{CP}$, shrimp larvae $=\mathrm{SR}$, crab zoea $=\mathrm{CZ}$, amphipod $=\mathrm{AM}$, Monstrillidae $=\mathrm{MT}$, isopod $=\mathrm{IP}$, cumacean $=\mathrm{CM}$, fish larvae $=$ FS, Lucifer sp. $=\mathrm{LC}$, ostracod $=\mathrm{OC}$, bivalve larvae $=\mathrm{BV}$, crab megalopa (single rostrum $)=\mathrm{M} 1$, nauplius $=\mathrm{NP}$, polychaete $=\mathrm{PY}$, gastropod larvae $=\mathrm{GL}$, megalopa $($ double rostrum $)=\mathrm{M} 2$, mantis shrimp $=\mathrm{MS}$, mysid $=\mathrm{MY}$, lobster larvae $=\mathrm{LB}$, barnacle larvae $=\mathrm{BR}$, hydropoid $=\mathrm{HP}$, crab megalopa (other) $=\mathrm{MO}$, leech $=\mathrm{LC}$, nematode $=$ $\mathrm{NM}$, parasitic copepod, PC, jellies $=\mathrm{JF}$, post-larval $\mathrm{crab}=\mathrm{PLC}$, cephalopoda $=\mathrm{CL}) \ldots . .30$

Figure 2.6. Nonmetric multidimensional scaling (NMDS) comparing zooplankton assemblages collected in plankton tow samples across site locations and habitat types. a. NMDS plot of study sites and types with environmental vectors driving community assemblages. ( $\mathbf{\Delta}=$ fishpond mangrove, $\Delta$ = fishpond non-mangrove, $\boldsymbol{O}$ = open coast mangrove, $\mathrm{O}=$ open coast non-mangrove, dark thick line $-\mathrm{p}=0-0.0001$, thin line $\mathrm{p}=0.001-0.01$, light dotted line $-\mathrm{p}=0.01-0.05) \mathbf{b}$ NMDS with taxa orientation. The number in parentheses following rare taxa $(<1 \%$ mean relative abundance) indicates the number of sites where the species was present. (Abbreviations as in Figure 2.5)............32 
Figure 2.7. Nonmetric multidimensional scaling (NMDS) comparing zooplankton assemblages collected excluding rare taxa $(<1 \%$ mean relative abundance) collected in light trap samples across site locations and habitat types. a. NMDS plot of study sites and types including environmental vectors driving community assemblages. $(\boldsymbol{\Lambda}=$ fishpond mangrove, $\Delta=$ fishpond non-mangrove, $\mathbf{O}=$ open coast mangrove, $\mathbf{O}=$ open coast non-mangrove, dark thick line $-\mathrm{p}=0-0.0001$, thin line $-\mathrm{p}=0.001-0.01$, light dotted line $\mathrm{p}=0.01-0.05)$ b. NMDS with taxa orientation.

Figure 2.8. Nonmetric multidimensional scaling (NMDS) comparing zooplankton assemblages excluding rare taxa $(<1 \%$ mean relative abundance $)$ collected in plankton tow samples across site locations and habitat types. a. NMDS plot of study sites and types including environmental vectors driving community assemblages. $(\boldsymbol{\Lambda}=$ fishpond mangrove, $\Delta$ = fishpond non-mangrove, $\mathbf{O}=$ open coast mangrove, $\mathbf{O}=$ open coast non-mangrove, dark thick line $-\mathrm{p}=0-0.0001$, thin line $-\mathrm{p}=0.001-0.01$, light dotted line $\mathrm{p}=0.01-0.05)$ b. NMDS with taxa orientation.

Figure 2.9. Nonmetric multidimensional scaling (NMDS) comparing zooplankton assemblages across all site locations, habitat types, and time collected in a. light traps (stress $=0.19$ ) and $\mathbf{b}$. plankton tows (stress $=0.21$ ). Arrows indicate changes in composition over time at the same sampling location. ( $\boldsymbol{\Delta}$ = fishpond mangrove, $\Delta=$ fishpond non-mangrove, $\mathbf{O}$ = open coast mangrove, $\mathbf{O}$ = open coast non-mangrove) 44

Figure 2.10. Nonmetric multidimensional scaling (NMDS) comparing zooplankton assemblages between open sites and fishpond sites a. light traps (stress $=0.16)$ and $\mathbf{a}$. plankton tows (stress = 0.195). $(\boldsymbol{\Delta}$ = fishpond mangrove, $\boldsymbol{\Delta}$ = fishpond non-mangrove, $=$ open coast mangrove, $\mathbf{O}=$ open coast non-mangrove) ...........................................46

Figure 3.1. A framework for optimizing novel ecosystem management through consideration of stakeholder socio-cultural attitudes and values.

Figure 3.2. Case study findings in the framework for optimizing novel ecosystem management through consideration of stakeholder socio-cultural attitudes and values....77 


\section{CHAPTER 1: Introduction}

\subsection{A history of human impacts and land-use changes on Moloka'i, Hawai'i}

The Hawaiian archipelago is comprised of a long chain of volcanoes and their remnants that extends a total distance of about 2,400 km (Field et al. 2008). Moloka'i is the fourth oldest (out of eight) island in the chain with an east-west orientation and a relatively storm and wave protected south shore, allowing for development of one of the most extensive and continuous fringing coral reefs in the Hawaiian chain (Field et al. 2008). The island was formed by two volcanoes, on the west and east sides of the island, about 1.9 and 1.76 million years ago, respectively (Clague and Dalrymple 1989). The first people arrived on the island around 600 C.E. from other Pacific island nations (Alexander 1899, Bryan 1915, Roberts and Field 2008). With them they brought their customs and traditions, including a land management system called ahupua'a (Roberts and Field 2008, Kirch 1985, Roberts 2000). The ahupua'a system runs from the top of a watershed down to the coastal waters and adjacent reef (Kirch 1985, Weisler and Kirch 1985, Roberts 2000, Roberts and Field 2008). The first inhabitants farmed traditional staples from their homeland, including taro, sweet potatoes, sugar cane, bananas, coconut, breadfruit, ginger, pepper, and mulberry (Bryan 1915, 1954). The island saw minimal influence for the first four centuries of human inhabitance due to the population being small and scattered (Roberts and Field 2008).

During the next 400 years ( 1000 C.E.), anthropogenic activities began to leave visible changes on the landscape (Roberts and Field 2008). Stone works were constructed 
for keeping soil and water in place, including more than 50 fishponds for raising fish that were built on the reef flats of the south coast (Roberts 2000, Roberts and Field 2008). The broad fringing reef is on a gradual sloping coastal shelf, creating prime habitat for prehistoric fishing of shellfish, seaweed, octopus, and fish (Weisler and Kirch 1985). With many fishponds completed by the early $15^{\text {th }}$ century, ranging from one to several hundred acres with walls averaging $1.5 \mathrm{~m}$ high and $3 \mathrm{~m}$ thick, the structures altered the natural pathways for water and sediment and required constant maintenance to function for raising fish and to prevent them from filling with sediment (Kepler and Kepler 1991, Roberts and Field 2008).

In the 1770s, permanent change came to the people and habitat of Moloka'i as the Europeans landed on the island (Roberts 2000, Kirch 2007, Roberts and Field 2008). Captains James Cook and George Vancouver brought with them not only firearms and fast ships, but also introduced grazing animals and commercial farming, which led to swift changes to the hillsides and reefs over the next one hundred years (Bryan 1915, Roberts 2000, Roberts and Field 2008). While grazing animals were originally brought as a food source for explores upon their return, the Ali'i, or king, soon realized that the Hawaiians could also raise these animals to use and sell (Roberts 2000, Roberts and Field 2008). By the end of the 1800s, goats, swine, sheep, cattle and horses were thriving on the island (Roberts and Field 2008). Additionally, in 1870, King Kamehameha V sent his small herd of deer to Moloka'i (Bryan 1915, Judd 1936). Part of the grazers' success was due to Hawaiian vegetation having evolved without native grazing animals thus it had developed soft bark, tender greenery, and lacked thorns, and was defenseless against 
animals (Bryan 1954). Increased grazing pressure altered the vegetation, especially in the cooler upper reaches of the island watersheds (Roberts and Field 2008). This increased susceptibility of exposed areas to wind and rain, leading to large amounts of soil being transported and deposited on the low southern slopes and then eventually on the reef flat (Roberts and Field 2008).

Soil loss from the uplands, led to further habitat damage and variability in local microclimates (Roberts and Field 2008). Rainfall declined in the upland areas due to loss of thick foliage to block the wet, rising winds (Roberts and Field 2008). Numerous springs dried up and many communities abandoned efforts to raise grazing animals, leaving pigs and goats to turn feral and migrate to the high slopes (Kepler and Kepler 1991). Along with deer, these feral grazers fed on small plants and grasses and excavated roots, further contributing to soil loss (Bryan 1915, Roberts 2000, Roberts and Field 2008, Calhoun and Field 2008). As the wild animal population grew, the human population was declining with estimates of 10,500 people on Moloka'i in 1779 dropping to merely 2,307 in 1896 , leaving fewer people to hunt and keep the feral grazers in check (Summers 1971, Roberts and Field 2008).

In addition to animal introductions, two other activities adversely affected the south slopes of Moloka'i: sandalwood trade and plantation-style agriculture (Roberts 2000, Roberts and Field 2008). Sandalwood was highly prized in the Orient and although Moloka'i's sandalwood trees were smaller than those found on other islands, they were considered large enough to justify logging, causing additional soil erosion (Roberts and Field 2008, Calhoun and Field 2008). Plantation monoculture began in the 1800s with 
sugar cane but was later abandoned when it was discovered that the water being used was too salty (Keesing 1936, Roberts 2000). This industry left lasting impacts on the island including removal of native vegetation and introduced insects and diseases associated with sugar cane resulting in taro and some other vegetables no longer growing in certain locations (Roberts and Field 2008). The land clearing for monoculture increased the susceptibility of soils to erosion in the lower coastal areas and left lasting impacts on land-use patterns visible long after the industry disappeared (Gast 1982, Calhoun and Field 2008).

By the mid-1800s, as cattle ranching intensified, soil loss likely accelerated (Roberts and Field 2008). Cattle ranching led to damage from trampling and grazing and by the end of the 1800 s, sediment was deposited in the central lowland plains at a rate of one foot every six years (Cooke 1949, D’Iorio 2008). In the 1930s, the island was mostly devoted to pineapple cultivation and by the late $20^{\text {th }}$ century there were increases in agriculture, construction, and road building all adding to runoff of water and sediment (Roberts and Field 2008, Calhoun and Field 2008). Residents and visitors to Moloka'i increased in number in the second half of the 1900s resulting in the construction of hotels, condos, and housing developments and an increase in sewage discharge (Roberts and Field 2008). Coastal areas on south Moloka'i, and consequently the adjacent coral reef, have been altered significantly by human activities ranging from farming and ranching, to the introduction of feral grazers and development. 


\subsection{Brief history of invasive and non-native species}

John Henslow, an English botanist, first outlined the concept of nativeness in 1835 (Henslow 1835, Chew and Hamilton 2011, Davis et al. 2011). By the late 1840s, Hewett Watson published the apparent first definitions for the terms native and alien, which came from English common law, to distinguish plants that were aboriginal British species (Watson 1847, Chew and Hamilton 2011). In the following century, numerous botanists and a few zoologists described and studied introduced species (Davis et al. 2011). About 40 other researchers had published descriptions of non-natives by 1958 when British ecologist Charles Elton wrote The Ecology of Invasions by Animals and Plants, but consensus had not been reached on the appropriateness of intervening when alien species were introduced (Davis et al. 2011).

Invasion biology didn't become its own discipline until the $1990 \mathrm{~s}$, by which time military metaphors and overstated claims of imminent harm had become common language used by advocates of biodiversity preservation and ecological restoration furthering the spread of the idea that introduced species are the enemies of man and nature (Chew and Hamilton 2011, Davis et al. 2011). These phrases represent certain moral imperatives about what nature ought to be (Tassin and Kull 2015). Even at present, concepts of pre-Darwinian botany and pre-Victorian English common law dictate beliefs and understanding of ecological nativeness (Chew and Hamilton 2011). Whether intentional or not, these characterizations have helped to create a pervasive bias against introduced species that has been encompassed by the public, conservationists, land managers, policy makers, and scientists throughout the world (Davis et al. 2011). 


\subsection{Overview of research}

The likely continued presence of mangroves on Hawai'i presents an opportunity to gain a new perspective on their functional roles within tropical coastal ecosystems (Allen 1998). To better understand the effects of non-native mangroves on Moloka'i, especially with their long history of land use changes, a socio-ecological analysis was undertaken. My research objectives were to determine if mangroves are providing habitat for zooplankton communities (Chapter 2), and what local attitudes and perceptions of non-native mangroves are and how support of management options varies (Chapter 3). Zooplankton are a key component of marine ecosystems forming the base of most marine food webs (Turner and Tester 1997, Johnson and Allen 2012). This study begins to dissect how non-native species interact in novel environments in both ecological and social systems. Taking advantage of this opportunity to study mangroves where they have not colonized naturally can lead to advances in understanding mangroves' larger role in coastal ecosystems and make the best of non-native species introductions (Allen 1998). In the face of climate change, assessing established non-native's overall impact is becoming more important and by addressing both the ecological and social aspects of the issue, a more comprehensive picture can be obtained leading to more effective management. 


\section{Chapter 2: Drivers of zooplankton community composition in a novel ecosystem}

\subsection{INTRODUCTION}

Ecosystems around the globe are being transformed into new configurations that differ in composition and function from historic systems (Hobbs et al. 2009). These changes can result from altered species distributions (extinction and invasion) and environmental modification through climate and land use changes (Root and Schneider 2006, Harris et al. 2006, Hobbs et al. 2009, Truitt et al. 2015). Such species invasions have been recognized as a leading threat to ecosystems (Wilcove et al. 1998), with the United States alone spending more than $\$ 100$ billion annually in economic damages and control (Pimentel et al. 2005a).

Despite attempts to conduct investigations objectively and recognition that nonnative species may provide ecosystem services in areas where climate and land use are rapidly changing, bias against non-native species exists among researchers (Geesing et al. 2004, Shackleton et al. 2007, Gozlan 2008, Davis et al. 2011, Schlaepfer et al. 2011). Although invasive species can be damaging in new environments, their potentially beneficial role in supporting new or replacing previously lost ecosystem services in novel ecosystems is rarely studied (Charles and Dukes 2007a; but see Shackleton et al. 2007, Kull et al. 2011, Dickie et al. 2014, Vaz et al. 2017). Non-native species often provide benefit to some component of native biodiversity and can provide positive effects on certain ecological processes (Gozlan 2008, Katsanevakis et al. 2014, Vaz et al. 2017). Additionally, unintended consequences may result from restoration efforts to remove 
established non-native species in attempts to return ecosystems to a previous state (Zavaleta et al. 2001, Hobbs et al. 2009). For example, the non-native eucalyptus tree in California supports the native butterflies in locales where most of the original host plants have disappeared; eucalyptus management strategies now consider this role (Graves and Shapiro 2003). For many species, such as coastal mangroves, similar assessments remain to be conducted.

Mangroves are salt tolerant (halophyte) trees or shrubs adapted to life in the harsh conditions found in the intertidal zone in tropical and subtropical regions generally between $30^{\circ} \mathrm{N}$ and $30^{\circ} \mathrm{S}$ (Wester 1981, Giri et al. 2011). Where mangroves occur naturally, they provide a number of well documented ecological functions, goods, and services, most of which have considerable value to human society (Odum et al. 1982, Ewel et al. 1998). These include: protection from floods, sediment trapping, nutrient uptake and transformation, carbon sequestration, water quality improvement, plant products, and habitat (Ewel et al. 1998, Mcleod et al. 2011). Worldwide, mangroves are in decline due to agriculture, aquaculture, tourism, urban development, and overexploitation (Field et al. 2007, Giri et al. 2011) with an estimated 35\% loss between 1980 to 2000 (MA 2005).

Due to their services, mangroves have been introduced to locations where they did not colonize naturally (Allen 1998). For instance, significant land use changes began on Moloka'i, Hawai'i in the mid-to-late 1800 s and early 1900s with cattle ranching, which led to severe loss of native vegetation, upland erosion, and subsequent ocean sedimentation (Roberts 2000). Following overgrazing by cattle and sheep, there was 
extensive sugar cane and pineapple plantation agriculture that further aggravated sedimentation and runoff (Field et al. 2007). Eventually, many people abandoned efforts to raise grazing animals and, as a result, pigs and goats turned feral and migrated to the high slopes where their feeding continued to contribute to soil loss (Field et al. 2007). In an attempt to stabilize eroding coastal mudflats on the south coast near Pālā'au and to protect adjacent coral reefs, Rhizophora mangle (red mangrove) was introduced to Moloka'i in 1902 by the American Sugar Company (Wester 1981, Allen 1998, Field et al. 2007). Mangroves have since spread along the coast and to adjacent islands creating novel habitat (Allen 1998).

The spread of $R$. mangle has created a novel ecosystem with numerous ecosystem impacts, both beneficial and detrimental (Allen 1998). Allen (1998) states that mangroves have not displaced native wetland plant communities directly and appear to have a generally positive influence on sediment retention and water quality. However, mangroves may threaten ancient Hawaiian fishponds (Clark and Rechtman 2010), some of the most advanced aquaculture of the original people of the Pacific (US EPA, Region 9 2003). Numerous alien species use them to nest, while only a few native bird species (black crowned night heron - Nycticorax nycticorax hoactli and great blue herons - Ardea herodias) are known to use the mangroves (Allen 1998). In addition, four waterbirds endemic to the Hawaiian islands (Hawaiian duck - Anas wyvilliana, Hawaiian coot Fulica alai, Hawaiian stilt - Himantopus mexicanus knudseni, Hawaiian moorhen Gallinula chloropus sandvicensis) have suffered large declines in the last century due to 
other anthropogenic factors, but mangroves may be limiting waterbird recovery, as they use mudflats for foraging and nesting habitat (Allen 1998, Meyerson and Reaser 2003).

Despite some research on mangrove effects on waterbirds, there has been little research on the effects non-native mangroves have had on marine community structure. Studying mangroves where they did not colonize naturally provides an opportunity to better understand the impact and functional roles of a non-native plant on tropical coastal ecosystems (Allen 1998, Meyerson and Reaser 2003). Specifically, it is unknown whether non-native mangroves improve fisheries or provide nursery habitat, as they do in their native range (Wester 1981, Allen 1998, Meyerson and Reaser 2003). For example, removal of native mangroves can dramatically decrease coral reef fish community abundance and alter zooplankton community structure (Nagelkerken et al. 2001, Mumby et al. 2004, Granek and Frasier 2007).

Hawai'ian non-native mangroves provide a unique case study to assess the habitat role of non-native species outside of their native range. Specifically, while mangrove benefits are well studied, their ecological role outside their native environment is poorly understood. In this study, novel mangrove habitat on Moloka'i, Hawai'i was examined to determine if non-native mangroves are providing habitat functions for zooplankton, including larval fish, and what environmental and watershed factors influence zooplankton composition. Additionally, zooplankton are a key component of marine ecosystems, forming the base of most marine food webs (Turner and Tester 1997, Johnson and Allen 2012). 
Since non-native mangroves are well established, this study provides important information to determine ecosystem function provided by this novel habitat. In its native range, zooplankton community structure differs between mangrove and open coast nonmangrove habitat due to intrinsic characteristics of mangroves, including habitat complexity, shading, and nutrient availability (Sasekumar et al. 1992, Kathiresan and Bingham 2001, Cocheret de la Morinière et al. 2004, Nagelkerken et al. 2008). Further, most zooplankton species are short lived so that populations are not influenced by the persistence of individuals from previous years and because they are free floating, zooplankton can easily respond to environmental changes (Hays et al. 2005). These features lead to a tight coupling between environmental variables and zooplankton population dynamics (Stenseth et al. 2002, Perry et al. 2004, Hays et al. 2005).

Specifically, this study aimed to (1) determine whether novel mangrove habitat increases or decreases zooplankton diversity and richness, (2) test the hypothesis that zooplankton community composition differs significantly among established mangrove and open coast non-mangrove habitat, and (3) assess other factors driving differences in zooplankton community assemblages. I expected non-native mangroves to support more diverse zooplankton assemblages with greater richness due to numerous taxa benefiting from increased habitat complexity, greater food availability, and the cooler temperatures mangroves provide. I hypothesized that zooplankton community composition would differ significantly among established mangroves and open coast non-mangrove habitat based on similar studies that reported differences in zooplankton communities in native mangrove and deforested mangrove habitat (Granek and Frasier 2007). 


\subsection{METHODS}

\subsubsection{Study Site}

This study was conducted adjacent to the island of Moloka'i in the Hawaiian Archipelago in the North Pacific Ocean. The coastline is characterized by open coastline and numerous Polynesian fishponds that range in size from less than one to $\sim 15$ hectares. The coast, including fishponds, is primarily dominated by either Rhizophora mangle (non-native red mangrove), Prosopis pallida (non-native mesquite/kiawe tree), Thespesia populnea (milo tree, possibly introduced by Polynesians; Wagner et al. 1990), Hibiscus tiliaceus (unknown native status hau tree), or sandy beach. The majority of fishponds have been partially or completely filled with mangroves except for the eastern-most ponds. Fishponds ranged in the amount of mangrove coverage from partially filled to fully overgrown.

Ten paired sites along the southeast coast of Moloka'i, Hawai'i were selected based on accessibility (Figure 2.1). Paired sites consisted of an area of mangrove habitat and an adjacent area of open coast (representing historical coastline conditions). Site types included: seven paired sites within fishponds (partially lined with mangrove and partially open coastline) (Figure 2.1c) and three paired sites outside of fishponds (Figure 2.1d). Selected sites had stretches at least 100 meters of mangrove shoreline habitat adjacent to at least 100 meters of open coast (Granek and Frasier 2007). All paired sites that met these criteria and were accessible were included in the study. A primary road of Moloka'i (Kamehameha V Hwy) travels along the southeast coast, ranging from $~ 10-600$ meters from shore with numerous residences between the road and the coast. 


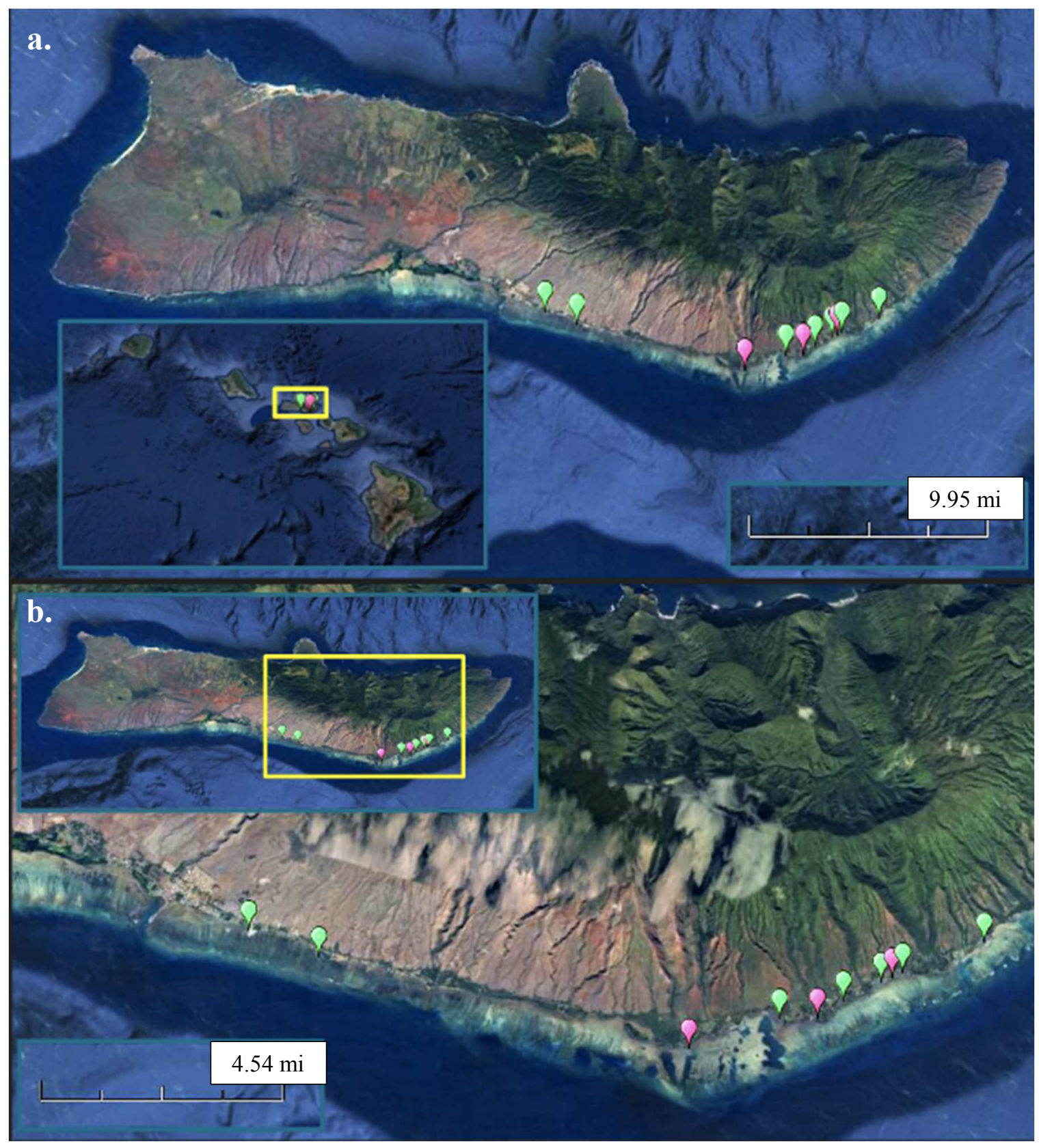




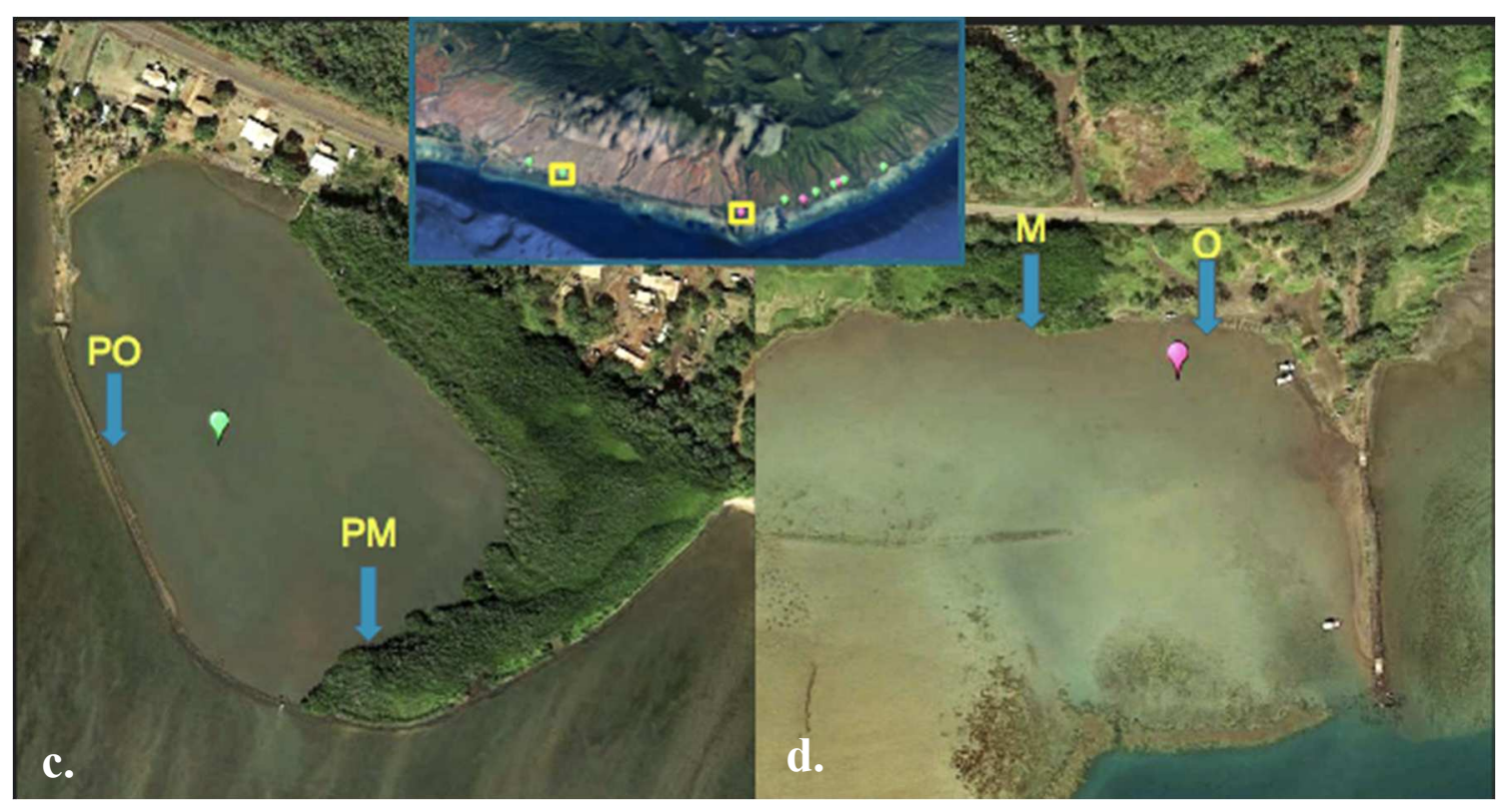

Figure 2.1. a) The island of Moloka'i and its location in the Hawaiian Islands. b)

Southeast Moloka'i with site locations. An example c) of a paired site within a fishpond and d) a paired site outside a fishpond. Blue arrows represent approximate sampling locations. Green pins indicate paired sites within fishponds and pink pins indicate paired sites outside of fishponds. ( $M$ open coast mangrove, $O$ open coast non-mangrove, $P M$ fishpond mangrove, $P O$ fishpond non-mangrove)

\subsubsection{Environmental Variables}

Site area, length of mangrove shoreline, and length of non-mangrove shoreline were measured in Google Earth. Site area for fishpond locations was calculated by defining fishpond perimeter and calculating the area within (excluding area occupied by mangroves); for open coast sites, area was defined by natural boundaries (i.e., other fishponds, piers, or end of habitat type). Within each defined site area, the mangrove and non-mangrove shoreline lengths were measured along either the fishpond perimeter or 
along the shoreline. For fishponds, non-mangrove lengths include fishpond walls. To determine percentage of shoreline length with mangroves per site, mangrove shoreline length was divided by total shoreline length (mangrove length + non-mangrove length).

Watershed relief, percentage of mature tree cover in watershed, mean annual precipitation, percentage of impervious surface area in watershed, and percentage of developed land in watershed were calculated using StreamStats (U.S. Geological Survey 2012). Mature tree cover is defined as "areas dominated by trees generally greater than 5 meters tall, greater than $20 \%$ of total vegetation cover, more than $75 \%$ of the tree species maintain their leaves all year, and canopy is never without green foliage" (Homer et al. 2007).

Mangrove leaves were collected at each mangrove site to evaluate the extent of biologically available nitrogen and carbon and to understand inputs from sewage (Costanzo et al. 2001). Sewage inputs can be distinguished from other nitrogen sources entering marine ecosystems due to their elevated $\delta^{15} \mathrm{~N}$ signature (Costanzo et al. 2001). Upon collection, two green leaves from different trees were composited, oven dried, and ground to a fine powder. Nitrogen and carbon were analyzed by an elemental analyzer interfaced to a continuous flow isotope ratio mass spectrometer (EA-IRMS) for tissue $\% \mathrm{~N} / \% \mathrm{C}$ and $\delta^{15} \mathrm{~N} / \delta^{13} \mathrm{C}$ isotopic signatures at the University of California Davis Stable Isotope Facility following methods from Costanzo et al. 2001.

\subsubsection{Zooplankton Sampling}

Plankton are defined as the small organisms suspended in the water column that are not attached to the bottom (benthos) nor able to effectively swim against most 
currents (nekton) (Johnson and Allen 2012). Plankton includes both phytoplankton (plants) and zooplankton (animals) within two main groups: holoplankton (permanent members of the plankton) and meroplankton (temporary members) (Johnson and Allen 2012). For this study, only zooplankton larger than the sampling mesh diameter were included.

Community composition differs between light trap and plankton tow sampling, due to the range of swimming abilities and photosensitivity across zooplankton species (Doherty 1987, Hickford and Schiel 1999, Granek and Frasier 2007, Porter et al. 2008; see Appendix Section A1 for additional locomotion information). Therefore, light traps and plankton tows were used simultaneously to assess zooplankton communities in mangrove and open coast areas. Marine larval fish have been sampled in both light traps (Doherty 1987) and plankton tows (Baier and Purcell 1997) and are therefore included in this study.

In June 2015, sampling was conducted for eight consecutive nights. Each paired site was sampled once with two paired sites sampled per night using both sampling methods simultaneously. For two sites, sampling was repeated for a total of three nights to examine temporal variability at spatially fixed sites.

\subsubsection{Light traps}

The light trap design, modeled after Granek and Frasier (2007), consisted of an inverted 3.8 liter (1 gallon) transparent blue plastic water jug, with side funnels and a 220- $\mu \mathrm{m}$ mesh-lined cod-end made of perforated PVC tubing attached (Figure 2.2). A white LED light stick (Trident Long Life LED Glow Stick Dive Light) suspended inside 
the bottle from the top of each trap was used as the light source. Two funnel-shaped entry points on the bottle's sides led inward to a hole measuring approximately $1 \mathrm{~cm}$ in diameter providing access points for phototactic zooplankton. The small entry point was designed to limit both the size of individuals entering the trap and the ability of the zooplankton to leave the traps after entering. When the light traps were lifted from the water, zooplankton were flushed into the mesh-lined cod-end.

Traps were deployed for one hour at sunset. In mangrove areas, light traps were anchored within the root structure; using weights tied to a line to anchor them, air was removed from traps until the top of the trap was just above the surface of the water. In open areas within fishponds, traps were deployed near the fishpond wall and in open coast areas, traps were deployed off beach areas in water depth similar to mangrove areas. 


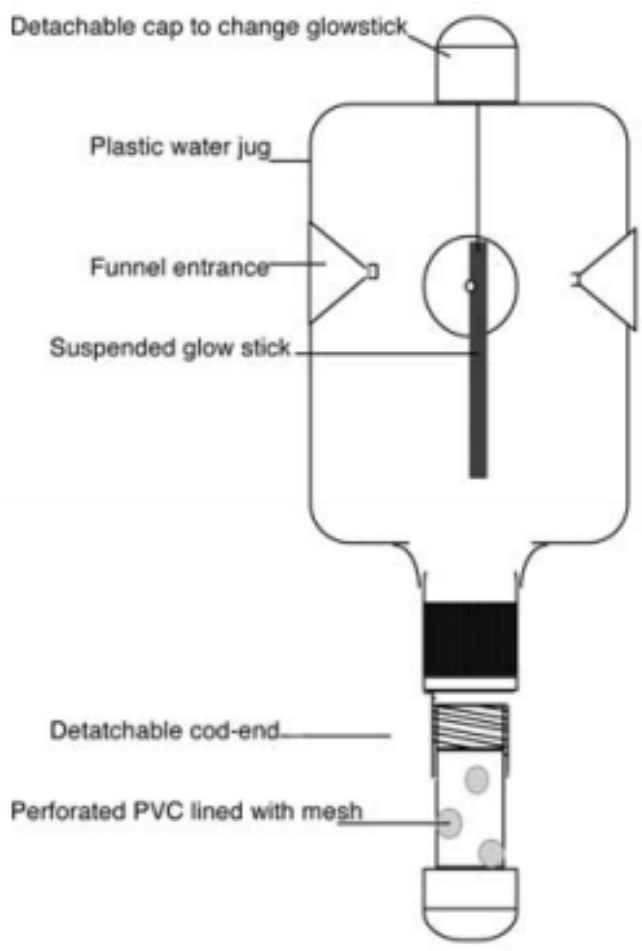

Figure 2.2. Diagram of zooplankton light trap design (from Granek and Frasier 2007; not to scale).

\subsubsection{Plankton tows}

Plankton nets were towed alongside waders in the vicinity of the light traps for 1 minute (approximately $20 \mathrm{~m}$ ) during the time period in which the light trap was deployed (Granek and Frasier 2007). The plankton nets had 210- $\mu \mathrm{m}$ mesh, a mouth diameter of 30 $\mathrm{cm}$, and a length of $120 \mathrm{~cm}$. In mangrove areas, the tow was pulled through water as close to the root structure of the mangroves as possible while tows near the fishpond walls and open coast mirrored the topography of the paired habitat. All tows were pulled at a similar speed to have consistent water flow between paired sites to control for water volume sampled. 


\subsubsection{Sample processing}

The contents of the light trap and plankton tow cod-ends were fixed in a $2-4 \%$ formalin solution then transferred to a $70 \%$ ethanol solution for preservation. A dissecting light microscope was used for sample identification. When feasible, all individuals were counted in each sample and identified following methods in Granek and Frasier 2007 using various taxonomic keys, but when further identification of taxa was possible, they were considered a separate taxon. A Folsom splitter was used on highly dense samples ( $>2000$ individuals; average individuals per sample $=11,040$, standard deviation $=36,646$ ) and abundances were scaled up to estimate total number (Milroy 2015). Subsamples had a mean of 898 individuals $($ minimum $=483, \mathrm{SD}=337)$. Split samples were fully scanned for rare species.

\subsubsection{Data analysis}

Separate analyses were conducted for each sampling method (light traps and plankton tows). To characterize zooplankton assemblages among habitat types (open coast mangrove, open coast non-mangrove, fishpond mangrove, fishpond nonmangrove), the relative abundance of each taxon to the total organism count in a sample was calculated. Species accumulation and individual-based rarefaction and extrapolation curves of species richness were constructed for each habitat type (Appendix; Figures A9

and A10) (Hortal et al. 2006, Colwell et al. 2012, Chao et al. 2014, Katayama 2016). For rarefaction curves, bootstrap replicates were used to estimate $95 \%$ confidence intervals and all estimates were obtained using the "iNEXT" package in R (Hsieh et al. 2016). Richness and Shannon diversity (both based on lowest identifiable taxon) were calculated 
for each sample. Taxa with multiple developmental life stages were aggregated for this analysis. I compared richness and diversity of all mangrove sites to all non-mangrove sites, mangrove to non-mangrove sites only within fishponds, and mangrove to nonmangrove sites only outside of fishponds with paired t-tests to test the hypothesis that richness and diversity in mangroves are greater than in non-mangrove habitat. With zooplankton data (natural) log transformed to reduce the influence of dominant taxa, all groups met the assumption of normality and equal variance.

The hypothesis that mangrove presence affects zooplankton community composition was tested using permutational multivariate analysis of variance (PERMANOVA) (Anderson 2001). PERMANOVA was performed on all 20 samples from the four groups of the major habitats in ten paired locations to test the null hypothesis that the centroids of each habitat as defined in the space of Bray-Curtis dissimilarity were equivalent (i.e., there is no difference in zooplankton communities between habitats) using "adonis" function in "Vegan" R package (Oksanen et al. 2015). Prior to using PERMANOVA, the homogeneity of multivariate dispersions among habitats was assessed with Bray-Curtis dissimilarity measure using "betadisper" function in "Vegan" R package (Oksanen et al. 2015). Zooplankton abundance was again (natural) $\log$ transformed prior to analysis to reduce the influence of dominant taxa on dissimilarity patterns. Due to the unbalanced design between habitat types, the results should be interpreted cautiously.

To visually examine differences in zooplankton community assemblages among habitats, I performed nonmetric multidimensional scaling (NMDS), a multivariate 
ordination technique commonly used in ecological community analysis (Clarke 1993). NMDS was also performed for sites sampled multiple times to visualize differences in community composition over time. Zooplankton abundance was again log transformed to dampen the impacts of dominant species on the ordination analysis. Multiple developmental life stages within a taxon were separated for this analysis to understand how community assemblages vary not only by taxa but also by developmental stages. Rare taxa $(<1 \%$ mean relative abundance) were included in this analysis due to the possibility that rare taxa may help understand community patterns. This was expected because $98 \%$ of regionally rare fish species support highly vulnerable functions in coral reef ecosystems with similar function support expected with other groups of rare taxa (Mouillot et al. 2013). Additional NMDS analyses were performed on community composition excluding rare taxa to further understand their influence. Bray-Curtis dissimilarity index values were calculated among the samples. NMDS projects each sample into a species-defined ordination space with two or more dimensions based on their ranked dissimilarity. Goodness-of-fit for the NMDS was measured as a stress value that quantifies the deviation from the relationship based on the distance among samples in the original Bray-Curtis dissimilarity matrix and the distance among samples in the ordination plot. Stress below 0.2 is considered adequate and NMDS plots with stress above 0.2 should be interpreted with caution (Clarke 1993). Each NMDS was run 100 times with a random starting configuration. Final NMDSs were selected based on the lowest stress value. NMDSs for each sampling method were related to measured environmental variables using the "envfit" function in "Vegan" R package (Oksanen et 
al. 2015). This function fits explanatory variables in the ordination space defined by the species data (Oksanen et al. 2015). Each environmental variable was analyzed

independently and a permutation test (permutations $=1000)$ assessed the importance of each vector using a squared correlation coefficient $\left(r^{2}\right)$ (Oksanen et al. 2015, Pan et al. 2016). Prior to envfit analysis, principal component analysis (PCA) was conducted on highly correlated variables to reduce repetition in order to create a summary variable related to human disturbance (see Appendix; Figures A11-12 and Table A12 for full output and details). All analyses were performed using R version 3.3.2 (R Core Team 2016).

To understand differences in community composition and their relation to environmental variables (particularly to mangrove metrics), Spearman correlation coefficients were calculated comparing taxa abundance to mangrove and open shoreline length and percentage of mature forest in the watersheds. Additional NMDS plots were used to assess temporal variation and differences between samples collected within and outside of fishponds.

\subsection{RESULTS}

\subsubsection{Environmental conditions}

Environmental conditions varied between fishpond and open coast habitat (Table 2.1). Fishponds were generally larger than open coast sites (median $=12.65$ ha for fishponds and 1.76 ha for open coast), leading to longer mangrove and non-mangrove shoreline lengths in fishponds. Though, in both fishponds and open coast sites, the 
percentage of shoreline colonized by mangroves was similar ( $50 \%)$. Nutrients in mangrove leaves collected from sites had an average $45.72 \%$ carbon (range of $42.62-$ $48.34 \%$ ) and an average $1.05 \%$ nitrogen (range of $0.87-1.31 \%$ ).

Watershed conditions also varied (Table 2.1). In general, most watersheds draining into fishpond sites had greater human disturbance than open coast sites. When comparing fishponds to open coast sites, fishponds had a lower median percentage of mature forest ( $6.0 \%$ to $32.5 \%$ respectively) and a higher median percentage of impervious surfaces (1.7\% to $0.4 \%$ respectively) and developed land (13.2\% to $3.3 \%$ respectively). For environmental and watershed conditions of individual sites see Appendix Figure A9. 


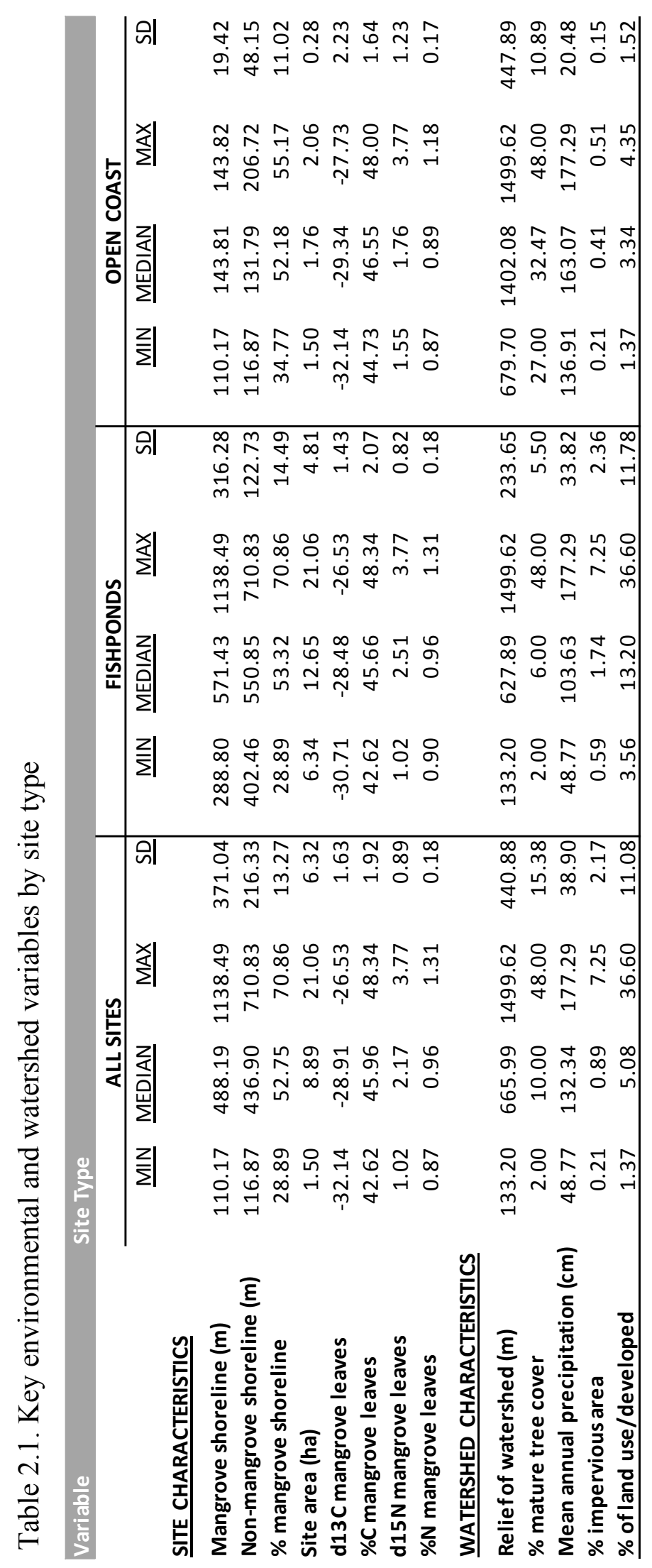




\subsubsection{Variation in zooplankton assemblages among habitats}

A total of 28 zooplankton taxa were identified. Copepods had the greatest abundance (mean relative abundance in light traps $=15-26 \%$ and plankton tows $=25-$ $32 \%$ ) followed by shrimp larvae (light traps $=14-17 \%$ and plankton tows $=14-20 \%$ ), combined developmental stages of crabs (light traps $=12-16 \%$ and plankton tows $=7$ $12 \%)$ and amphipods (light traps $=11-20 \%$ and plankton tows $=6-8 \%)($ Figure 2.3$)$. For light traps the only other taxon that had a mean relative abundance greater than $5 \%$ were isopods (8-11\%). In plankton tows, the only other taxa that had mean relative abundances greater than 5\% were ostracods (5-9\%) and bivalves (4-9\%). In light traps, the largest abundances were found within the first two nights of sampling but tows saw relatively large abundances later in the lunar cycle.

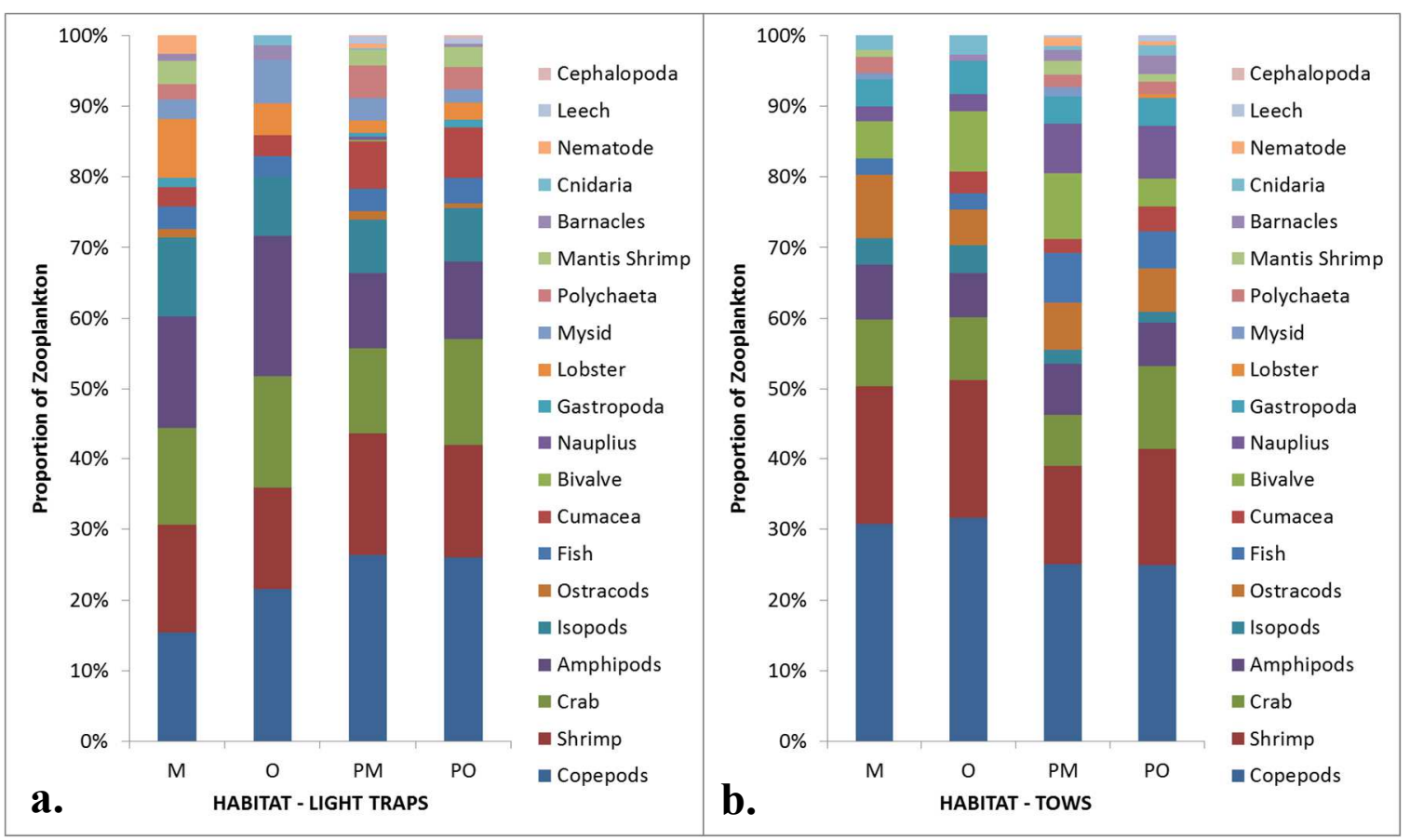


Figure 2.3. Comparison of proportional abundance values of major zooplankton groups among habitat type. a) Light trap sampling b) Plankton tow sampling ( $M$ open coast mangrove, $O$ open coast non-mangrove, $P M$ fishpond mangrove, $P O$ fishpond nonmangrove)

Number of taxa per sample varied across sites from 6 to 15 (average number of taxa per sample $=10.8$, standard deviation $=2.4$ ). Open coast mangroves (not within fishponds) sampled with light traps had the greatest mean richness (15.3) and for plankton tow sampling, non-mangrove open coast sites had the greatest mean richness (11.7) (Figure 2.4a,b). Richness was more variable in light trap samples (Figure 2.4a). However, richness did not vary significantly among site types (Figure 2.4a,b, Table 2.2), possibly due to small sample size. For both sampling methods, species accumulation and rarefaction curves reached asymptotes except rarefaction on open coast mangroves sampled with light traps (Appendix Figures A9, A10).

Diversity per sample varied across sites from 0.04 to 1.68 (average Shannon diversity per sample $=0.90$, standard deviation $=0.49$ ). Light trap samples from open coast mangroves had the greatest mean Shannon diversity (1.184) and plankton tow samples had the greatest mean diversity at non-mangrove fishpond sites (0.995) (Figure 2.4c,d). Diversity in fishpond samples had greater variance than sites not located in fishponds. However, there was no significant difference in diversity among site type (Figure 2.4c,d, Table 2.2), potentially due to the small sample size. 

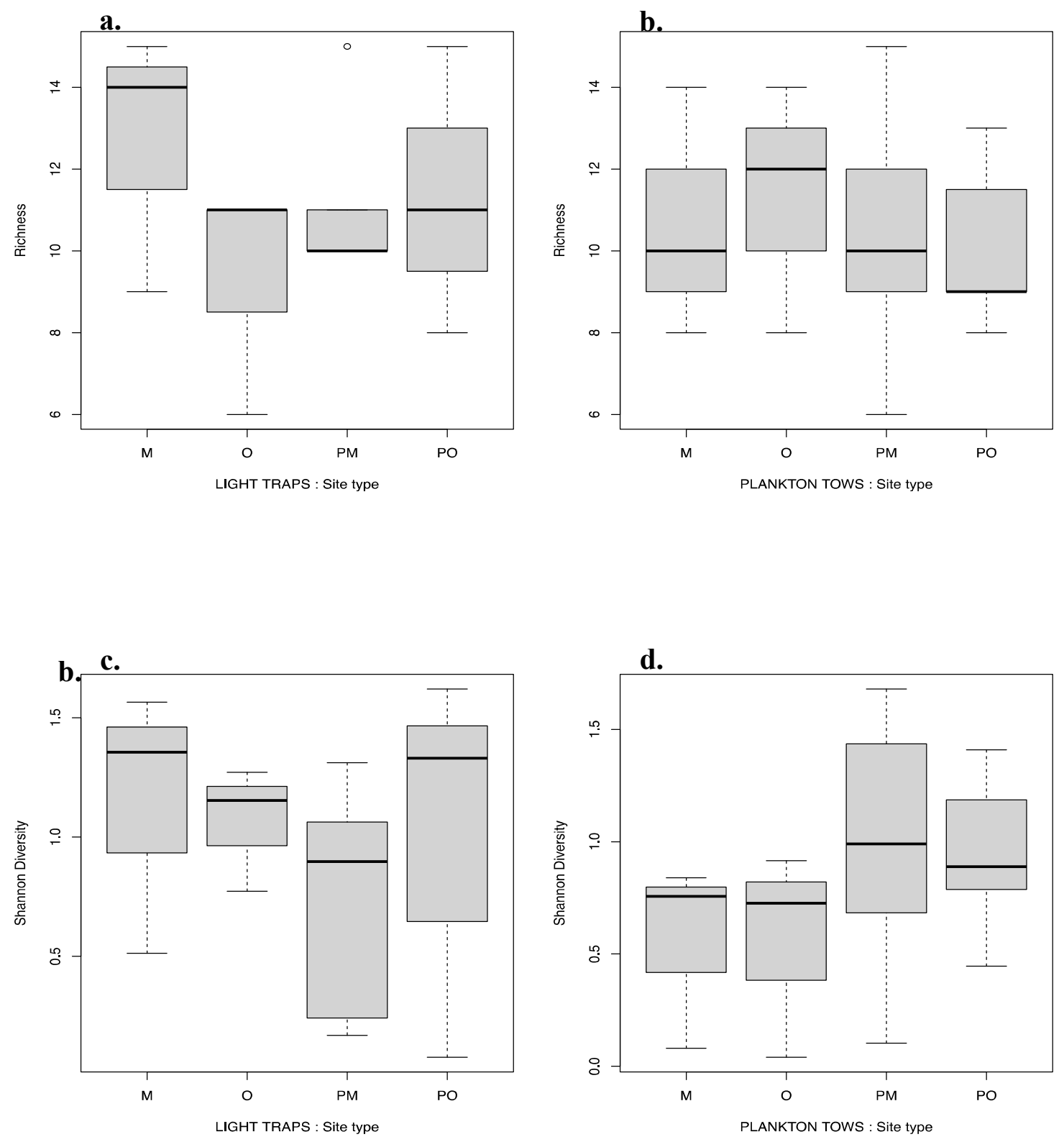

Figure 2.4. Boxplots of richness (a,b) and Shannon diversity $(\mathrm{c}, \mathrm{d})$ between habitat types and sampling method $(M$ open coast mangrove $(\mathrm{n}=3), O$ open coast non-mangrove $(\mathrm{n}=$ 3), $P M$ fishpond mangrove $(\mathrm{n}=7), P O$ fishpond non-mangrove $(\mathrm{n}=7))$ 
Table 2.2. Paired t-tests comparing richness and diversity of all mangrove and open coast sites, fishpond mangroves to fishpond open coast, and open coast mangrove to open coast non-mangrove for both sampling methods.

\begin{tabular}{|c|c|c|c|c|c|}
\hline & \multicolumn{5}{|l|}{ Richness } \\
\hline & \multicolumn{2}{|l|}{ Light Traps } & \multicolumn{3}{|c|}{ Plankton Tows } \\
\hline & $t$ & $p$ & $t$ & $p$ & $d f$ \\
\hline All mangrove to open & 0.647 & 0.5338 & 0 & 1 & 9 \\
\hline Fishpond mangroves to open & -0.2402 & 0.8182 & 0.3203 & 0.7596 & 6 \\
\hline \multirow[t]{4}{*}{ Open coast mangroves to open } & 1.1471 & 0.3701 & -1 & 0.4226 & 2 \\
\hline & \multicolumn{5}{|l|}{ Diversity } \\
\hline & \multicolumn{2}{|l|}{$\underline{\text { Light Traps }}$} & \multicolumn{3}{|c|}{ Plankton Tows } \\
\hline & $t$ & $p$ & $t$ & $p$ & $d f$ \\
\hline All mangrove to open & -1.0161 & 0.3361 & 0.2075 & 0.8402 & 9 \\
\hline Fishpond mangroves to open & -1.2062 & 0.2731 & 0.2068 & 0.843 & 6 \\
\hline Open coast mangroves to open & 0.4063 & 0.7239 & -0.0504 & 0.9644 & 2 \\
\hline
\end{tabular}

Zooplankton community composition was highly similar within pairs for mangrove-open paired sites, thus NMDS on ten paired sites for both light traps and plankton tows showed no significant dissimilarities between open coast mangrove, open coast non-mangrove, fishpond mangrove, and fishpond non-mangrove habitat types (Figure 2.5,2.6) (PERMANOVA: light traps: $\mathrm{df}=3, F=1.12, P=0.31$, stress $=0.16$; plankton tows: $\mathrm{df}=3, F=1.15, P=0.28$, stress $=0.19$, see Appendix; Table A1). The assumption of homogeneity of multivariate dispersions was met; there was not statistically significant heterogeneity in dispersions among the habitats $(P>0.05)$. Because paired sites were found to be highly similar, further analyses focus on overall sites and environmental characteristics to understand differences in zooplankton community composition. 
To visualize differences in taxa contributions to the NMDS, individual taxa were overlaid on the NMDS (Figure 2.5b, 2.6b, for examples of individual taxa abundance plots see Appendix; Figures A6 and A7). For both sampling methods, rare taxa $(<1 \%$ mean relative abundance) were generally located closer to the edges of the plot, indicating that they may be highly influential to the NMDS. To determine if this was the case, NMDS plots excluding rare taxa were constructed (Figure 2.7b,2.8b). Site locations and taxa orientations did not change significantly when rare taxa were excluded (Figure 2.7, 2.8, see also PERMANOVA results excluding rare taxa in Appendix; Table A10). The exclusion of rare taxa allowed clearer visualization of the trends among the common taxa. However, these trends do not differ from the general patterns seen when rare taxa are included. 
a.

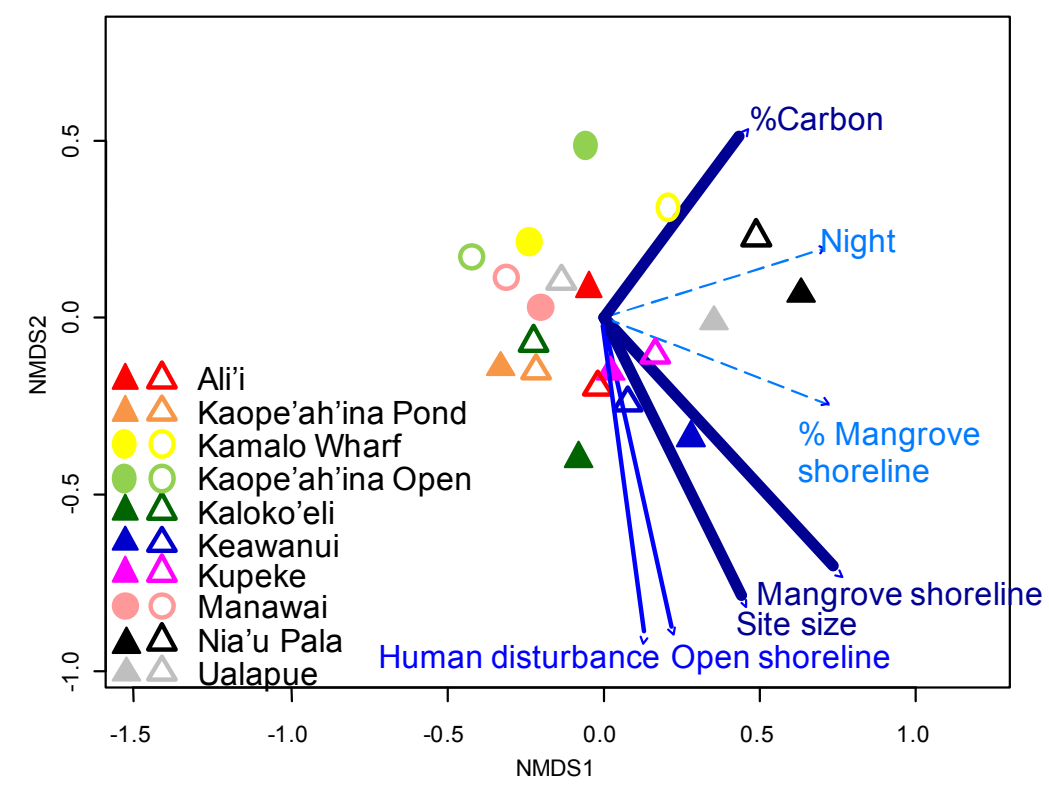

b.

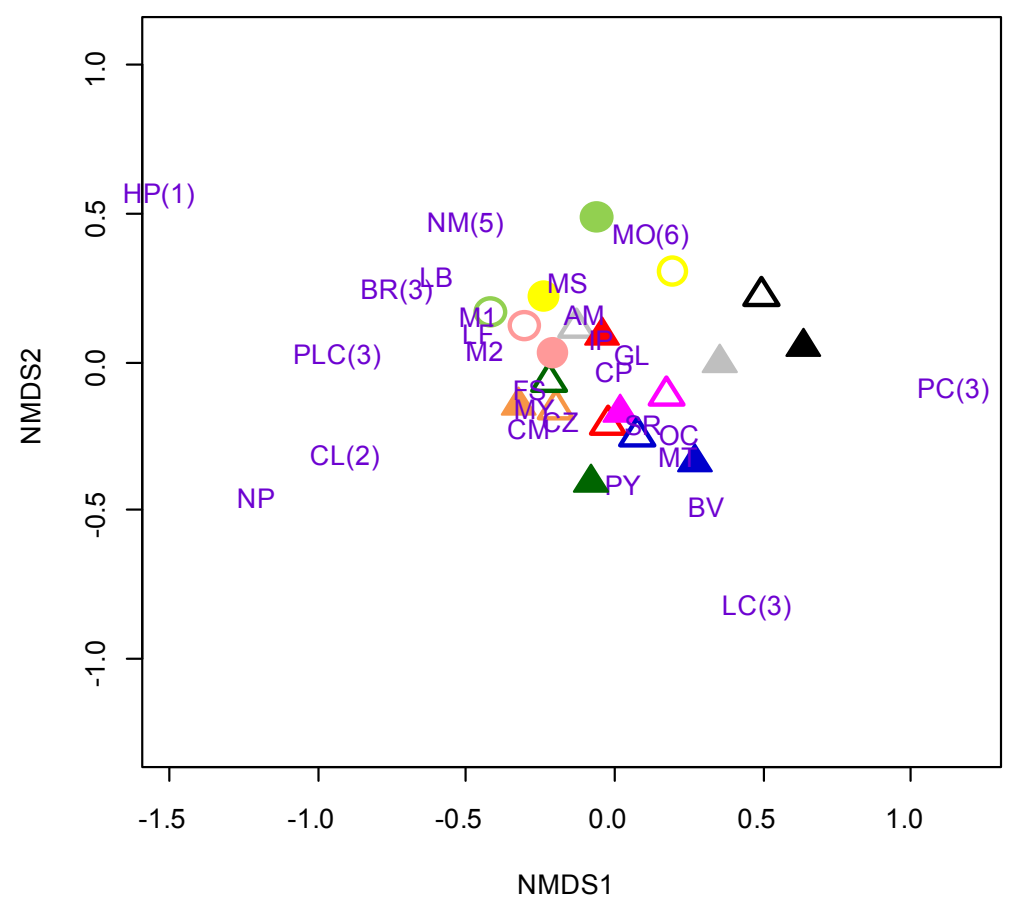


Figure 2.5. Nonmetric multidimensional scaling (NMDS) comparing zooplankton assemblages collected in light trap samples across site locations and habitat types. a. NMDS plot of study sites and types including environmental vectors driving community assemblages. $(\boldsymbol{\Lambda}$ = fishpond mangrove, $\Delta$ = fishpond non-mangrove, $\boldsymbol{O}=$ open coast mangrove, $\mathrm{O}=$ open coast non-mangrove, dark thick line $-\mathrm{p}=0-0.0001$, thin line $p=0.001-0.01$, light dotted line $-p=0.01-0.05)$ b. NMDS with taxa orientation. The number in parentheses following rare taxa $(<1 \%$ mean relative abundance) indicates the number of sites where the species was present. (Copepod $=\mathrm{CP}$, shrimp larvae $=\mathrm{SR}$, crab zoea $=\mathrm{CZ}$, amphipod $=\mathrm{AM}$, Monstrillidae $=\mathrm{MT}$, isopod $=\mathrm{IP}$, cumacean $=\mathrm{CM}$, fish larvae $=$ FS, Lucifer $s p .=\mathrm{LC}$, ostracod $=\mathrm{OC}$, bivalve larvae $=\mathrm{BV}$, crab megalopa $($ single rostrum $)=\mathrm{M} 1$, nauplius $=\mathrm{NP}$, polychaete $=\mathrm{PY}$, gastropod larvae $=\mathrm{GL}$, megalopa $($ double rostrum $)=M 2$, mantis shrimp $=$ MS, mysid $=$ MY, lobster larvae $=$ LB, barnacle larvae $=\mathrm{BR}$, hydropoid $=\mathrm{HP}$, crab megalopa $($ other $)=\mathrm{MO}$, leech $=\mathrm{LC}$, nematode $=$ $\mathrm{NM}$, parasitic copepod, PC, jellies $=\mathrm{JF}$, post-larval crab $=$ PLC, cephalopoda $=\mathrm{CL}$ ) 
a.

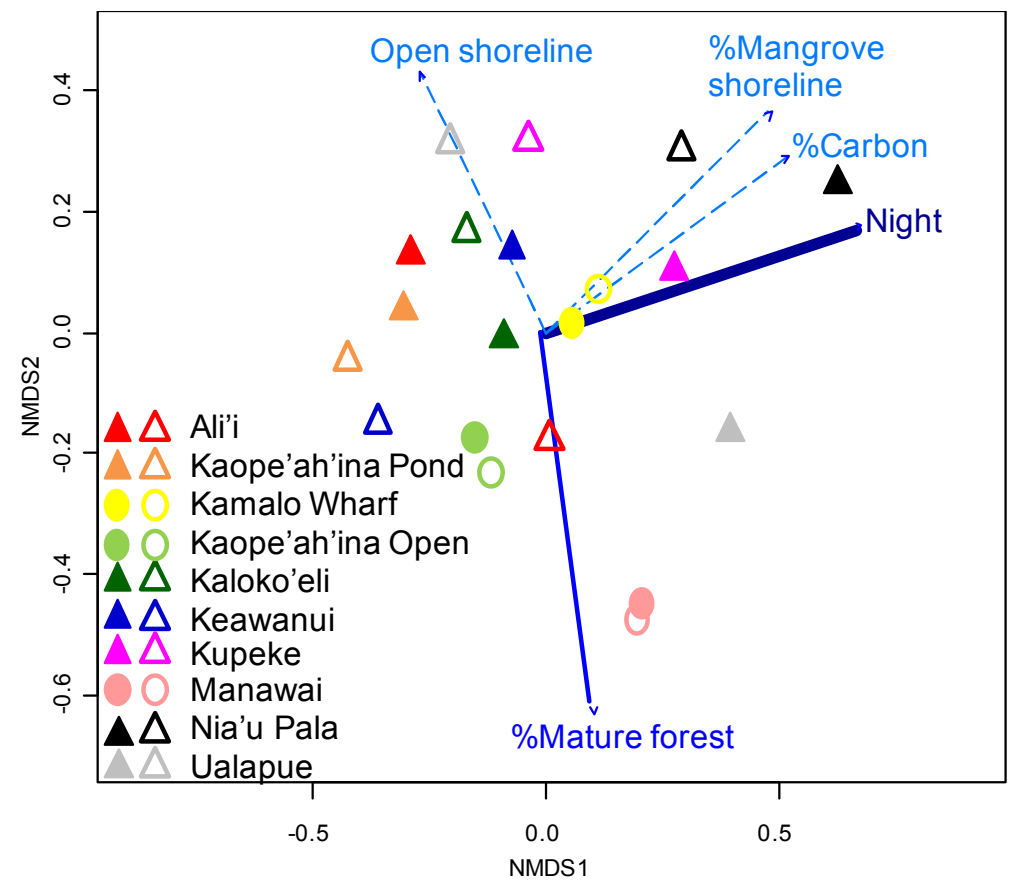

b.

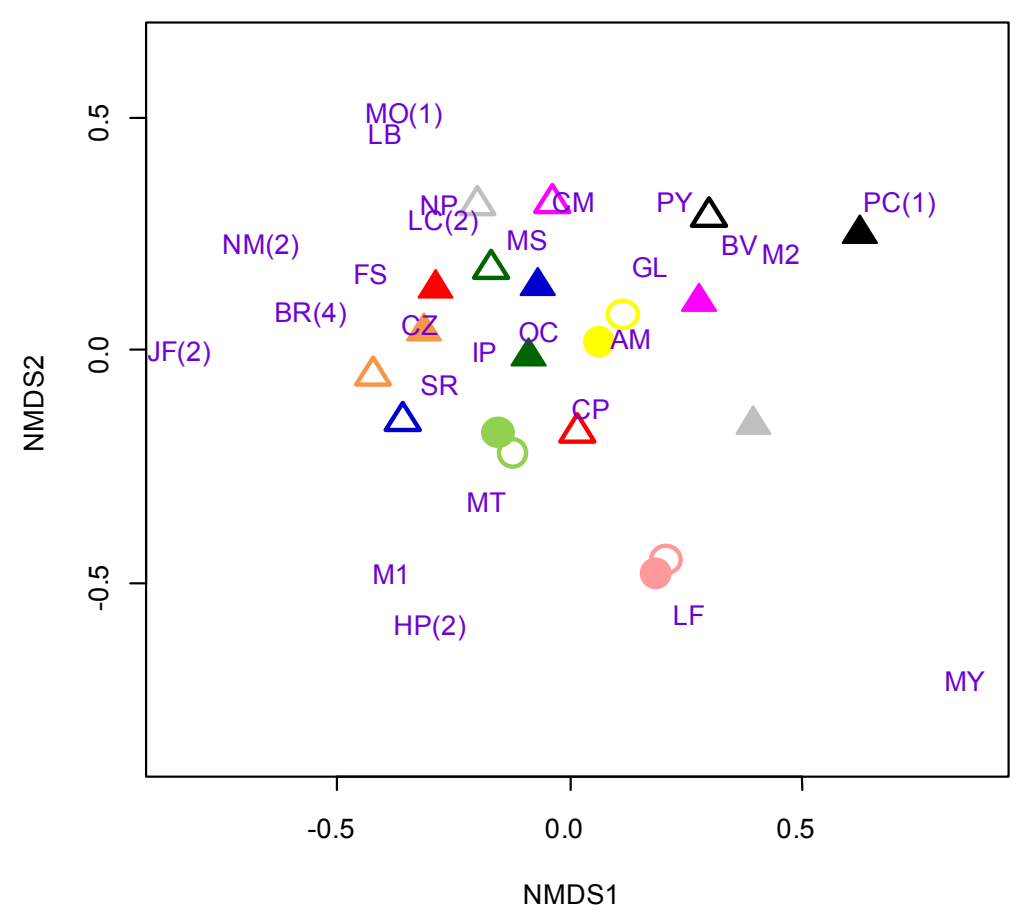


Figure 2.6. Nonmetric multidimensional scaling (NMDS) comparing zooplankton assemblages collected in plankton tow samples across site locations and habitat types. a. NMDS plot of study sites and types with environmental vectors driving community assemblages. ( $\boldsymbol{\Delta}$ = fishpond mangrove, $\boldsymbol{\Delta}$ = fishpond non-mangrove, $\boldsymbol{O}=$ open coast mangrove, $\mathrm{O}=$ open coast non-mangrove, dark thick line $-\mathrm{p}=0-0.0001$, thin line $\mathrm{p}=0.001-0.01$, light dotted line $-\mathrm{p}=0.01-0.05)$ b NMDS with taxa orientation. The number in parentheses following rare taxa $(<1 \%$ mean relative abundance $)$ indicates the number of sites where the species was present. (Abbreviations as in Figure 2.5) 
a.

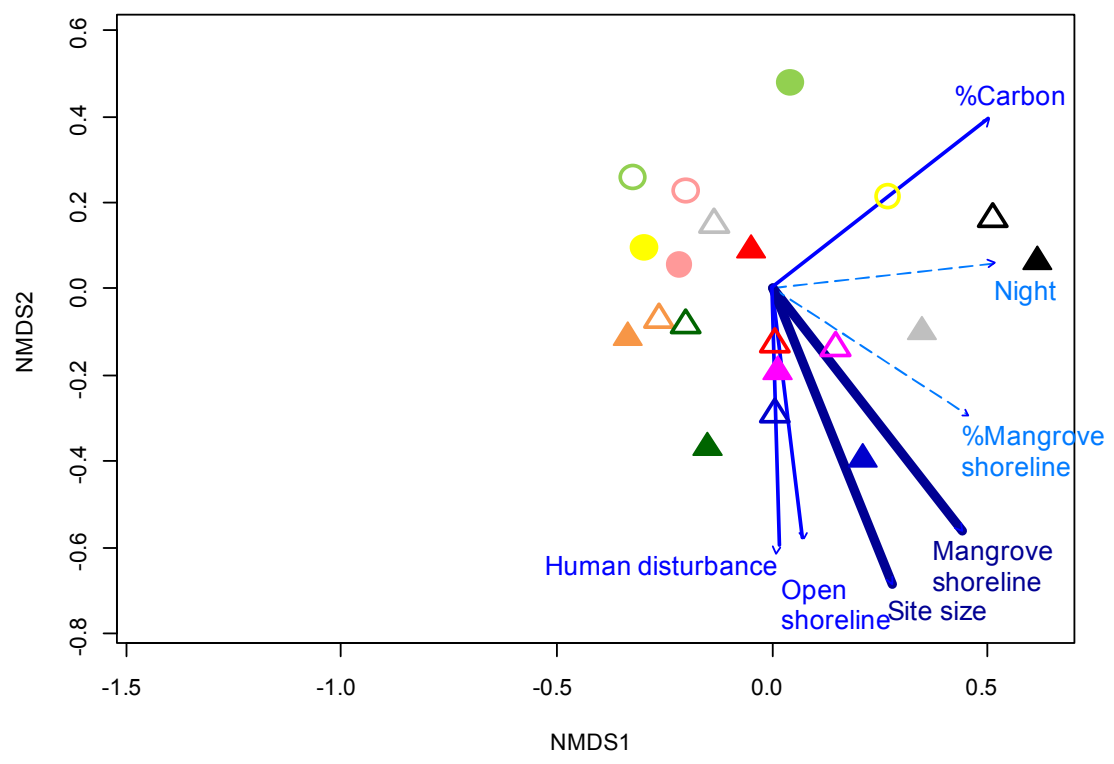

b.

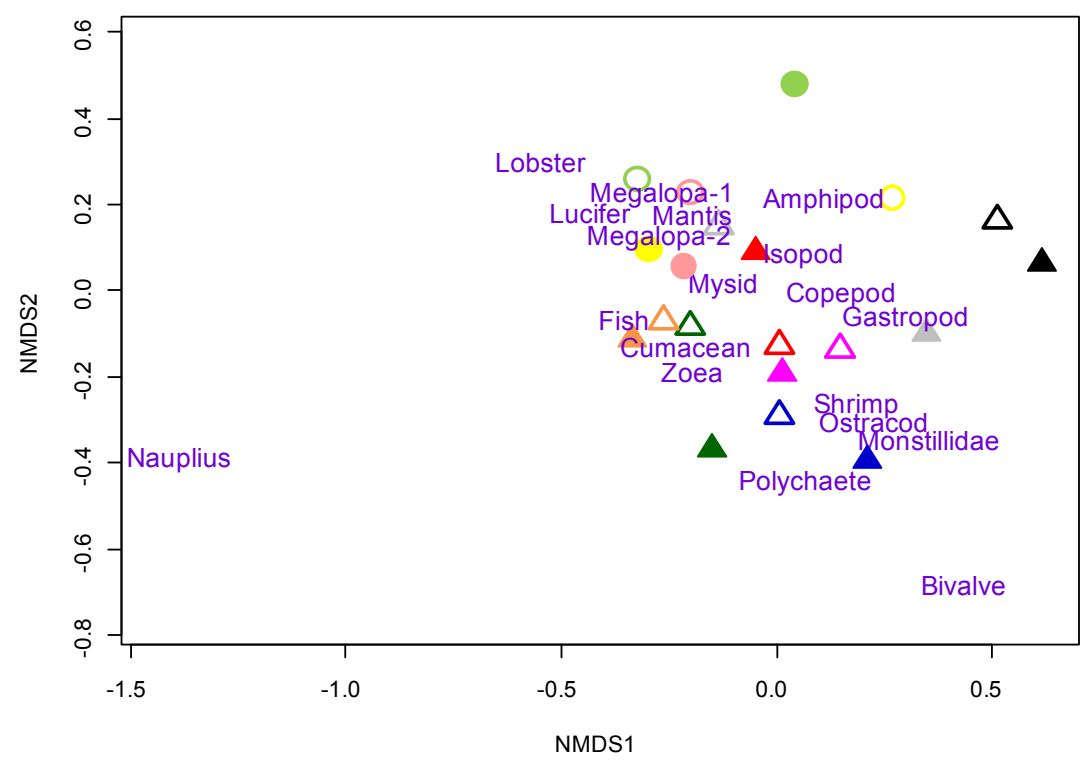

Figure 2.7. Nonmetric multidimensional scaling (NMDS) comparing zooplankton assemblages collected excluding rare taxa $(<1 \%$ mean relative abundance) collected in light trap samples across site locations and habitat types (stress $=0.16$ ). a. NMDS plot of study sites and types including environmental vectors driving community assemblages. ( 
$\boldsymbol{\Delta}$ = fishpond mangrove, $\Delta$ = fishpond non-mangrove, $\boldsymbol{O}=$ open coast mangrove $\mathrm{O}=$ open coast non-mangrove, dark thick line $-\mathrm{p}=0-0.0001$, thin line $-\mathrm{p}=0.001-0.01$, light dotted line $-\mathrm{p}=0.01-0.05)$ b. NMDS with taxa orientation. 
a.

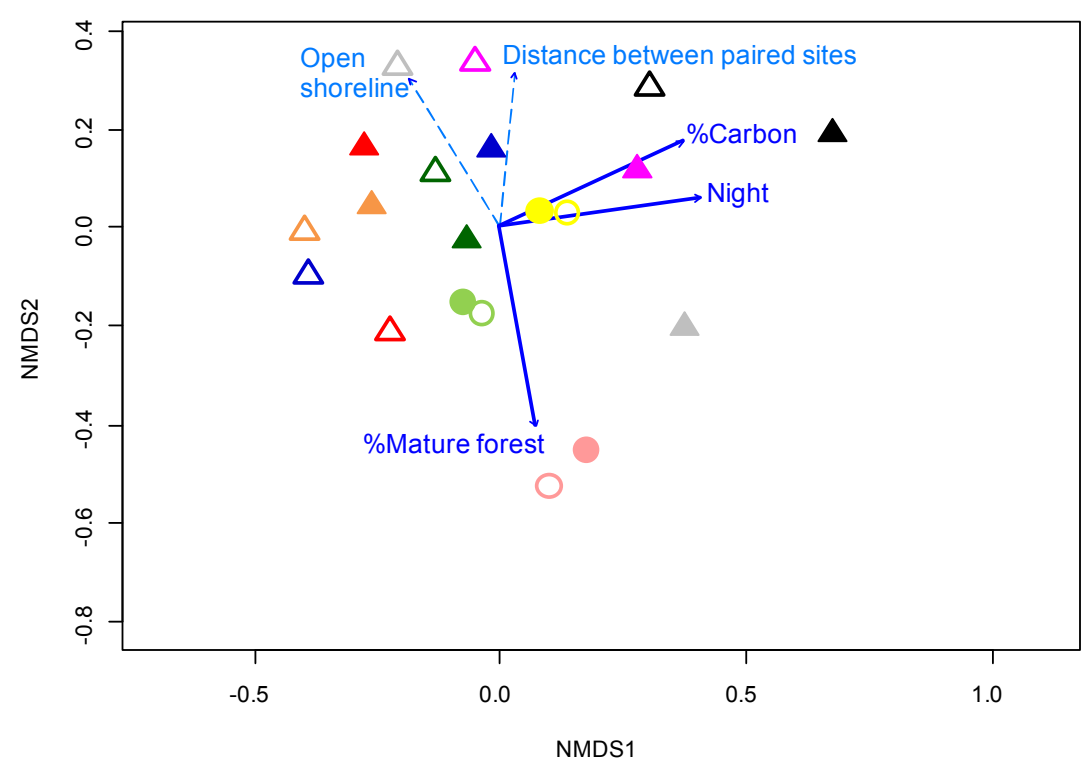

b.

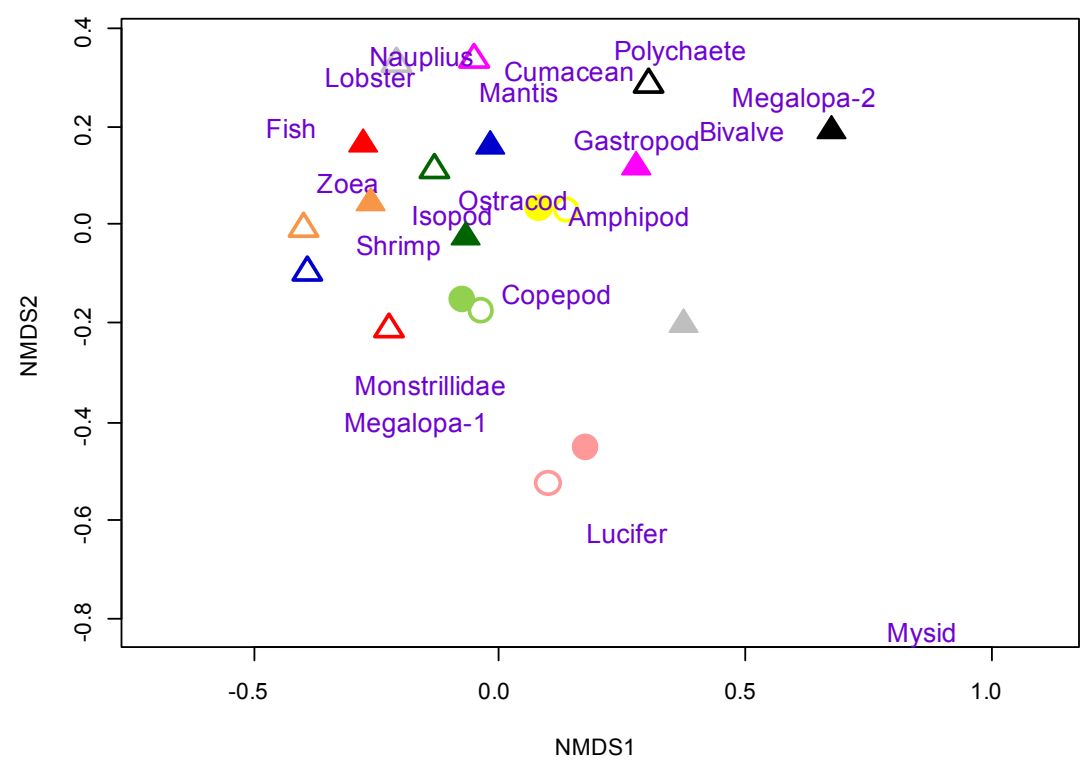

Figure 2.8. Nonmetric multidimensional scaling (NMDS) comparing zooplankton assemblages excluding rare taxa $(<1 \%$ mean relative abundance) collected in plankton tow samples across site locations and habitat types (stress $=0.18$ ). a. NMDS plot of study sites and types including environmental vectors driving community assemblages. $(\mathbf{A}=$ 
fishpond mangrove, $\Delta$ = fishpond non-mangrove, $O$ = open coast mangrove, $\mathrm{O}=$ open coast non-mangrove, dark thick line $-\mathrm{p}=0-0.0001$, thin line $-\mathrm{p}=0.001-0.01$, light dotted line $-\mathrm{p}=0.01-0.05)$ b. NMDS with taxa orientation.

Several environmental variables co-varied with differences in zooplankton community composition. In the NMDS analysis, rare species appeared visually to have a strong effect on the community composition. However, when comparing environmental fit analysis between all taxa with rare taxa excluded, there is little difference (for tows, distance between paired sites (mangrove and non-mangrove) was significant when rare taxa were excluded and percentage of mangrove shoreline length was significant when rare taxa were included), indicating that the rare taxa are not having a strong influence on community composition and environmental vector patterns (Tables $2.3,2.4$ ).

For light trap samples, site variables including site size, total shoreline length of mangroves within a site, and total mangrove leaf carbon varied with zooplankton composition $(\mathrm{p}<0.001)$ (Figure 2.5; Table 2.4). Other significant environmental variables co-varying with zooplankton community composition in light traps included non-mangrove shoreline length, sampling night, percentage of mangrove shoreline length, and a human disturbance gradient $(\mathrm{p}<0.05)$. Within the human disturbance gradient, undisturbed sites are characterized by greater watershed relief, percentages of mature forest, and annual precipitation, while more disturbed sites had greater percentages of impervious surfaces and developed land in the watersheds. 
Sampling night (lunar cycle) was the most significant variable that co-varied with zooplankton community composition in plankton tows $(\mathrm{p}<0.001)$ (Figure 2.6; Table 2.4). Other environmental variables that varied with zooplankton composition in tows included percentage of mature tree cover in the watershed, total mangrove leaf carbon, non-mangrove shoreline length within a site, and percentage of mangrove shoreline length $(\mathrm{p}<0.05)$.

Table 2.3. Envfit analysis of NMDS (excluding rare taxa) showing environmental variables co-varying with zooplankton community composition

\begin{tabular}{llllllll}
\hline & \multicolumn{3}{l}{ Light Traps } & \multicolumn{3}{l}{ Tows } \\
\cline { 2 - 6 } & $\mathrm{r}^{2}$ & $\mathrm{P}$ & & $\mathrm{r}^{2}$ & $\mathrm{P}$ & \\
\hline Night & 0.356 & 0.025 & $*$ & 0.517 & 0.002 & $* *$ \\
Distance between paired sites & & & & 0.304 & 0.046 & $*$ \\
Mangrove shoreline & 0.676 & 0.000 & $* * *$ & & & \\
Open shoreline & 0.449 & 0.007 & $* *$ & 0.383 & 0.017 & $*$ \\
\% mangrove shoreline length & 0.393 & 0.015 & $*$ & & & \\
Site size & 0.720 & 0.000 & $* * *$ & & & \\
\%Carbon & 0.541 & 0.001 & $* *$ & 0.518 & 0.002 & $* *$ \\
Human disturbance & 0.529 & 0.002 & $* *$ & & & \\
\%Mature forest & & & & 0.509 & 0.003 & $* *$ \\
\cline { 1 - 3 } Significance levels: ${ }^{*}(<0.05)$, & $* *(<0.01), * * *(<0.001)$ & &
\end{tabular}


Table 2.4. Envfit analysis of NMDS showing environmental variables co-varying with zooplankton community composition

\begin{tabular}{llllllll}
\hline & \multicolumn{1}{l}{ Light Traps } & \multicolumn{3}{l}{ Tows } \\
\cline { 2 - 7 } & $\mathrm{r}^{2}$ & $\mathrm{P}$ & & $\mathrm{r}^{2}$ & $\mathrm{P}$ & \\
\hline Night & 0.362 & 0.023 & $*$ & 0.608 & 0.000 & $* * *$ \\
Mangrove shoreline & 0.695 & 0.000 & $* * *$ & & & \\
Open shoreline & 0.496 & 0.003 & $* *$ & 0.328 & 0.034 & $*$ \\
\% mangrove shoreline length & 0.389 & 0.016 & $*$ & 0.314 & 0.040 & $*$ \\
Site size & 0.719 & 0.000 & $* * *$ & & & \\
\%Carbon & 0.643 & 0.000 & $* * *$ & 0.459 & 0.006 & $* *$ \\
Human disturbance & 0.533 & 0.001 & $* *$ & & & \\
\%Mature forest & & & & 0.498 & 0.003 & $* *$ \\
\hline Significance levels: ${ }^{*}(<0.05)$, & $* *(<0.01), * * *(<0.001)$ & & &
\end{tabular}

Taxon abundances either decreased or were not affected by increasing mangrove shoreline length, while about an equal number of taxa increased as decreased in abundance when open coast shoreline length increased (Table 2.5). In light trap samples, the abundance of amphipods, megalopae (single and double rostrum), nematodes, lobster larvae, and Lucifer shrimp declined in areas with greater mangrove shoreline. As open coast shoreline increased the abundances of several taxa decreased including lobster larvae and isopods in light traps, and copepods and Lucifer shrimp in plankton tows. The decline in abundance of lobster larvae at mangrove and non-mangrove sites is likely an artifact of lunar cycle having stronger influences on this taxon. Taxon abundances that increased with greater open shoreline length include polychaetes and Monstrillidae copepods in light traps and jellies in plankton tows.

Taxon abundances either increased or were not affected by increasing percentage of mature forest in the upland watersheds (Table 2.6). In light trap samples, the 
abundance of Lucifer shrimp, lobster larvae, amphipods, and megalopae (single rostrum) increased in areas with a greater percentage of mature forest. For plankton tows, copepod and Lucifer shrimp abundances increased with increasing percentage of mature forest cover. 


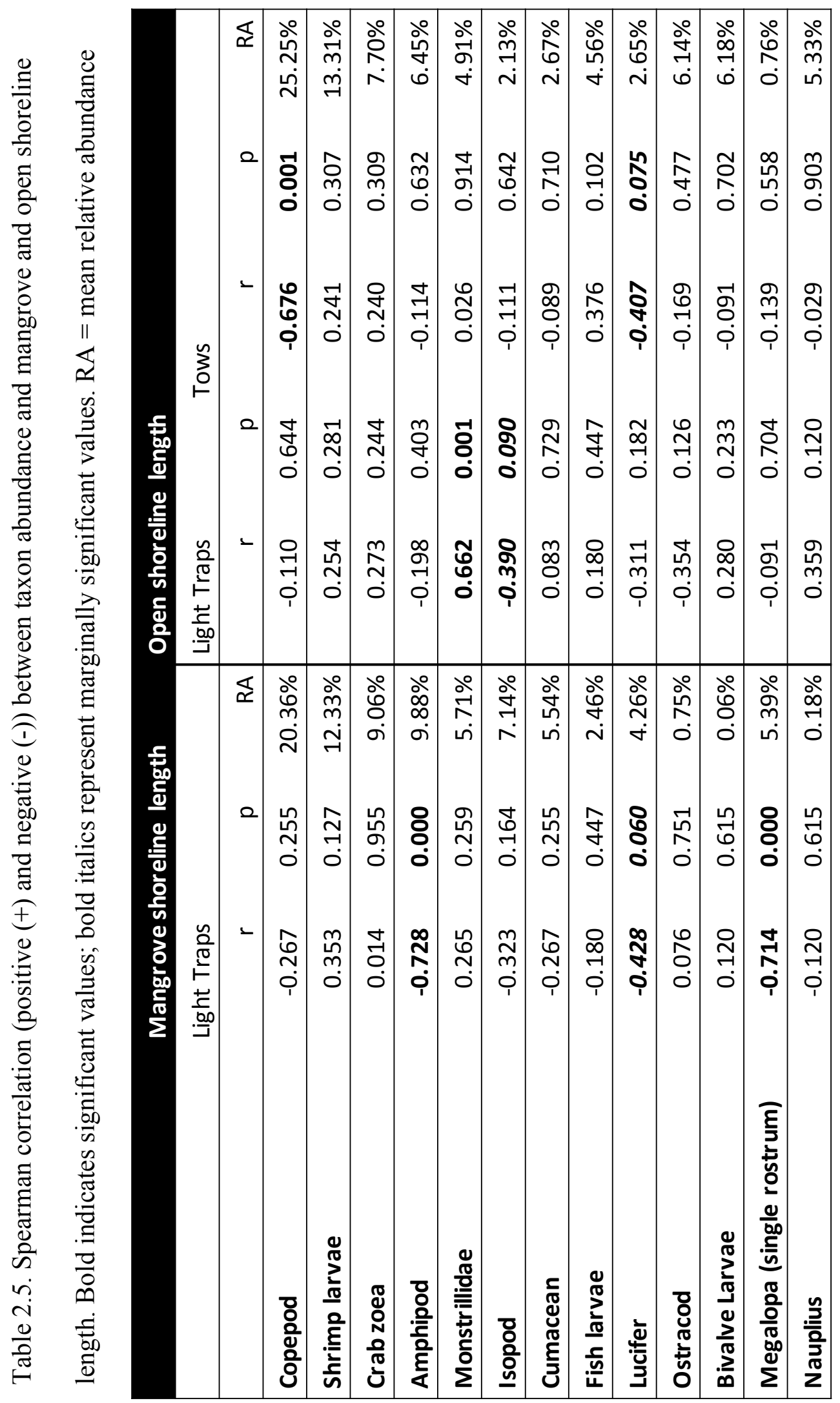




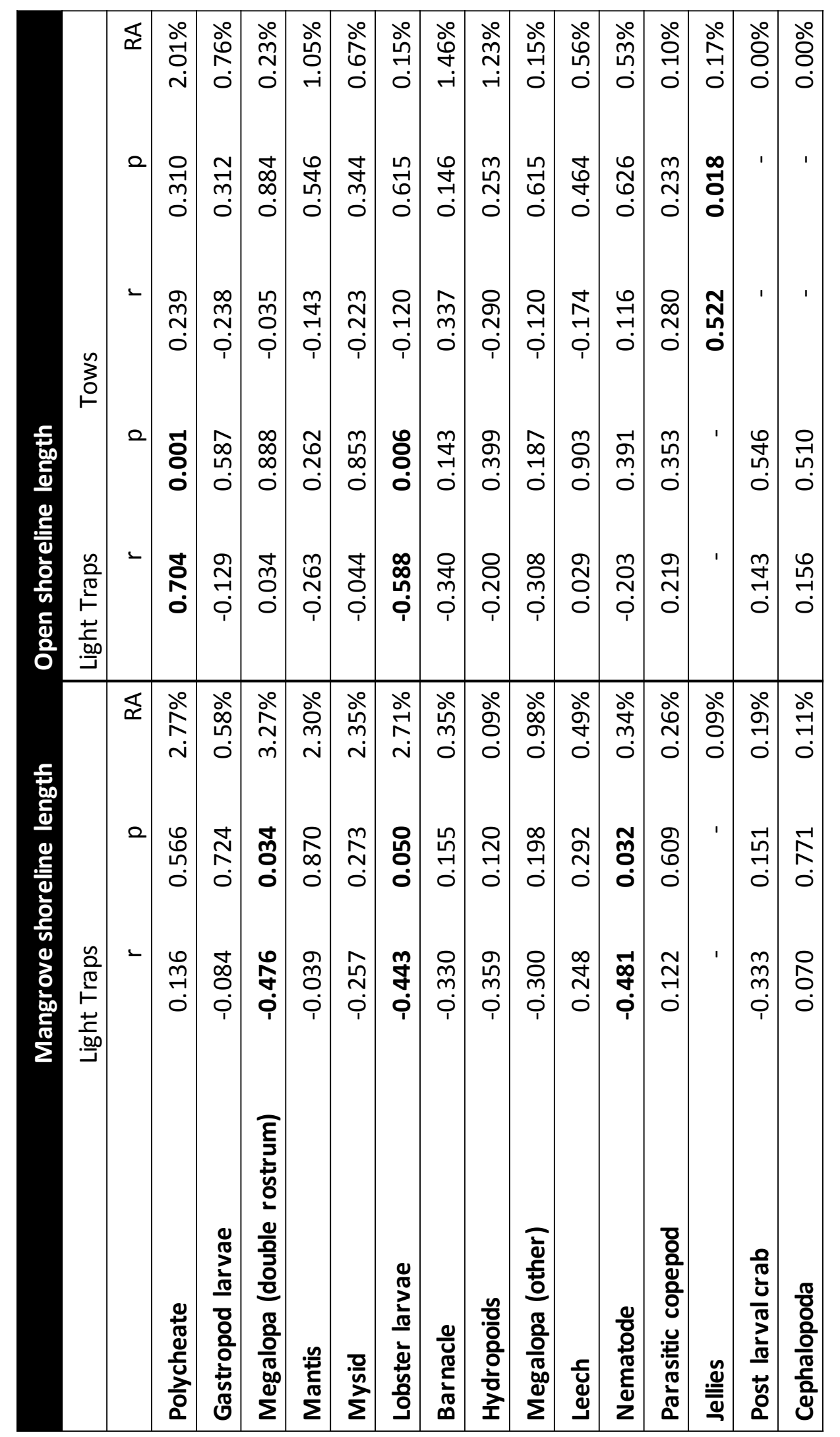


Table 2.6. Spearman correlation (positive $(+)$ and negative $(-))$ between taxon abundance and percentage of mature forest in the watershed. Bold indicates significant values; bold italics represent marginally significant values. $\mathrm{RA}=$ mean relative abundance

\begin{tabular}{|c|c|c|c|c|c|c|}
\hline & $\% \mathbf{M}$ & & & & & \\
\hline & Light Traps & & & Tows & & \\
\hline & $r$ & $p$ & $\mathrm{RA}$ & r & $\mathrm{p}$ & $\mathrm{RA}$ \\
\hline Copepod & 0.178 & 0.453 & $20.36 \%$ & 0.713 & 0.000 & $25.25 \%$ \\
\hline Shrimp larvae & -0.371 & 0.107 & $12.33 \%$ & -0.117 & 0.624 & $13.31 \%$ \\
\hline Crab zoea & -0.080 & 0.739 & $9.06 \%$ & 0.095 & 0.690 & $7.70 \%$ \\
\hline Amphipod & 0.467 & 0.038 & $9.88 \%$ & -0.106 & 0.657 & $6.45 \%$ \\
\hline Monstrillidae & -0.222 & 0.347 & $5.71 \%$ & 0.230 & 0.206 & $4.91 \%$ \\
\hline Isopod & 0.152 & 0.521 & $7.14 \%$ & 0.126 & 0.598 & $2.13 \%$ \\
\hline Cumacean & -0.088 & 0.713 & $5.54 \%$ & -0.156 & 0.512 & $2.67 \%$ \\
\hline Fish larvae & 0.060 & 0.802 & $2.46 \%$ & -0.258 & 0.273 & $4.56 \%$ \\
\hline Lucifer & 0.680 & 0.001 & $4.26 \%$ & 0.489 & 0.029 & $2.65 \%$ \\
\hline Ostracod & 0.142 & 0.551 & $0.75 \%$ & -0.297 & 0.204 & $6.14 \%$ \\
\hline Bivalve Larvae & -0.361 & 0.118 & $0.06 \%$ & 0.002 & 0.992 & $6.18 \%$ \\
\hline Megalopa (single rostrum) & 0.402 & 0.079 & $5.39 \%$ & 0.319 & 0.170 & $0.76 \%$ \\
\hline Nauplius & 0.120 & 0.614 & $0.18 \%$ & 0.012 & 0.959 & $5.33 \%$ \\
\hline Polycheate & -0.176 & 0.459 & $2.77 \%$ & -0.272 & 0.245 & $2.01 \%$ \\
\hline Gastropod larvae & -0.205 & 0.387 & $0.58 \%$ & -0.096 & 0.689 & $0.76 \%$ \\
\hline Megalopa (double rostrum) & 0.154 & 0.516 & $3.27 \%$ & -0.081 & 0.733 & $0.23 \%$ \\
\hline Mantis & -0.071 & 0.768 & $2.30 \%$ & -0.007 & 0.976 & $1.05 \%$ \\
\hline Mysid & 0.346 & 0.135 & $2.35 \%$ & 0.279 & 0.234 & $0.67 \%$ \\
\hline Lobster larvae & 0.472 & 0.036 & $2.71 \%$ & -0.200 & 0.397 & $0.15 \%$ \\
\hline Barnacle & 0.258 & 0.272 & $0.35 \%$ & 0.224 & 0.342 & $1.46 \%$ \\
\hline Hydropoids & 0.200 & 0.397 & $0.09 \%$ & 0.291 & 0.214 & $1.23 \%$ \\
\hline Megalopa (other) & 0.123 & 0.607 & $0.98 \%$ & -0.200 & 0.397 & $0.15 \%$ \\
\hline Leech & -0.353 & 0.127 & $0.49 \%$ & -0.291 & 0.214 & $0.56 \%$ \\
\hline Nematode & 0.319 & 0.170 & $0.34 \%$ & -0.029 & 0.903 & $0.53 \%$ \\
\hline Parasitic copepod & 0.049 & 0.838 & $0.26 \%$ & -0.361 & 0.118 & $0.10 \%$ \\
\hline Jellies & - & - & $0.09 \%$ & 0.175 & 0.462 & $0.17 \%$ \\
\hline Post larval crab & 0.041 & 0.862 & $0.19 \%$ & - & - & $0.00 \%$ \\
\hline Cephalopoda & -0.070 & 0.770 & $0.11 \%$ & - & - & $0.00 \%$ \\
\hline
\end{tabular}




\subsubsection{Temporal variation in zooplankton assemblages}

NMDS for sites with repeated sampling shows strong temporal variation in zooplankton community composition (Figure 2.9). Zooplankton assemblages in samples collected in the fourth lunar quarter were generally more similar to each other than to samples from the same site sampled during the third quarter.

a.

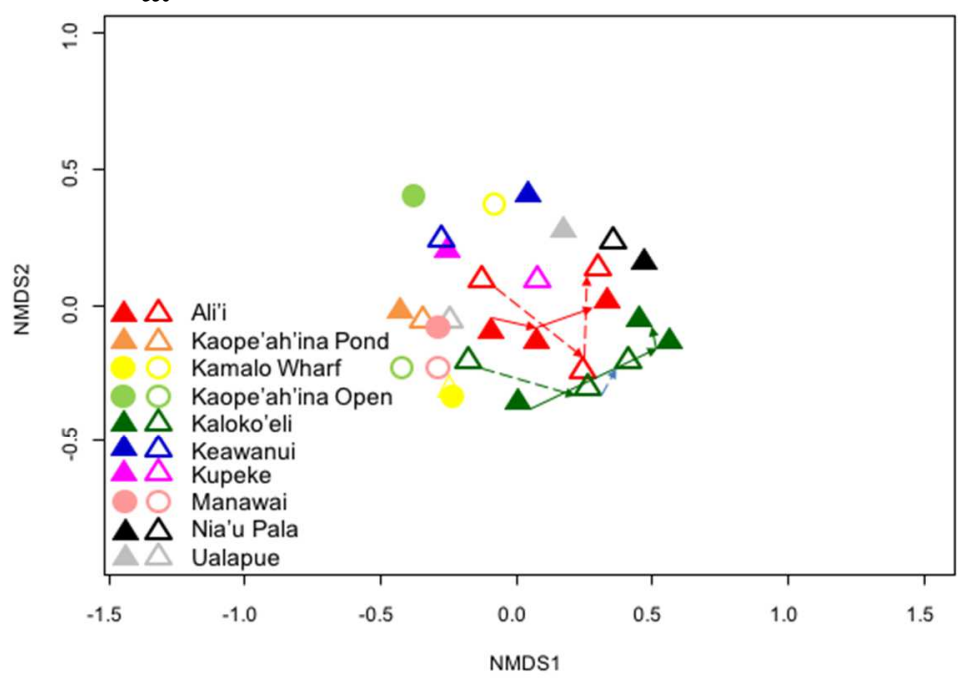

b.

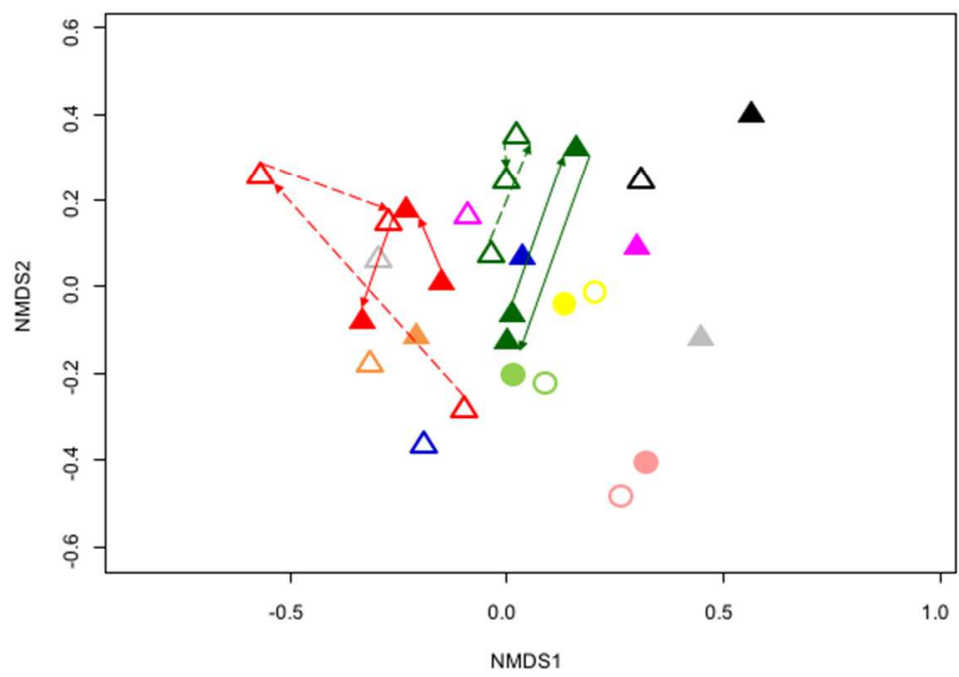


Figure 2.9. Nonmetric multidimensional scaling (NMDS) comparing zooplankton assemblages across all site locations, habitat types, and time collected in a. light traps $($ stress $=0.19)$ and $\mathbf{b}$. plankton tows $($ stress $=0.21)$. Arrows indicate changes in composition over time at the same sampling location. $(\mathbf{\Delta}=$ fishpond mangrove, $\Delta=$ fishpond non-mangrove, $\mathrm{O}$ = open coast mangrove, $\mathrm{O}$ = open coast non-mangrove)

\subsubsection{Fishponds create novel habitat}

When disregarding mangrove presence and only considering whether samples were collected within or outside of fishponds, zooplankton community composition was different inside and outside of fishponds (Figure 2.10) (PERMANOVA: light traps: $\mathrm{df}=$ $1, F=2.55, P=0.01$, stress $=0.16$; plankton tows: $\mathrm{df}=1, F=1.70, P=0.09$, stress $=$ 0.195). For ellipses with 95\% confidence intervals see Appendix Figure A8. The assumption of homogeneity of multivariate dispersions was met; there was not statistically significant heterogeneity in dispersions among the habitats $(P>0.05)$. 
a.

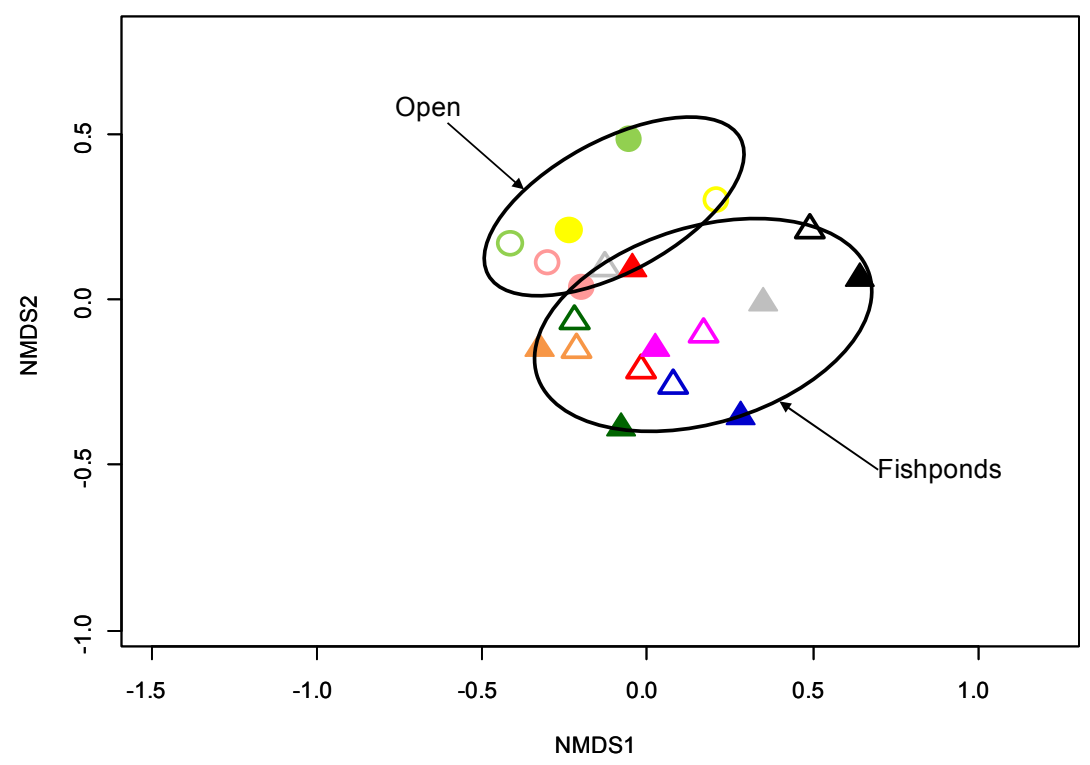

b.

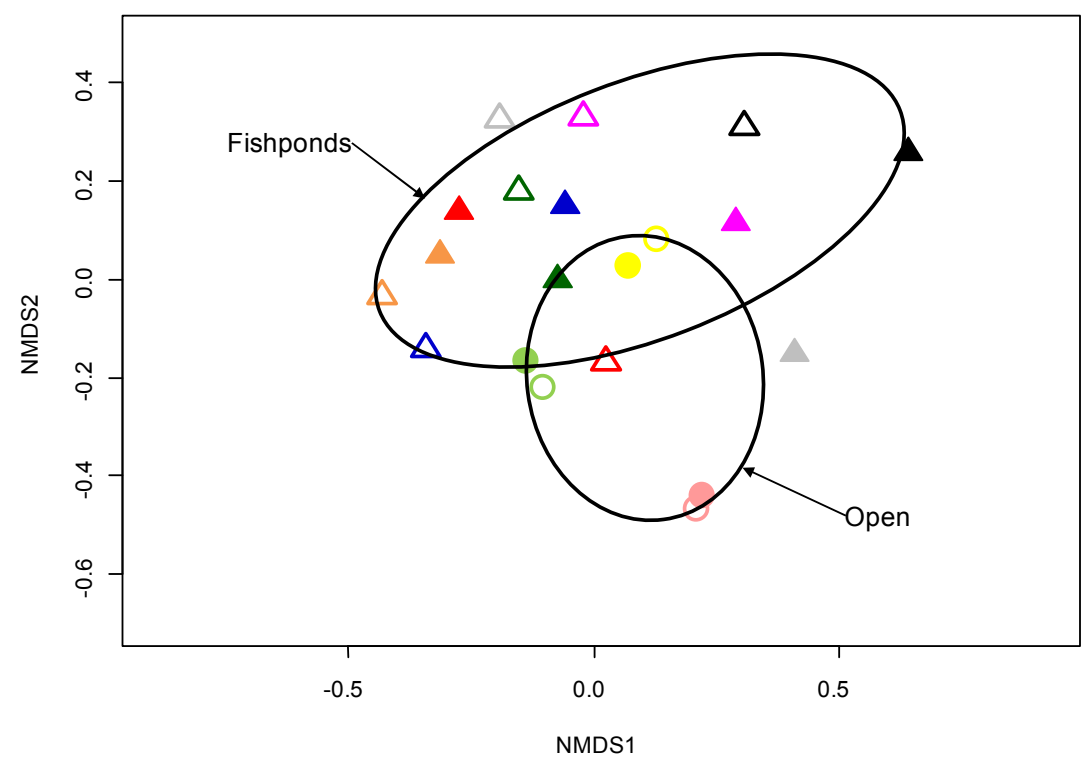

Figure 2.10. Nonmetric multidimensional scaling (NMDS) comparing zooplankton assemblages between open sites and fishpond sites $\mathbf{a}$. light traps (stress $=0.16)$ and $\mathbf{a}$. plankton tows (stress = 0.195). ( $\boldsymbol{\Delta}$ = fishpond mangrove, $\boldsymbol{\Delta}$ = fishpond non-mangrove, = open coast mangrove, $\mathrm{O}=$ open coast non-mangrove) 


\subsection{DISCUSSION}

I hypothesized that mangroves on Moloka'i would have similar patterns as in their native habitat including greater richness and diversity of zooplankton and different community composition than non-mangrove sites. This study found no significant differences between sites with and without mangroves in terms of richness, diversity, or community composition (also see Appendix; Figures A4 and A5). However, there are notable trends in richness and diversity among habitat groups (Figure 2.4), indicating that the lack of significance may be due to the small sample size. In fish ponds, light trap samples in mangrove and non-mangrove areas are similar in terms of richness and seem to be an intermediate between mangrove and non-mangrove open coast habitats. Open coast mangrove sites had the highest richness while open coast non-mangrove sites were lowest. Rarefaction analysis indicated that open coast mangroves sampled in light traps did not reach an asymptote indicating that richness may not have been fully captured for this habitat and may be under-represented in my dataset (Appendix Figure A10).

Further, when just assessing differences between open coast sites and fishpond sites, their community assemblages are different (Figure 2.10). These differences suggest that fishponds create microcosms with unique community assemblages. The novel habitat created within fishponds may be partially due to the accumulation of mud and sediment within ponds when they are not actively cleared out (Kepler and Kepler 1991, Roberts and Field 2008). The sediment buildup creates a different habitat for not only zooplankton but other marine organisms. Moreover, fishpond walls change habitat complexity by adding additional structure to the environment that limits flow and entry 
by larger species while also providing protection for zooplankton. Additionally, since zooplankton samples for non-mangrove sites were collected along fishpond walls and not in sand habitat as in open sites, the community composition may be different along pond walls from that in open coast habitat and possibly more similar to that of mangrove habitat due to the structure complexity of pond walls, so that we did not observe as large of a difference in community composition as possible.

Paired open coast sites have more variable communities of photosensitive zooplankton (light trap sampling) than those collected with plankton tows as reflected in the richness. This may indicate that open coast mangroves are providing habitat not offered by historical open coast habitat and fishponds may provide a habitat barrier such that paired pond sites experience extensive mixing or spillover between mangrove and non-mangrove areas. This effect may mask differences in community composition and variations in habitat diversity where mangroves are present and therefore, analysis of overall site characteristics is necessary to understand differences in community composition. Hence, further discussion focuses on significant drivers of zooplankton community composition rather than the four habitat groupings.

Zooplankton community composition varied by night in the lunar cycle and with a suite of environmental differences among sites, including site size and mangrove shoreline length. In general, paired sites were more similar to each other than to sites of a similar habitat category, though paired sites sampled across different periods of the lunar cycle show notable differences in community composition across the lunar month (Figure 2.5,2.6,2.9). Based on repeat sampling across multiple lunar nights at Ali'i and 
Kaloko'eli, differences among sites may be an artifact of lunar night rather than a reflection of actual differences in community composition (as seen in Figures 2.5, 2.6, 2.9).

\subsubsection{Habitat complexity}

Changes in zooplankton community composition co-varied with the length of non-mangrove open shoreline within a site for both sampling methods. Differences in mangrove shoreline length only co-varied with changes in community composition in light trap samples. Within light trap samples, taxon abundances either decreased or were not affected as the length of mangrove shoreline increased (Table 2.5). For both sampling methods, an about equal number of taxa had abundances that increased or decreased with increasing open coast shoreline (also see correlation to overall community parameters and percentage of mangrove shoreline length in Appendix; Tables A6 and A8).

Decreased abundances of certain taxa with increasing mangrove shoreline is contrary to how many zooplankton behave in native mangrove habitat where mangroves have higher abundances of certain taxa and diversity in mangroves is more than $50 \%$ higher than nonmangrove habitat (Granek and Frasier 2007). This finding indicates that mangroves interact with zooplankton taxa differently in non-native habitat. While most mangrove environments support more diverse and abundant zooplankton communities than adjacent non-mangrove embayments (Robertson and Blaber 1992, Kathiresan and Bingham 2001), such high abundances do not occur in all mangrove environments. For example, Goswami (1992) found lower zooplankton biomass in mangroves than in contiguous estuarine and neritic habitats in India due to the relatively harsh environment of these 
mangroves. Moloka'i's mangroves have a larger tidal range than the Caribbean where mangroves are permanently flooded; this environment only permits zooplankton and zooplanktivores to periodically enter the mangroves at higher tides so marine species can only take advantage of mangrove benefits at certain times of day and creates a harsher environment due to greater fluctuations in salinity and other physio-chemical parameters.

Mangroves are known to provide habitat for juvenile reef fish, including zooplanktivores (Kathiresan and Bingham 2001, Krumme and Liang 2004, Mumby et al. 2004, Nagelkerken et al. 2008). In tropical estuaries, mangroves increase the diversity and quantity of food available to these juvenile fish (Blaber and Blaber 1980, Blaber 1987). For mangroves that drain at lower tides, fish typically enter the mangroves at high tide to feed (Vance DJ et al. 1996, Sheaves and Molony 2000, Lugendo et al. 2006). As sampling on Moloka'i was conducted when the mangroves were inundated, a similar process could be taking place in Moloka'i mangroves. Greater zooplanktivores at higher tides can exert higher predation pressure on zooplankton assemblages in mangroves than in open coast habitat and may be reducing mangrove zooplankton abundances. In our study, zooplankton taxon abundances either decreased or were not affected by greater mangrove shoreline. This trend may be due to both zooplankton and zooplanktivores utilizing mangrove habitat when the tide is in and hence lower recorded zooplankton abundance. This finding is further supported by a study that determined non-native mangroves in Hawai'i are not having an adverse effect on native fish assemblages and may even provide nursery habitat for native and exotic fish (MacKenzie and Kryss 2013). 


\subsubsection{Lunar cycles}

Community composition varied by sampling night across methods, likely due to lunar phase and associated tides. Zooplankton are influenced by lunar cycle, generally being most abundant in samples collected at the full moon (Hernández-León 1998, Hernández-León et al. 2002, 2004). Repeat sampling at two sites across three nights each allowed for evaluation of temporal differences by controlling spatial heterogeneity. These sites were first sampled during the middle of the third lunar quarter (five days after the full moon) and then sampled twice more in the middle of the fourth lunar quarter. Community composition of sites sampled in the fourth lunar quarter were more similar to each other than to samples from the same site collected during the third quarter, with later samples associated with lower abundances (Figure 2.9, Appendix; Table A7).

In the Canary Islands, decreased zooplankton biomass after the full moon was due to timing of the rising moon (Hernández-León et al. 2002). As the moon rises later each night after the full moon there is an increasing period of darkness during the first hours of the night. During these hours, diel vertical migrants, many of which are zooplankton predators, move to shallower waters and subsequently reduce zooplankton biomass (Hernández-León et al. 2002). I observed a similar pattern, whereby abundances of crab (zoea, megalopa, and post larval), shrimp larvae, Monstrillidae, isopods, fish larvae, hydropoids, and jellies decreased the later samples were collected after the full moon (Figure 2.5,2.6, Appendix; Table A7). In some studies, diel vertical migration increased predators in shallow waters by $\sim 70 \%$, which are then able to prey on epipelagic zooplankton (Longhurst and Williams 1979, Hernández-León et al. 2002). This pattern 
could explain significant decreases in zooplankton abundance across habitat types during third quarter sampling and may explain differences in community composition, abundance, and diversity patterns across sites, as sites were sampled on different nights and all sites were sampled after the full moon.

More specifically, many taxa that had significant decreases in abundance later in the lunar cycle were developmental stages of crab (see also meroplankton/holoplankton and species relevant to human consumption analysis in Appendix; Figures A1, A2, and A3 and Section A2). These decreases may be associated with the timing of the larval release of crabs as release of crab larvae varies by intertidal habitat (Morgan and Christy 1995). Crabs in the high and middle intertidal zones release their larvae during the largest-amplitude nocturnal high tides of the lunar month (Morgan and Christy 1995). This timing corresponds with the safest time because larvae can be transported quickly from shore at night when predation by visual zooplanktivores is limited (Morgan and Christy 1995). A large-amplitude nocturnal high tide occurred prior to sample collection and another after sampling concluded. If crab reproduction on Moloka'i follows a similar pattern, larval release may explain why multiple crab developmental stages significantly decreased over time. The longer after reproduction the greater the chances of larvae dispersing, dying, or becoming prey. This same pattern has been observed generally for decapod crustaceans (Forward 1987), which can explain why decreases in abundance of lobster larvae were observed in both mangrove and non-mangrove sites. 


\subsubsection{Human disturbance}

For light trap sampling, human disturbance were correlated with changes in zooplankton community composition. For both sampling methods, taxon abundances increased as the percentage of mature tree cover in the watershed (lower human disturbance) increased (Table 2.6). In light traps, amphipods, lobster larvae, Lucifer shrimp, and megalopae had greater abundances as percentage of mature forest increased; in plankton tows, only copepods and Lucifer shrimp abundances significantly increased as the percentage of mature forest increased. This trend may indicate an environmental impact gradient where locations with lower anthropogenic impacts support more abundant populations of certain taxa than those with greater impacts (there is a similar trend when only considering meroplankton but it does not extend to overall community parameters, see Appendix; Table A2 and A3). This pattern is consistent with other research on the sensitivity of zooplankton to human influences (Attayde and Bozelli 1998, Micheli 1999, Rogers and Greenaway 2005). Additionally, greater mangrove shoreline length is strongly correlated with more disturbed watersheds (Appendix; Table A11, though the pattern is not as strong when considering percent mangrove shoreline length Appendix; Table A4, A5). This correlation may indicate that mangroves are benefiting from terrestrial anthropogenic nutrient inputs and possible habitat benefits might be obscured due to negative impacts of human influence on zooplankton communities.

In general, greater nutrient inputs (which would be expected in more disturbed watersheds) lead to greater phytoplankton biomass (Smith et al. 1999, Micheli 1999). In a 
simple food web, an increase in phytoplankton should lead to an increase in herbivorous zooplankton due to a greater food abundance. In contrast, Moloka'i's zooplankton had lower abundances or were not affected by more disturbed watersheds (Table 2.6). Greater productivity due to anthropogenic nutrient enrichment often leads to increased proportions of inedible algae (Paerl 1988, McCauley et al. 1989, Smith et al. 1999, Micheli 1999), which may explain observed patterns (Leibold 1989, Brett and MullerNavarra 1997, Micheli 1999). This pattern has been observed in mesocosm experiments in addition to numerous natural marine systems worldwide (Turner and Tester 1997, Micheli 1999), but it is unknown whether such a pattern occurs in the tropical Pacific. In particular, copepods have the ability to test single particles to determine if they are suitable or not and can, therefore, avoid consuming noxious algae or cyanobacteria (DeMott 1986, Lampert 1987). On Moloka'i, there were significantly more copepods in plankton tows in areas where watersheds were less impacted by human disturbance.

Some taxa on Moloka'i display sensitivity to human disturbance with greater abundances observed at sites below less disturbed watersheds. Similar to other studies that have proposed using zooplankton as environmental indicators (Attayde and Bozelli 1998, Rogers and Greenaway 2005), this may be a viable option on Moloka'i. However, most of the sites in this study had minimal development, so without further confirmation that these trends are not only seen at the lower range of human disturbance, caution should be taken in interpretation. Additionally, even though shifts in distributions of zooplankton can provide visual indications of disturbance, additional work is necessary to 
determine the processes that most influence changes over time (Rogers and Greenaway 2005).

\subsubsection{Conclusion}

Overall, lunar cycles and site dynamics, including fishpond structure, mangrove and open shoreline length, percentage of mangrove shoreline length, total percentage of carbon in mangrove leaves and disturbance in the upstream watershed influenced zooplankton community composition. The influence of mangroves on community assemblages are difficult to identify within fishponds likely because of extensive mixing within these structures; differences in community composition are only visible when looking at the length or percentage of mangrove shoreline at a site. The findings presented here suggest that non-native mangroves support community composition, richness, and diversity similar to non-mangrove areas, though some widespread taxa have lower abundances in mangrove habitat, as found in Granek and Frasier (2007).

My research suggests that in the face of declining fisheries, threatened reef habitat, and changing climate and ocean conditions, mangroves may provide zooplankton habitat in novel locations similar to that provided by native habitat, such that habitat availability for zooplankton are not hindered by non-native mangroves. For non-native species that have become established in an ecosystem, evaluation of the suite of benefits and detriments can facilitate more comprehensive and cost effective management decisions. In addition to zooplankton habitat, the role non-native mangroves play in providing habitat for adult fish and invertebrates species, buffering adjacent coral reefs from sedimentation (Ogston et al. 2004, Field et al. 2007), and sequestering carbon 
(Alongi 2012) are poorly known. As the impacts of climate change on marine environments include physical, biological, and chemical modifications, novel solutions may be necessary. For example, as sea level rises and storm frequency and intensity increase, if mangroves are not detrimentally affecting the ecosystem, their benefits may outweigh their detriments. Species introductions are an ongoing phenomenon and management of non-native species worldwide could be improved by incorporating evaluations of services and disservices provided under changing climatic and demographic conditions. 


\section{CHAPTER 3: Assessing local attitudes and perceptions of non-native species to inform management of novel ecosystems}

\subsection{INTRODUCTION}

Novel ecosystems (species combinations and abundances that have not been previously present within a given ecosystem) are becoming increasingly abundant and management approaches require their consideration (Hobbs et al. 2006, 2014). These ecosystems can be created by non-native species, changing land use and climatic conditions, and demographic factors, posing challenges for natural resource managers (Truitt et al. 2015). The difficulty of balancing limited scientific information about the costs and benefits of non-native species and novel habitat coupled with the often strong attitudes and perceptions held by local stakeholders about such ecosystems complicate management decision-making. Given these complex scenarios, integration of local stakeholders' aspirations and perceptions into biodiversity conservation has become more commonplace (Mehta and Kellert 1998). Such efforts facilitate community participation, support, and benefits of sustainable natural resource management and can enhance project success (Gillingham and Lee 1999). Yet the first step to such integration is to identify people's values and beliefs, attributes that provide the foundation for attitudes about natural resources and perceptions of management actions and institutions (Ajzen 2001, Stern 2008).

Both scientific and societal perceptions of non-native species have demonstrated a persistent negative bias (Slobodkin 2001, Gurevitch and Padilla 2004, Stromberg et al. 
2009), which can impede consideration of potential benefits (Schlaepfer et al. 2011). As rapid globalization with increasing international trade and intercontinental transportation continue, the rate of non-native introductions is expected to increase (Meyerson and Mooney 2007, Katsanevakis et al. 2014, Tittensor et al. 2014). Although invasive species can negatively affect their new environments, they may provide ecosystem services in areas experiencing rapid climate-related and land use changes (Schlaepfer et al. 2011, Tassin and Kull 2015), yet this potentially beneficial role in supporting new or replacing previously lost ecosystem services is rarely studied (Charles and Dukes 2007b; but see Pyšek et al. 2008, Ewel and Putz 2004, Tassin and Kull 2015). While the potential benefits of invaders on native species is largely unappreciated, assessments must recognize that many natural conditions have been altered and invasive species can be a key part of ecosystem function (Lugo 2004, Goodenough 2010, Schlaepfer et al. 2011, Eviner et al. 2012, Rodewald 2012, Lugo et al. 2012, Tassin and Kull 2015).

Managing non-native species is as much a social issue as it is a scientific one (Reaser 2001). From functioning as agents of introduction (intentional or accidental), to dealing with ecological changes from, and making management decisions about nonnative species, humans are involved in the entire invasion process and, therefore, the issue is both a socio-economic and ecological problem (García-Llorente et al. 2008). Truitt et al. (2015) argue that management approaches need to consider ecological conditions, ecosystem services, management resources, and stakeholder interests and priorities to determine the most appropriate action. 
Where non-native species management programs are well established, community surveys to better understand people's perceptions towards non-native species and their reactions to proposed management are becoming more common (Johnston and Marks 1997, Fraser 2001, 2006, Bardsley and Edwards-Jones 2007, Sharp et al. 2011). Though recent projects have shown increasing efforts to incorporate social viewpoints, relatively little attention has been placed on public attitudes towards invasive or non-native species management, likely due to the difficulty in measurement (Simberloff 2005, Fraser 2006, Hulme 2006, Bremner and Park 2007, Fischer and Van Der Wal 2007, García-Llorente et al. 2008; but see Estévez et al. 2015). Addressing factors influencing public attitudes has led to greater support and increased success for biodiversity management measures, policies, and planning decisions (Balram and Dragićević 2005, Bremner and Park 2007, Fischer and Van Der Wal 2007). Thus, for more successful management outcomes, there is an urgent need to better understand societal perceptions toward non-native species (García-Llorente et al. 2008).

Mangroves on Moloka'i, Hawai'i present a unique case study to examine societal perceptions towards non-native species due to the intentional nature of their introduction and the length of time since introduction. On Moloka'i, human land use changes have affected the landscape since the late 1800s and led to the introduction of red mangroves (Rhizophora mangle) in an attempt to reduce sedimentation on the near-shore coral reef (Roberts 2000). Since their introduction in 1902 (Wester 1981, Allen 1998, Field et al. 2007), mangroves have become well established and, despite localized removal programs, eradication may be a near impossible endeavor. Invasive species removal is 
expensive, time consuming, and is not guaranteed to be successful (Pimentel et al. 2005b). In addition, as climate change impacts the frequency and intensity of hurricanes and tropical storms (Michener et al. 1997), non-native mangroves may aid Moloka'i in coastal climate adaptation considering mangroves' role as a natural buffer for these events (Spalding et al. 2010). In addition, in their native habitat, mangroves provide a multitude of ecosystem services, prompting numerous conservation efforts. Finally, public support of mangrove management in Hawai'i remains undetermined; gaining an understanding of which management practices may be supported and why, would aid in management planning.

This study explores Moloka'i residents' perspectives of non-native mangroves and their management through analysis of questionnaire responses to provide an understanding of residents' evaluation of non-native mangroves, including attitudinal influences that can be used to predict the degree of public support and/or opposition managers may experience. Specifically, the study addresses the following questions:

1. What are residents' attitudes towards non-native mangroves?

2. What factors influence these attitudes?

3. How may attitudes towards mangroves and coastal management influence support of management practices?

These questions serve as a proposition for a framework (Figure 3.1) to assess and incorporate diverse perceptions and attitudes into decision-making around novel ecosystems created by non-native species. Specifically, this framework allows managers and scientists to identify project scope including management priorities and relevant 
stakeholders. As novel environments are complex socio-ecological systems, consideration of both stakeholder attitudes and scientific research on services and disservices of the novel ecosystem are important. Information can then be synthesized to develop management options and educational goals that provide more effective stakeholder engagement. This framework describes an integrated and adaptive approach to managing novelty in complex socio-ecological systems in an ever-evolving world.

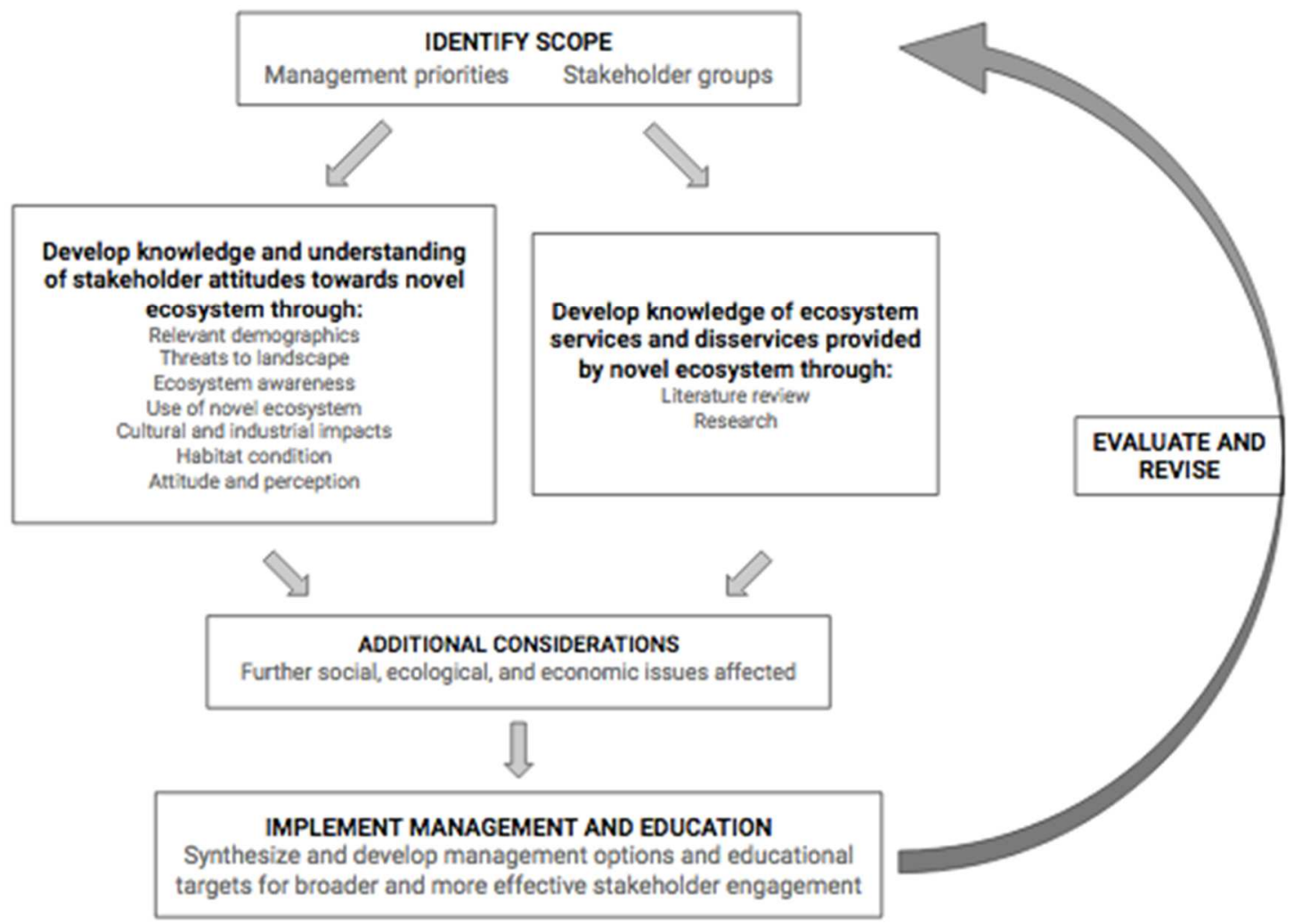

Figure 3.1. A framework for optimizing novel ecosystem management through consideration of stakeholder socio-cultural attitudes and values 


\subsection{METHODS}

\subsubsection{Study area}

The study was conducted on the island of Moloka'i (population 6,885; US Census 2014) in the Hawaiian Archipelago in the Pacific Ocean. Moloka'i provides an interesting case study due to the significant history of land use changes leading to purposeful introduction of the non-native red mangrove. While there are numerous conservation and restoration projects for native mangroves throughout the tropics, in the Hawaiian Islands there are removal and eradication programs. The health of Moloka'i's near-shore coral reefs is of concern due to sedimentation caused by previous and current land use conditions, and mangroves may play a role in buffering this reef stressor. Given the pressure to manage Moloka'i's mangroves and current land use, demographic, and climatic conditions, it is important to examine residents' uses of and attitudes towards non-native mangroves.

\subsubsection{Data collection}

For this study, attitude is considered a learned and summative assessment that influences thoughts and actions (Ajzen and Fishbein 1980, Vogel and Wanke 2016). As attitudes are not directly observable, optimal methods to assess them involve questionnaires (Dawes 1972). Previous studies have identified demographics, place connections and value systems, perceptions of costs and benefits, knowledge, and distrust in conservation authorities as factors that influence attitudes towards the environment and public opposition to management (Schultz and Zelezny 1999, Blake 2001, Lakhan and Lavalle 2002, Genovesi 2007). 
To assess both attitudes and factors influencing those attitudes, an intercept survey was used (Appendix B; Internal Review Board human subjects' approval in Appendix C). I conducted a paper and pencil questionnaire distributed on Moloka'i during June 2015 with the intent of sampling a minimum of 200 adult Moloka'i residents. Participants were required to be 18 or older and have lived on Moloka'i for two or more years. A quasi-chain sampling method was employed with some individuals providing additional participants or intercept venues. Surveys were distributed to stakeholders and non-profit organization staff by trained researchers at venues including the Moloka'i Ka Hula Piko (hula festival), a local grocery store, Saturday market, local churches, and the high school.

\subsubsection{Measures}

The questionnaire included 32 questions, comprised of 7-point Likert-scale response, multiple choice, and open-ended response items. Questions assessed respondents' attitudes towards Moloka'i's mangroves, threats to Moloka'i's coastal areas, and support for management of Moloka'i's mangroves using a 7-point Likert-scale that ranged from "Strongly Agree" (3) to "Strongly Disagree" (-3), with a midpoint of "Neither Agree nor Disagree" (0). Awareness of benefits and costs of mangroves was measured on a 7-point Likert-scale that ranged from "Very Well Informed" (3) to "Very Uninformed" (-3). Frequency of interaction with mangroves was measured on a 5-point unipolar scale that ranged from "Never" to "Daily". Using a 7-point Likert scale, condition of Moloka'i's southern coast was measured on a range from "Very Healthy" (3) to "Very Unhealthy" (-3), and the quality of management of Moloka'i's southern 
coast was measured using a range from "Very Well Managed" (3) to "Very Poorly Managed" (-3).

\subsubsection{Data analysis}

Summary statistics on attitudes towards mangroves were used to address the first question (residents' attitudes towards non-native mangroves). Responses were averaged into a summary attitude index due to high correlations and conceptual consistency. Cronbach's alpha was used to measure the index's internal consistency $(0.70-0.90$ is considered adequate) (Cronbach 1951, Tavakol and Dennick 2011). This averaged index was used as the dependent variable to answer the second question (what influences attitudes towards non-native mangroves) and then used as a predictor when assessing the third question, support of management.

For the second question, logistic regression was as a model to predict negative attitudes compared to all other attitudes (positive and neutral). Some predictor variables were indexed due to high correlations and conceptual consistency, and Cronbach's alpha was used to measure internal consistency. The response variable (attitude toward mangroves) was divided into two categories according to the valence of the attitude index: positive/neutral (0) and negative (1). As mangrove management planning is ongoing, logistic regression provides important information on the difference in predictors of positive/neutral versus negative attitudes. A full logistic regression model was built and then reduced by removing variables that increased the Akaike Information Criterion (AIC) from that of the null model's using a hybrid approach (stepwise and criterion based). I used Variance Inflation Factor (VIF) to assess the model for 
multicollinearity issues, with a VIF greater than or equal to 4 indicating possible collinearity. VIF was less than 2 for all variables in the full and reduced models. I assessed how well the model fit the data by using a $\mathrm{Chi}^{2} \mathrm{p}$-value of the deviance of the residuals where a p-value greater than 0.05 indicates the model fits the data well. The McFadden and Nagelkerke $\mathrm{R}^{2}$ values were calculated to further evaluate model fit compared to a null model. ANOVA was used to compare the full logistic model to the reduced logistic model. Variables were standardized to make coefficients comparable. For multinomial logistic regression analysis see Appendix D.

The final research question was assessed using ordinary least squares (OLS) regression to predict what attitudes and perceptions influence support of certain management decisions. Several aspects of management were modeled, including quality of coastal management and mangrove management approaches including active management, leaving alone, and eradicating mangroves. A full model was built for each management activity, then reduced by removing variables that increased Akaike Information Criterion (AIC) from that of the null model's using a hybrid approach (stepwise and criterion based). Variance Inflation Factor (VIF) was used to assess all models for potential multicollinearity, with a VIF greater than or equal to 4 indicating possible collinearity. VIF was less than 2 for all variables in the full and reduced models. ANOVA was used to compare the full and reduced models. Variables were standardized to make coefficients comparable. All statistical analyses were performed using "R" version 3.2.2. 


\subsection{RESULTS}

\subsubsection{Descriptive Results}

A total of 204 survey responses were collected. Relative to Moloka'i's general population (US Census 2014) there were more female (65\% survey; $51 \%$ census) and older (median age of respondents was 46-50 years; median age per US Census was 38 years) respondents. These respondents had a higher level of education (half of survey respondents had at least an associate/vocational degree; most residents have a high school degree per US census) than census data. The median reported survey income and the range reported by the census were comparable. Residence times on Moloka'i and Hawai'i ranged from two to over 81 years, with averages of 31 and 40 years, respectively (Table $1)$.

Table 3.1. Summary of demographic and place connection variables used in regression.

\begin{tabular}{|c|c|c|c|}
\hline Variables & Mean (SD) & $\%$ & $\mathrm{~N}$ \\
\hline \multicolumn{4}{|l|}{ DEMOGRAPHICS } \\
\hline Gender & & & 195 \\
\hline Female (1) & & 65.1 & \\
\hline Male (0) & & 34.9 & \\
\hline Household Income & & & 181 \\
\hline Less than $\$ 25,000(1)$ & & 25.4 & \\
\hline $25,000-\$ 49,999(2)$ & & 29.3 & \\
\hline $50,000-\$ 74,999(3)$ & & 23.8 & \\
\hline $75,000-\$ 99,999(4)$ & & 11.6 & \\
\hline Greater than $\$ 100,000(5)$ & & 9.9 & \\
\hline \multicolumn{4}{|l|}{ PLACE CONNECTION } \\
\hline Lived on Moloka'i (Years) & $30.7(17.5)$ & & 194 \\
\hline Lived in Hawai'i (Years) & $39.0(18.1)$ & & 194 \\
\hline Hawaiian or Pacific Island ethnicity & & & 203 \\
\hline Yes (1) & & 61.8 & \\
\hline No $(0)$ & & 38.2 & \\
\hline
\end{tabular}


Responses to three 7-point Likert-style questions were assessed to examine general attitudes towards mangroves (Table 2). When asked if mangroves on Moloka'i are beneficial, the plurality of respondents (43\%) agreed, while 33\% disagreed (the remainder were neutral). In comparison, when asked if mangroves on Moloka'i are harmful, a near majority (49\%) agreed, while only $21 \%$ disagreed. When asked whether mangroves improve the coast, about a quarter (24\%) agreed, while the plurality (45\%) disagreed. Correlations among these three items averaged 0.66 indicating an overarching summary attitude towards Moloka'i's mangroves. The three attitude items were averaged to create a mangrove attitude index with a Cronbach's alpha of 0.87 (mean $=-0.33$, median $=0$, standard deviation $=1.44$; ranging from -3 to 3 ). Overall, $48 \%$ of respondents had a negative attitude, $21 \%$ neutral, and $31 \%$ positive toward mangroves.

Forty-eight percent of respondents reported feeling informed when considering benefits and costs of Moloka'i's mangroves (Table 2 ). While $85 \%$ of survey respondents reported visiting the mangroves in person, over 50\% interacted with them at least annually and $46 \%$ rely on mangroves for some benefit. Over $20 \%$ of respondents reported using mangroves for two or more benefits, with crabbing and fishing being the highest reported benefits, respectively. Many respondents wrote in using mangroves for building material. Although only $42 \%$ of respondents described Moloka'i's southern coast as unhealthy, 78\% identified sedimentation, runoff, and invasive species as concerns. 
Table 3.2. Summary of variables used in regressions. Some items were indexed using the average of items with conceptual consistency and high correlations; Cronbach's alpha $(\alpha)$ is reported as a measure of internal validity of indexed items.

\begin{tabular}{|c|c|c|c|c|c|}
\hline Variables & Mean (SD) & N & $\%+$ & $\%$ - & $\alpha$ \\
\hline Attitude towards mangroves index & $-0.3(1.4)$ & 197 & 31.2 & 48.0 & 0.87 \\
\hline Beneficial $^{a}$ & $-0.1(1.7)$ & 200 & 42.5 & 33.0 & \\
\hline Harmful| ${ }^{\mathrm{a},+}$ & $0.5(1.6)$ & 197 & 49.3 & 21.3 & \\
\hline Improve the coast ${ }^{\mathrm{a}}$ & $-0.5(1.6)$ & 197 & 24.7 & 45.2 & \\
\hline \multicolumn{6}{|l|}{ VALUES \& EXPERIENCE \& AWARENESS } \\
\hline Familiarity with costs/benefits of mangroves ${ }^{b}$ & $0.3(1.5)$ & 197 & 47.7 & 24.9 & \\
\hline Have visited mangroves $(0 / 1)$ & $0.9(0.5)$ & 199 & 85.4 & 14.6 & \\
\hline Mangrove interactions ${ }^{c}$ & $1.7(1.6)$ & 203 & - & - & \\
\hline Frequency of interaction (days per year) & $30.5(1.3)$ & 199 & - & - & \\
\hline Rely on mangroves for benefit $(0 / 1)$ & $0.5(1.0)$ & 201 & 46.2 & 53.8 & \\
\hline \multicolumn{6}{|l|}{ COAST CONCERNS } \\
\hline Condition of Moloka'i's southern coast ${ }^{d}$ & $-0.3(1.3)$ & 200 & 29.5 & 42.0 & \\
\hline Coastal threat index & $1.8(1.0)$ & 201 & 91.0 & 3.0 & 0.73 \\
\hline Sedimentation is a concern for Moloka'i's coast ${ }^{a}$ & $1.7(1.2)$ & 197 & 80.2 & 3.1 & \\
\hline Chemical runoff is a concern for Moloka'i's coast ${ }^{a}$ & $2.3(1.4)$ & 197 & 78.7 & 6.6 & \\
\hline Invasive species are a concern for Moloka'i's coast ${ }^{a}$ & $2.0(1.1)$ & 201 & 86.6 & 1.5 & \\
\hline Mangroves hurt cultural sites ${ }^{a}$ & $0.8(1.5)$ & 193 & 52.9 & 12.4 & \\
\hline Mangroves hurt industry ${ }^{a}$ & $0.0(1.4)$ & 193 & 22.3 & 23.8 & \\
\hline \multicolumn{6}{|l|}{ MANAGEMENT } \\
\hline Quality of management on Moloka'i's southern coast ${ }^{\mathrm{e}}$ & $-0.6(1.3)$ & 199 & 18.6 & 50.3 & \\
\hline Public involvement in management index & $0.2(1.4)$ & 195 & 36.4 & 25.6 & 0.91 \\
\hline $\begin{array}{l}\text { Decisions about mangroves made with } \\
\text { consideration of public input }^{\text {a }}\end{array}$ & $0.2(1.5)$ & 193 & 35.2 & 23.3 & \\
\hline $\begin{array}{l}\text { Decisions about mangroves made with } \\
\text { consideration of all interests and values }\end{array}$ & $0.2(1.5)$ & 191 & 36.1 & 24.6 & \\
\hline Mangroves should be entirely removed ${ }^{a}$ & $0.2(1.9)$ & 198 & 40.9 & 36.4 & \\
\hline Mangroves should be left alone ${ }^{a}$ & $-1.5(1.5)$ & 199 & 9.1 & 76.4 & \\
\hline Mangroves should be actively managed ${ }^{a}$ & $2.0(1.2)$ & 199 & 88.4 & 3.5 & \\
\hline
\end{tabular}

${ }^{a}$ Variable ranged from strongly disagree (-3) to strongly agree (3) with neither agree nor disagree (0) as a midpoint.

${ }^{\mathrm{b}}$ Variable ranged from very uninformed (-3) to very well informed (3) with unsure (0) as a midpoint.

${ }^{c}$ Mangrove interactions were measured as the number of interaction types respondents had with mangroves (e.g., fishing, managing mangroves in fishponds, etc.) and ranges from 1 to 5.

d Variable ranged from very unhealthy (-3) to very healthy (3) with unsure (0) as a midpoint.

e Variable ranged from very poorly managed (-3) to very-well managed (3) with unsure (0) as a midpoint.

$\dagger$ For index creation, this item was reverse coded for logical consistency. 
Finally, with respect to management, respondents tended to indicate that the quality of coastal management on Moloka'i's southern coast was poor (18.6\% positive; $50.3 \%$ negative; mean management quality $=-0.6$ ). Over $50 \%$ of respondents indicated that the quality of management was somewhat, poorly, or very poorly managed, whereas only $19 \%$ indicated that management quality was somewhat, well, or very well managed. On average, respondents tended to be neutral about the quality of public involvement in mangrove management, with slightly more respondents agreeing than disagreeing that mangrove management decisions consider public input and all interests and values. Support for mangrove removal was evenly split between those supporting and opposing removal $($ mean $=0.2)$. However, respondents were overwhelmingly opposed to leaving them alone ( $76 \%$; versus $9 \%$ who supported leaving them alone), and were overwhelmingly in support of active management of mangroves ( $88 \%$; versus $<4 \%$ opposed to active management).

\subsubsection{Logistic Regression Results}

The stronger the belief that mangroves should be removed, the more likely respondents were to have a negative attitude towards mangroves $(\mathrm{p}<0.001)$, while inversely, the more respondents believed that mangroves should be left alone the less likely they were to have a negative attitude $(\mathrm{p}<0.01)$ (Table 3.3). When considering the coast, respondents who believed that sediment runoff and invasive species threaten the coast (measured through the coastal threat index) were more likely to view mangroves negatively $(\mathrm{p}<0.01)$. In addition, higher incomes and not relying on mangroves for benefit were associated with more negative attitudes $(p<0.05)$. Further, there was a weak 
relationship between belief that mangroves harm cultural sites and negative attitudes towards mangroves $(\mathrm{p}<0.10)$.

This model was significantly different when compared to the null model and ANOVA revealed no significant differences between the full and reduced models $\left(\mathrm{Chi}^{2} \mathrm{p}\right.$ $=0.98$, Nagelkerke $\mathrm{R}^{2}=0.64$, McFadden $\mathrm{R}^{2}=0.47$ ).

Table 3.3. Logistic regression predicting differences between positive/neutral (0) and negative (1) attitudes towards non-native mangroves (coefficients are standardized). $\mathrm{N}=146$ (74 negative, 72 positive/neutral). McFadden $\mathrm{R}^{2}=0.47$, Nagelkerke $\mathrm{R}^{2}=0.64 . \mathrm{Chi}^{2}$ $\mathrm{p}=0.98$

\begin{tabular}{lrrrrrr}
\hline \hline & $\beta$ & $\mathrm{SE}$ & $\mathrm{P}$ & Odds & $2.5 \%$ & $97.5 \%$ \\
\cline { 2 - 7 } Intercept & -0.03 & 0.25 & & 0.96 & 0.59 & 1.57 \\
Income & 0.58 & 0.26 & $*$ & 1.78 & 1.09 & 3.02 \\
Rely on mangroves for benefit & -0.59 & 0.26 & $*$ & 0.56 & 0.33 & 0.92 \\
Coastal threat index & 1.02 & 0.32 & $* *$ & 2.78 & 1.54 & 5.47 \\
Mangroves hurt cultural sites & 0.51 & 0.27 & + & 1.67 & 1.00 & 2.86 \\
Mangroves should be left alone & -0.89 & 0.30 & $* *$ & 0.41 & 0.22 & 0.73 \\
Mangroves should be removed & 1.01 & 0.28 & $* * *$ & 2.74 & 1.61 & 4.97 \\
\hline \hline
\end{tabular}

Significance levels: ${ }^{\dagger}(<0.10),{ }^{*}(<0.05),{ }^{* *}(<0.01), * * *(<0.001)$

\subsubsection{Ordinary Least Squares Regression Results}

An ordinary least squares (OLS) regression was used to predict support of various management activities (Table 3.4). First, respondents' perceptions of the overall quality of southern coastal management on Moloka'i were significantly influenced by their concerns for the coast and their experience and awareness of mangroves. Agreement that managers perform quality coastal management was greatest from respondents who 
perceived the condition of Moloka'i's southern coast as healthy, had low concern for coastal threats, found mangroves less influential on cultural sites, had frequent interaction with mangroves, and lower perceived familiarity with costs and benefits of mangroves. Predictive power of this model was relatively strong (adjusted $\mathrm{R}^{2}=0.54$ ).

Support for active management of mangroves (adjusted $\mathrm{R}^{2}=0.26$ ) was most influenced by concerns about coastal threats, agreeing that mangroves are a threat to cultural sites, experience visiting the mangroves, and perceiving a healthy southern coast. Predictability of support for leaving mangroves alone was relatively stronger than support of active management (adjusted $\mathrm{R}^{2}=0.34$ ), with the most influential predictors being a positive attitude toward mangroves, a shorter residence time in Hawai' $i$, and less frequent interactions with mangrove habitat (or never having visited the mangroves). Finally, the data strongly predict support for mangrove removal (adjusted $\mathrm{R}^{2}=0.54$ ). Negative attitudes towards mangroves were directly related to support for mangrove removal, as was having lived on Moloka'i longer, having a lower household income, having greater perceived familiarity with the costs and benefits of mangroves, and not using mangroves for benefits.

For all models, ANOVA revealed no significant difference between full and reduced models. 
Table 3.4. Ordinary least squares regression results predicting extent of support for mangrove management. Standardized coefficients are presented. ANOVA revealed no significant difference between the full and reduced models.

\begin{tabular}{|c|c|c|c|c|c|c|c|c|}
\hline \multirow[b]{2}{*}{ Intercept } & \multicolumn{2}{|c|}{$\begin{array}{l}\text { Overall } \\
\text { Quality of } \\
\text { Coastal } \\
\text { Management }\end{array}$} & \multicolumn{2}{|c|}{$\begin{array}{l}\text { Mangroves } \\
\text { Should be } \\
\text { Actively } \\
\text { Managed }\end{array}$} & \multicolumn{2}{|c|}{$\begin{array}{l}\text { Mangroves } \\
\text { Should be } \\
\text { Left Alone }\end{array}$} & \multicolumn{2}{|c|}{$\begin{array}{l}\text { Mangroves } \\
\text { Should be } \\
\text { Entirely } \\
\text { Removed }\end{array}$} \\
\hline & 0.06 & & 0.66 & $* * *$ & 0.05 & & -0.15 & \\
\hline Income & & & & & & & -0.19 & $*$ \\
\hline Years in Hawai'i & & & & & -0.01 & * & & \\
\hline Years on Moloka'i & & & & & & & 0.02 & $* *$ \\
\hline Positive attitude for mangroves & & & & & 0.45 & $* * *$ & -0.94 & $* * *$ \\
\hline Rely on mangroves for benefit & & & & & & & -0.44 &.$^{+}$ \\
\hline Log(Frequency of interaction) & -0.17 & & & & -0.34 & $*$ & & \\
\hline Have visited mangroves & & & 0.41 & + & -0.54 & + & & \\
\hline Mangrove cost/benefit familiarity & -0.11 & $*$ & & & & & 0.16 & $*$ \\
\hline Positive condition of South coast & 0.543 & $* * *$ & 0.11 & + & & & & \\
\hline Coastal threat index & -0.177 & $*$ & 0.33 & $* * *$ & -0.15 & & & \\
\hline Mangroves hurt cultural sites & -0.133 & $*$ & 0.22 & $* * *$ & & & & \\
\hline \multicolumn{9}{|l|}{ Mangroves hurt industry } \\
\hline \multicolumn{9}{|l|}{ Model Fit } \\
\hline Adjusted $R^{2}$ & 0.54 & & 0.26 & & 0.34 & & 0.54 & \\
\hline$n$ & 150 & & 151 & & 152 & & 152 & \\
\hline
\end{tabular}

Significance levels: ${ }^{\dagger}(<0.10),{ }^{*}(<0.05),{ }^{* *}(<0.01),{ }^{* * *}(<0.001)$

\subsection{DISCUSSION}

\subsubsection{Attitude: A cornerstone for behavioral intent}

Survey responses indicate that, overall, slightly more residents have a negative than positive view of Moloka'i's non-native mangroves. The "Unsure” responses may indicate that a third of the population is uninformed or has very little contact with the mangroves and therefore has relatively little basis for opinion. As individuals' attitudes are formed from experiences and interactions with their social and natural environment (Schwarz and Bohner 2001, Balram and Dragićević 2005), this could represent a group of 
people who are not actively engaged with this coastal issue. Having an understanding of the ecosystem resulted in most respondents having an attitude, either positive or negative, a finding consistent with other attitude studies (Bremner and Park 2007). Since residents may feel less inclined to participate in local issues if they are uniformed, this may highlight an educational opportunity.

A considerable number of respondents (31\%) had positive attitudes about mangroves, many of whom indicated a perception that mangroves provide important habitat and regulating ecosystem services by controlling sedimentation and reducing erosion runoff to the near-shore coral reefs. These are important services that mangroves provide in their native habitat (Ewel et al. 1998, Mcleod et al. 2011) that have not been fully evaluated on Moloka'i nor in other locales with non-native mangroves. Respondents that reported using mangroves for beneficial uses had a more positive attitude, which may reflect normalization to the plants' presence and recognition of their benefits and usefulness. This phenomenon has been documented with other non-native species in Australia and California (Schlaepfer et al. 2011).

More respondents (48\%) had a negative attitude towards mangroves. Given the recognized negative bias against non-native species (Schlaepfer et al. 2011), negative attitudes towards Moloka'i's non-native mangroves are congruent with and may be influenced by broader negative attitudes toward non-native species. In addition, while many respondents $(12.7 \%)$ wrote in that mangroves were harmful solely because they were non-native or invasive (although $22 \%$ described issues of overgrowth), there were also concerns expressed about the effects on fishponds, ocean access, and views. This 
group is important to understand since negative beliefs and information are more influential than positive ones, exercise a stronger influence on judgments and attitudes (Fiske and Taylor 1991, Cacioppo et al. 1997), and ultimately can exert stronger effects on behavior than positive beliefs (Eagly and Chaiken 1998). Individuals with negative attitudes may be more likely to express these feelings (vocally or with action), especially if management decisions are not in accordance with their beliefs. For instance, in Hawai'i mangrove management, previous actions have focused on removal by chainsaw or chemical poisoning due to negative beliefs many have about this non-native species. In contrast, there has been little mobilization by those with positive beliefs to form effective advocacy coalitions.

\subsubsection{Building blocks of attitude: Influential components}

Determining what variables are influencing attitudes is important as strong attitudes are known to be resistant to change, persist over time, lead to selective information processing, and predict behavior (Eagly \& Chaiken 1998). Respondents that believed mangroves should be entirely removed were more likely to have a negative attitude towards mangroves. The strength of this relationship $(\mathrm{p}<0.001)$ indicates that those who hold negative beliefs have strong feelings about what management actions should be taken with mangroves. Depending on future management decisions, this group is important to consider because if management decisions are not in accordance with their beliefs, they are likely to oppose such decisions.

Though previous studies have noted economic costs of aquatic invasive or nonnative species (Lovell et al. 2006), relatively few have quantified economic benefits 
(Schlaepfer et al. 2011). Positive and neutral attitudes towards Moloka'i's mangroves were more common among respondents who use mangroves for their benefit. Value is a demonstrated component of general environmental attitudes and can manifest in management support or opposition (Balram and Dragićević 2005, Selge et al. 2011). With $46 \%$ of respondents relying on mangroves for some benefit, a large proportion of respondents have learned to utilize this non-native plant to their advantage. In addition to benefits, perceiving that mangroves did not impact cultural sites led to a less negative view of mangroves.

Place connection is a fundamental reason why people partake in action to protect natural areas (Norton and Hannon 1997, Vaske and Kobrin 2001, Lokocz et al. 2011) and may facilitate support for certain management actions. Since time in an area can lead to a stronger connection to place (Gieryn 2000, Lewicka 2005) and the median length of residency for our respondents on Moloka'i was 31 years, it is likely that many have developed a strong sense of place. When respondents perceived coastal threats such as sedimentation, invasive species, and chemical runoff, they were more likely to view mangroves negatively. While $91 \%$ of respondents perceived coastal threats, only $42 \%$ found the condition of Moloka'i's southern coast as unhealthy. This relationship may indicate that respondents have varied beliefs concerning mangroves. Some respondents view mangroves as providing sediment retention and runoff filtration leading to a healthier coast, while other respondents who agreed that Moloka'i's coast was threatened had negative attitudes about mangroves suggesting that mangroves are part of the problem faced by the coastline. Conflicting beliefs of whether mangroves are reducing 
coastal threats or contributing to them may provide an opportunity to improve knowledge gaps concerning the ecosystem services provided by Moloka'i's mangroves.

\subsubsection{Attitudes and management: Assessing levels of management support}

Understanding and incorporating public attitudes into biodiversity management decisions leads to greater support, which can translate into increased project success (Fischer and Van Der Wal 2007). Support of various management actions was most influenced by attitudes towards mangroves, concerns about Moloka'i's coast, and experience with Moloka'i's mangroves. Similar attributes have been found in other studies looking at public support for or opposition to non-native species management (Genovesi 2007, Selge et al. 2011). As attitudes are one predictor of behavior (Ajzen 1985) and negative attitudes are more likely to result in behavior than positive attitudes (Eagly and Chaiken 1998), management planning should investigate stakeholder attitudes to minimize conflict and better inform how management plans may be perceived and acted on by the public (Figure 3.2). 


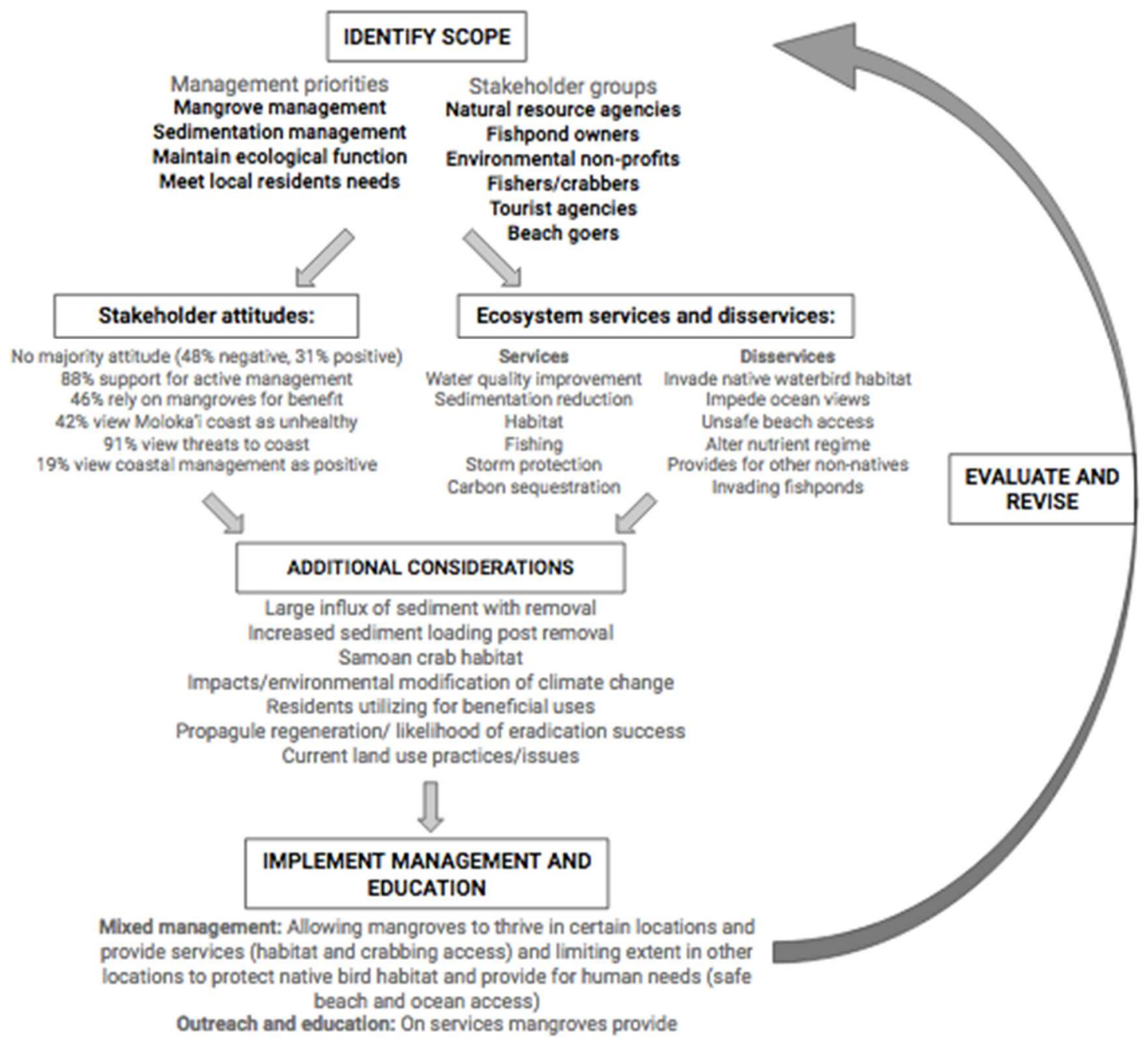

Figure 3.2. Case study findings in the framework for optimizing novel ecosystem

management through consideration of stakeholder socio-cultural attitudes and values

More specifically, when considering respondents' perception of management quality of Moloka'i's southern coast, those who viewed the condition of the coast as healthier had greater support for management. This relationship suggests that successful 
coastal management is perceived as a function of coastal health and provides a simple and straightforward evaluation of the coast and its management practices.

Concern of mangroves damaging cultural sites (e.g., traditional fishponds) and the perception of coastal threats (e.g., sedimentation, runoff, invasive species) were most predictive of support for active management of Moloka'i's mangroves. Eighty-eight percent of respondents agreed that Moloka'i's mangroves should be actively managed. Non-native mangroves may provide beneficial ecosystem services such as reducing coastal storm damage while also creating disservices such as overgrowing fishponds and shorebird habitat. This dichotomy of socio-ecological costs and benefits can be difficult for managers to balance, but survey responses indicate that Moloka'i residents recognize an array of effects by non-native mangroves. Therefore, clear communication between managers and the public about managing tradeoffs may be an effective strategy.

The experiences and interactions that Moloka'ians find valuable provide insight into what residents deem important and drive their positive and negative attitudes. These implications are relevant to environmental management actions more broadly and can increase the likelihood of public support in a variety of settings (Fischer and Van Der Wal 2007).

\subsubsection{Next steps: Education and management}

Overall, there was near consensus among survey respondents $(88 \%)$ that Moloka'i's non-native mangroves should be actively managed. This attitude is also the case where other non-native species have established (Schlaepfer et al. 2011). An active management approach allowing mangroves in certain locations to thrive and provide 
services such as habitat and crabbing access, while in other locations limiting their extent to protect native bird habitat and provide for human needs, including safe beach and ocean access, may ultimately provide the greatest benefits to both the ecosystem and society (Figure 3.2). The findings from this and other studies offer a framework for assessing knowledge, attitudes and perceptions about socio-ecological costs and benefits of non-native species in this and other locales. The framework also offers targets for educational efforts that may increase awareness about non-native species and allow for broader and more effective stakeholder engagement in management planning (Figure $3.1)$.

There was neither a majority positive or negative perception about the mangroves nor majority support for complete eradication, likely because many respondents have found beneficial uses for or recognize positive ecosystem services provided by the mangroves. This dichotomy of perception has been documented in Papua New Guinea where local people have been known to spread non-natives due to their potential use as a commodity (Dudgeon and Smith 2006). It is important to incorporate social perceptions and local uses of non-natives in addition to invasion dynamics when determining appropriate management options. In areas where established non-natives are utilized for beneficial uses, management strategies may need to consider allowing for future use of the species, especially with native populations. For newly, unintentionally introduced species, local use and benefits are unlikely to manifest instantly and eradication may be considered. Consideration of length of establishment, invasive implications, and how 
locals interact with the non-native species are critical to determining appropriate management actions with local support.

Applying the framework, my research approached a novel ecosystem with a goal of better understanding stakeholder attitudes (Figure 3.2). Knowledge of local perceptions towards Moloka'i's mangroves and other non-native species can help managers design strategies that better address ecosystem services and disservices provided, while framing management in a manner that addresses the public's concerns. Without evaluation of societal perceptions, attitudes may be easily misinterpreted, in part because negative beliefs can exert a strong influence on behavior. The combination of social findings and ecological research allows managers to objectively develop effective management options and educational targets that will provide more valuable and cooperative stakeholder engagement. Although this approach may require recognition of ecosystem services and human valuations that are contrary to the negative bias against non-native species, it also may lead to more pragmatic and objective decisions (Walther et al. 2009, Schlaepfer et al. 2011). In doing so, the framework proposed provides a basis for better understanding the net impacts of non-native introductions.

In our globalized world, non-native introductions to coastal ecosystems will continue to have both positive and negative effects that vary over time. Human perceptions towards the novelty created by non-native introductions, especially foundation species, will change, and require an array of management approaches (Maris and Béchet 2010). There may be locations where non-native species fulfill ecosystem functions no longer provided by extirpated native species or where new functions are 
needed due to changing land cover or global environmental conditions (Truitt et al. 2015). Predicting the socio-cultural and ecological effects of these non-native species is increasingly difficult under changing environmental conditions (Walther et al. 2009). Yet considering diverse perspectives through an understanding of local attitudes and factors influencing those attitudes, can allow for a more comprehensive evaluation of the positive and negative effects of non-native species to facilitate more effective management with greater public support (Balram and Dragićević 2005, Bremner and Park 2007, Fischer and Van Der Wal 2007). 


\section{CHAPTER 4: Conclusions}

Sustainability requires understanding the feedbacks and dynamics of the interrelations of both social and ecological systems (Berkes et al. 2003). As Earth becomes increasingly human dominated, many of the changes we see, including biodiversity loss and land-use changes, are driven by human activities (Berkes et al. 2003). Traditionally, researchers have studied the ecological and human world from within the boundaries of one discipline or the other, failing to integrate the relationships between the two systems (Redman et al. 2004). Studying social and ecological systems in isolation is no longer reasonable as humans are an integral part of all ecosystems (McDonnell and Pickett 1993, Vitousek et al. 1997, Redman 1999, Low et al. 1999, Kinzig 2001, Gunderson and Holling 2002).

Within this study, I examined both social perceptions of non-native mangroves on Moloka'i, Hawai'i and ecological interactions of the plant within the marine community. This integration of both social and ecological interactions provides a more comprehensive perspective to better inform management decisions. Since the intentional introduction of red mangroves on Moloka'i, perceptions are fluid and so too are the ecological benefits and disservices the plant may be providing. My study found that currently there is not a prevailing positive or negative attitude towards mangroves on Moloka'i and that they are providing novel habitat that is used similarly to native habitat by zooplankton communities. Variations in zooplankton assemblages depended on lunar cycles and site dynamics, including fishponds, mangrove shoreline length, percentage of mangrove shoreline length, and human disturbance. For certain taxa, abundance 
decreased in samples taken further after the full moon, sites with greater percentages of mangroves, and sites with greater human disturbance. This study indicates that in addition to lunar fluctuations, human influences are altering zooplankton community composition. With zooplankton near the bottom of the food web, these changes may have cascading effects through the ecosystem. As there are numerous benefits of native mangroves, further studies to understand other services and disservices (i.e., protection from wave events, sedimentation reduction, carbon sequestration) of non-native mangroves may provide additional clarity on their role in a novel environment.

With mangroves having spread along the island of Moloka'i, as well as to additional Hawaiian Islands, they are currently embedded in both the social and ecological systems. At their current extent, attempted eradication would be very costly (estimates range from $\$ 108,000-377,000 /$ ha; Allen 1998) and require enormous effort to be successful, so the more relevant question becomes how best to manage them within the context of a socio-ecological system. This study begins to provide answers to this question. While in my survey there were concerns expressed about the tree's impact on native waterbird recovery, beach access, and ocean views, respondents also describe benefits such as tourism, habitat, and plentiful crabbing especially for the highly prized, though also introduced, Samoan crab (Scylla serrata). These findings suggest that in the Hawaiian Islands, mangroves should neither be eradicated nor entirely unmanaged. An active management approach allowing mangroves in certain locations to thrive and provide services such as habitat and crabbing access while in other locations limiting their extent to protect native bird habitat and provide for human needs, including safe 
beach and ocean access, may ultimately provide the greatest benefits to both the ecosystem and society.

Other novel ecosystems created by non-native species, especially when removal poses difficulties, would benefit from similar socio-ecological evaluations. In some cases, attempting to revert systems to some pre-existing condition is a waste of precious resources and we may be better off if these systems were accepted for what they are and what benefits they provide (Hobbs et al. 2006). Addressing both societal concerns and scientific questions about how processes associated with non-native introductions change over time provides integrative results that are more useful than one discipline alone (Redman et al. 2004). A fundamental challenge in analyzing these systems stems from their complexity both spatially and temporally in addition to the interconnectedness of their relationships, many of which are nonlinear (Levin 1992, Janssen 2002, Ostrom 2009). Additional resources are being devoted to socio-ecological research and frameworks are being further revised and developed to enhance the sustainability and usability of these complex systems (Ostrom 2009, Turner II et al. 2016). The lens provided by socio-ecological systems highlights humans' dependence on nature, our growing influence on it, and our ethical obligations towards it, hence both sustainability scientists and policy makers are increasingly interested in these systems and their applicability (Fischer et al. 2015). As environmental issues become increasingly complicated in the age of the Anthropocene, with intricate relationships made more difficult in the face of climate change, progress involving linked socio-ecological systems may provide a comprehensive way to better evaluate and understand our changing world. 


\section{Literature Cited}

Ajzen, I. 1985. From intentions to actions: A theory of planned behavior. Pages 11-39

Action control. Springer.

Ajzen, I. 2001. Nature and Operation of Attitudes. Annual Review of Psychology 52:27-

58.

Ajzen, I., and M. Fishbein. 1980. Understanding attitudes and predicting social behavior. Prentice-Hall, New Jersey.

Alexander, W. D. W. 1899. A Brief History of the Hawaiian People. American Book Company.

Allen, J. 1998. Mangroves as alien species: the case of Hawaii. Global Ecology \& Biogeography Letters 7:61-71.

Alongi, D. M. 2012. Carbon sequestration in mangrove forests. Carbon management 3:313-322.

Anderson, M. J. 2001. A new method for non-parametric multivariate analysis of variance. Austral Ecology 26:32-46.

Attayde, J. L., and R. L. Bozelli. 1998. Assessing the indicator properties of zooplankton assemblages to disturbance gradients by canonical correspondence analysis. Canadian Journal of Fisheries and Aquatic Sciences 55:1789-1797.

Baier, C., and J. Purcell. 1997. Trophic interactions of chaetognaths, larval fish, and zooplankton in the South Atlantic Bight. Marine Ecology Progress Series 146:4353. 
Balram, S., and S. Dragićević. 2005. Attitudes toward urban green spaces: integrating questionnaire survey and collaborative GIS techniques to improve attitude measurements. Landscape and Urban Planning 71:147-162.

Bardsley, D. K., and G. Edwards-Jones. 2007. Invasive species policy and climate change: social perceptions of environmental change in the Mediterranean. Environmental Science \& Policy 10:230-242.

Berkes, F., J. Colding, and C. Folke, editors. 2003. Navigating social-ecological systems: building resilience for complexity and change. Cambridge University Press, New York, NY.

Blaber, S. J. M. 1987. Factors affecting recruitment and survival of Mugilids in estuaries and coastal waters of southeastern Africa. American Fisheries Society Symposium 1:507-518.

Blaber, S. J. M., and T. G. Blaber. 1980. Factors affecting the distribution of juvenile estuarine and inshore fish. Journal of Fish Biology 17:143-162.

Blake, D. E. 2001. Contextual effects on environmental attitudes and behavior. Environment and Behavior 33:708-725.

Bremner, A., and K. Park. 2007. Public attitudes to the management of invasive nonnative species in Scotland. Biological conservation 139:306-314.

Brett, M., and D. Muller-Navarra. 1997. The role of highly unsaturated fatty acids in aquatic foodweb processes. Freshwater Biology 38:483-499.

Bryan, E. H. 1954. The Hawaiian Chain. Bishop Museum Press, Honolulu. 
Bryan, W. A. 1915. Natural History of Hawaii: Being an account of the Hawaiian people, the geology and geography of the islands, and the native and introduced plants and animals of the group. The Hawaiian Gazette Co. Ltd., Honolulu, Hawaii.

Cacioppo, J. T., W. L. Gardner, and G. G. Berntson. 1997. Beyond bipolar conceptualizations and measures: The case of attitudes and evaluative space. Personality and Social Psychology Review 1:3-25.

Calhoun, R. S., and M. E. Field. 2008. Sand composition and transport history on a fringing coral reef, Molokai, Hawaii. Journal of Coastal Research 24:1151-1160.

Chao, A., N. J. Gotelli, T. C. Hsieh, E. L. Sander, K. H. Ma, R. K. Colwell, and A. M. Ellison. 2014. Rarefaction and extrapolation with Hill numbers: a framework for sampling and estimation in species diversity studies. Ecological Monographs $84: 45-67$.

Charles, H., and J. S. Dukes. 2007a. Impacts of invasive species on ecosystem services. Pages 217-237 Biological invasions. Springer.

Charles, H., and J. S. Dukes. 2007b. Impacts of Invasive Species on Ecosystem Services. Pages 217-237 in W. Nentwig, editor. Biological Invasions. Springer Berlin Heidelberg, Berlin, Heidelberg.

Chatterjee, S., and J. S. Simonoff. 2013. Multinomial Regression. Hoboken, NJ, USA: John Wiley \& Sons, Inc. 
Chew, M. K., and A. L. Hamilton. 2011. The rise and fall of biotic nativeness: a historical perspective. Pages 35-47 in D. M. Richardson, editor. Fifty years of Invasion Ecology: the legacy of Charles Elton. Wiley-Blackwell.

Clague, D. A., and G. B. Dalrymple. 1989. Tectonic, geochronology and origin of the Hawaii-Emperor Chain. Pages 188-217 in E. L. Winterer, D. M. Hussong, and R. W. Decker, editors. The Eastern Pacific Ocean and Hawaii. The Geological Society of America, Boulder, Colorado.

Clark, M. R., and R. B. Rechtman. 2010. Archaeological Monitoring Plan for the Proposed Eradication of Mangroves at 'Alula Bay. Page 37. Kealahekhe Ahupua'a; Rechtman Consulting, LLC.

Clarke, K. R. 1993. Non-parametric multivariate analyses of changes in community structure. Australian Journal of Ecology 18:117-143.

Cocheret de la Morinière, E., I. Nagelkerken, H. van der Meij, and G. van der Velde. 2004. What attracts juvenile coral reef fish to mangroves: habitat complexity or shade? Marine Biology 144:139-145.

Colwell, R. K., A. Chao, N. J. Gotelli, S.-Y. Lin, C. X. Mao, R. L. Chazdon, and J. T. Longino. 2012. Models and estimators linking individual-based and sample-based rarefaction, extrapolation and comparison of assemblages. Journal of Plant Ecology 5:3-21.

Cooke, G. P. 1949. Moolelo o Molokai, a ranch story of Molokai. Honolulu Star-Bulletin, Honolulu. 
Costanzo, S. D., M. J. O’Donohue, W. C. Dennison, N. R. Loneragan, and M. Thomas. 2001. A New Approach for Detecting and Mapping Sewage Impacts. Marine Pollution Bulletin 42:149-156.

Cronbach, L. J. 1951. Coefficient alpha and the internal structure of tests. Psychometrika $16: 297-334$.

Davis, M. A., M. K. Chew, R. J. Hobbs, A. E. Lugo, J. J. Ewel, G. J. Vermeij, J. H. Brown, M. L. Rosenzweig, M. R. Gardener, S. P. Carroll, and others. 2011. Don't judge species on their origins. Nature 474:153-154.

Dawes, R. M. 1972. Fundamentals of attitude measurement. Wiley, New York.

DeMott, W. R. 1986. The role of taste in food selection by freshwater zooplankton. Oecologia 69:334-340.

Dickie, I. A., B. M. Bennett, L. E. Burrows, M. A. Nuñez, D. A. Peltzer, A. Porté, D. M. Richardson, M. Rejmánek, P. W. Rundel, and B. W. van Wilgen. 2014. Conflicting values: ecosystem services and invasive tree management. Biological Invasions 16:705-719.

D'lorio, M. 2008. Invasive mangroves and coastal change on Moloka'i. Pages 129-134 in M. E. Field, S. A. Cochran, J. B. Logan, and C. D. Storlazzi, editors. The coral reef of south Moloka'i, Hawai'i: portrait of a sediment-threatened fringing reef. U.S. Geological Survey Scientific Investigations Report 2007-5101. 
Doherty, P. J. 1987. Light-traps: selective but useful devices for quantifying the distributions and abundances of larval fishes. Bulletin of Marine Science 41:423431.

Dudgeon, D., and R. E. W. Smith. 2006. Exotic species, fisheries and conservation of freshwater biodiversity in tropical Asia: the case of the Sepik River, Papua New Guinea 16:203-215.

Eagly, A. H., and S. Chaiken. 1998. Attitude structure and function. Page The handbook of social psychology. McGraw-Hill, New York.

Eldredge, L. G., and C. M. Smith. 2001. A guidebook of introduced marine species in Hawaii. Page 70. Bishop Museum Techinical Report, B.P. Bishop Museum and University of Hawai'i.

Estévez, R. A., C. B. Anderson, J. C. Pizarro, and M. A. Burgman. 2015. Clarifying values, risk perceptions, and attitudes to resolve or avoid social conflicts in invasive species management. Conservation Biology 29:19-30.

Eviner, V. T., K. Garbach, J. H. Baty, and S. A. Hoskinson. 2012. Measuring the Effects of Invasive Plants on Ecosystem Services: Challenges and Prospects. Invasive Plant Science and Management 5:125-136.

Ewel, J. J., and F. E. Putz. 2004. A place for alien species in ecosystem restoration. Frontiers in Ecology and the Environment 2:354-360.

Ewel, K., R. TWILLEY, and J. I. N. Ong. 1998. Different kinds of mangrove forests provide different goods and services. Global Ecology \& Biogeography Letters 7:83-94. 
Field, M. E., S. A. Cochran, J. B. Logan, and C. D. Storlazzi. 2007. The Coral Reef of South Moloka'i Hawai'i: Portrait of a Sediment-Threatened Fringing Reef. Page 180. U.S. Geological Survey Scientific Investigations Report.

Field, M. E., S. A. Cochran, J. B. Logan, C. D. Storlazzi, M. E. Field, S. A. Cochran, J. B. Logan, and C. D. Storlazzi. 2008. The south Molokai reef: origin, history and status. Pages 3-10 in M. E. Field, S. A. Cochran, J. B. Logan, and C. D. Storlazzi, editors. The Coral Reef of South Moloka'i, Hawai'i: A portrait of a sedimentthreatened fringing reef. U.S. Geological Survey Scientific Investigations Report 2007-5101.

Fischer, A., and R. Van Der Wal. 2007. Invasive plant suppresses charismatic seabird-the construction of attitudes towards biodiversity management options. Biological Conservation 135:256-267.

Fischer, J., T. A. Gardner, E. M. Bennett, P. Balvanera, R. Biggs, S. Carpenter, T. Daw, C. Folke, R. Hill, T. P. Hughes, T. Luthe, M. Maass, M. Meacham, A. V. Norström, G. Peterson, C. Queiroz, R. Seppelt, M. Spierenburg, and J. Tenhunen. 2015. Advancing sustainability through mainstreaming a social-ecological systems perspective. Current Opinion in Environmental Sustainability 14:144-149.

Fiske, S. T., and S. E. Taylor. 1991. Social cognition. 2nd edition. New York.

Forward, J., Richard B. 1987. Larval release rhythms of decapod crustaceans: an overview. Bulletin of Marine Science 41:165-176. 
Fraser, A. 2006. Public attitudes to pest control: a literature review. Science \& Technical Pub., Department of Conservation.

Fraser, W. 2001. Introduced wildlife in New Zealand: a survey of general public views. Page 45 Landcare reserach science series no. 23. Manaaki Whenua Press, Lincoln.

García-Llorente, M., B. Martín-López, J. A. González, P. Alcorlo, and C. Montes. 2008. Social perceptions of the impacts and benefits of invasive alien species: implications for management. Biological Conservation 141:2969-2983.

Gast, R. H. 1982. Traveling Hawaiian byways with pen and camera; extracts from my 1936 logbook. Old Blanc House Press, Julian, California.

Geesing, D., M. Al-Khawlani, and M. L. Abba. 2004. Management of introduced Prosopis species: Can economic explotation control invasive species? Unasylva 217:36-44.

Genovesi, P. 2007. Limits and potentialities of eradication as a tool for addressing biological invasions. Pages 385-402 in W. Nentwig, editor. Biological Invasions. Springer Berlin Heidelberg, Berlin, Heidelberg.

Gieryn, T. F. 2000. A Space for Place in Sociology. Annual Review of Sociology 26:463496.

Gillingham, S., and P. C. Lee. 1999. The impact of wildlife-related benefits on the conservation attitudes of local people around the Selous Game Reserve, Tanzania. Environmental Conservation 26:218-228. 
Giri, C., E. Ochieng, L. L. Tieszen, Z. Zhu, A. Singh, T. Loveland, J. Masek, and N. Duke. 2011. Status and distribution of mangrove forests of the world using earth observation satellite data. Global Ecology and Biogeography:154-159.

Goodenough, A. 2010. Are the ecological impacts of alien species misrepresented? A review of the "native good, alien bad" philosophy. Community Ecology 11:13-21.

Goswami, S. C. 1992. Zooplankton ecology of the mangrove habitats of Goa. Pages 321332 in K. P. Singh and J. S. Singh, editors. Tropical ecosystems: ecology and management. Wiley Eastern, New Delhi.

Gozlan, R. E. 2008. Introduction of non-native freshwater fish: is it all bad? Fish and Fisheries 9:106-115.

Granek, E. F., and K. Frasier. 2007. The Impacts of Red Mangrove (Rhizophora Mangle) Deforestation on Zooplankton Communities in Bocas Del Toro, Panama. Bulletin of Marine Science 3:905-914.

Graves, S. D., and A. M. Shapiro. 2003. Exotics as host plants of the California butterfly fauna. Biological Conservation:413-433.

Gunderson, L. H., and C. Holling. 2002. Panarchy: understanding transformations in human and natural systems. Island Press.

Gurevitch, J., and D. K. Padilla. 2004. Are invasive species a major cause of extinctions? Trends in Ecology \& Evolution 19:470-474.

Harris, J. A., R. J. Hobbs, E. Higgs, and J. Aronson. 2006. Ecological Restoration and Global Climate Change. Restoration Ecology 14:170-176. 
Hays, G. C., A. J. Richardson, and C. Robinson. 2005. Climate change and marine plankton. SPECIAL ISSUE: BUMPER BOOK REVIEW 20:337-344.

Henslow, J. S. 1835. Observations concerning the indigenousness and distinctness of certain species of plants included in the British floras. The Magazine of Natural History 8:84-88.

Hernández-León, S. 1998. Annual cycle of epiplanktonic copepods in Canary Island waters. Fisheries Oceanography 7:252-257.

Hernández-León, S., C. Almeida, P. Bécognée, L. Yebra, and J. Arístegui. 2004. Zooplankton biomass and indices of grazing and metabolism during a late winter bloom in subtropical waters. Marine Biology 145:1191-1200.

Hernández-León, S., C. Almeida, L. Yebra, and J. Arístegui. 2002. Lunar cycle of zooplankton biomass in subtropical waters: biogeochemical implications. Journal of Plankton Research 24:935-939.

Hickford, M. J., and D. R. Schiel. 1999. Evaluation of the performance of light traps for sampling fish larvae in inshore temperate waters. Marine ecology. Progress series 186:293-302.

Hobbs, R. J., S. Arico, J. Aronson, J. S. Baron, P. Bridgewater, V. A. Cramer, P. R. Epstein, J. J. Ewel, C. A. Klink, A. E. Lugo, D. Norton, D. Ojima, D. M. Richardson, E. W. Sanderson, F. Valladares, M. Vilà, R. Zamora, and M. Zobel. 2006. Novel ecosystems: theoretical and management aspects of the new ecological world order. Global Ecology and Biogeography 15:1-7. 
Hobbs, R. J., E. Higgs, C. M. Hall, P. Bridgewater, F. S. Chapin, E. C. Ellis, J. J. Ewel, L. M. Hallett, J. Harris, K. B. Hulvey, S. T. Jackson, P. L. Kennedy, C. Kueffer, L. Lach, T. C. Lantz, A. E. Lugo, J. Mascaro, S. D. Murphy, C. R. Nelson, M. P. Perring, D. M. Richardson, T. R. Seastedt, R. J. Standish, B. M. Starzomski, K. N. Suding, P. M. Tognetti, L. Yakob, and L. Yung. 2014. Managing the whole landscape: historical, hybrid, and novel ecosystems. Frontiers in Ecology and the Environment 12:557564.

Hobbs, R. J., E. Higgs, and J. A. Harris. 2009. Novel ecosystems: implications for conservation and restoration. Trends in Ecology \& Evolution 24:599-605.

Homer, C., J. Dewitz, J. Fry, M. Coan, N. Hossain, C. Larson, N. Herold, A. McKerrow, J. N. VanDriel, and J. Wickham. 2007. Completion of the 2001 National Land Cover Database for the Conterminous United States. Photogrammetric Engineering and Remote Sensing 73:337-341.

Hortal, J., P. A. V. Borges, and C. Gaspar. 2006. Evaluating the performance of species richness estimators: sensitivity to sample grain size. Journal of Animal Ecology 75:274-287.

Hsieh, T. C., K. H. Ma, and A. Chao. 2016. iNEXT: an R package for rarefaction and extrapolation of species diversity (Hill numbers). Methods in Ecology and Evolution 7:1451-1456.

Hulme, P. E. 2006. Beyond control: wider implications for the management of biological invasions. Journal of Applied Ecology 43:835-847. 
Janssen, M. 2002. Complexity and ecosystem management: the theory and practice of multi-agent systems. Edward Elgar, Cheltenham, UK.

Johnson, W. S., and D. M. Allen. 2012. Zooplankton of the Atlantic and Gulf Coasts: A guide to their identification and ecology. JHU Press, Baltimore, Maryland.

Johnston, M. J., and C. A. Marks. 1997. Attitudinal survey on vertebrate pest management in Victoria. Department of Natural Resources and Environment Melbourne, Australia.

Judd, G. P. 1936. Puleoo; the story of Molokai. Porter Publishing Co., Honolulu.

Katayama, N. 2016. Bird diversity and abundance in organic and conventional apple orchards in northern Japan 6:34210.

Kathiresan, K., and B. L. Bingham. 2001. Biology of mangroves and mangrove ecosystems. Advances in marine biology 40:81-251.

Katsanevakis, S., I. Wallentinus, A. Zenetos, E. Leppäkoski, M. E. Çinar, B. Oztürk, M. Grabowski, D. Golani, A. C. Cardoso, and others. 2014. Impacts of invasive alien marine species on ecosystem services and biodiversity: a pan-European review. Aquatic Invasions 9:391-423.

Keesing, F. M. 1936. Hawaiian homesteading on Molokai. University of Hawaii, Honolulu.

Kepler, A. K., and C. B. Kepler. 1991. Majestic Molokai; a nature lover's guide. Mutual Publishing, Honolulu. 
Kinzig, A. P. 2001. Bridging Disciplinary Divides to Address Environmental and Intellectual Challenges. Ecosystems 4:709-715.

Kirch, P. V. 1985. Feathered Gods and Fishhooks: An Introduction to Hawaiian Archaeology and Prehistory. University of Hawaii Press, Honolulu, Hawaii.

Kirch, P. V. 2007. "Like shoals of fish": Archaeology and population in pre-contact Hawai 'i. Pages 52-69 in P. V. Kirch and J. Rallu, editors. The growth and collapse of Pacific Island societies: Archaeological and demographic perspectives. University of Hawaii Press, Honolulu.

Krumme, U., and T.-H. Liang. 2004. Tidal-induced changes in a copepod-dominated zooplankton community in a macrotidal mangrove channel in northern Brazil. Zoological Studies 43:404-414.

Kull, C. A., C. M. Shackleton, P. J. Cunningham, C. Ducatillon, J.-M. Dufour-Dror, K. J. Esler, J. B. Friday, A. C. Gouveia, A. R. Griffin, E. Marchante, S. J. Midgley, A. Pauchard, H. Rangan, D. M. Richardson, T. Rinaudo, J. Tassin, L. S. Urgenson, G. P. von Maltitz, R. D. Zenni, and M. J. Zylstra. 2011. Adoption, use and perception of Australian acacias around the world. Diversity and Distributions 17:822-836. Lakhan, V. C., and P. D. Lavalle. 2002. Use of loglinear models to assess factors influencing concern for the natural environment. Environmental management $30: 77-87$.

Lampert, W. 1987. Laboratory studies on zooplankton-cyanobacteria interactions. New Zealand Journal of Marine and Freshwater Research 21:483-490. 
Leibold, M. A. 1989. Resource Edibility and the Effects of Predators and Productivity on the Outcome of Trophic Interactions. The American Naturalist 134:922-949.

Levin, S. A. 1992. The Problem of Pattern and Scale in Ecology: The Robert H. MacArthur Award Lecture. Ecology 73:1943-1967.

Lewicka, M. 2005. Ways to make people active: The role of place attachment, cultural capital, and neighborhood ties. Journal of environmental psychology 25:381395.

Lokocz, E., R. L. Ryan, and A. J. Sadler. 2011. Motivations for land protection and stewardship: Exploring place attachment and rural landscape character in Massachusetts. Landscape and urban planning 99:65-76.

Longhurst, A., and R. Williams. 1979. Materials for plankton modelling: Vertical distribution of Atlantic zooplankton in summer. Journal of Plankton Research $1: 1-28$

Lovell, S. J., S. F. Stone, L. Fernandez, and others. 2006. The economic impacts of aquatic invasive species: a review of the literature. Agricultural and Resource Economics Review 35:195.

Low, B., R. Costanza, E. Ostrom, J. Wilson, and C. P. Simon. 1999. Human-ecosystem interactions: a dynamic integrated model. Ecological Economics 31:227-242.

Luckenbach, M. W., and R. J. Orth. 1992. Swimming Velocities and Behavior of Blue Crab (Callinectes sapidus Rathbun) Megalopae in Still and Flowing Water. Estuaries 15:186-192. 
Lugendo, B. R., I. Nagelkerken, G. Van Der Velde, and Y. D. Mgaya. 2006. The importance of mangroves, mud and sand flats, and seagrass beds as feeding areas for juvenile fishes in Chwaka Bay, Zanzibar: gut content and stable isotope analyses. Journal of Fish Biology 69:1639-1661.

Lugo, A. E. 2004. The outcome of alien tree invasions in Puerto Rico. Frontiers in Ecology and the Environment 2:265-273.

Lugo, A. E., T. A. Carlo, and J. M. Wunderle. 2012. Natural mixing of species: novel plantanimal communities on Caribbean Islands. Animal Conservation 15:233-241.

MA. 2005. Millennium Ecosystem Assessment. Page Ecosystems and human well-being. Island press, Washington, DC.

MacKenzie, R., and C. Kryss. 2013. Impacts of exotic mangroves and chemical eradication of mangroves on tide pool fish assemblages. Marine Ecology Progress Series 472:219-237.

Maris, V., and A. Béchet. 2010. From adaptive management to adjustive management: a pragmatic account of biodiversity values. Conservation biology 24:966-973.

McCauley, E., J. A. Downing, and S. Watson. 1989. Sigmoid Relationships between Nutrients and Chlorophyll among Lakes. Canadian Journal of Fisheries and Aquatic Sciences 46:1171-1175.

McDonnell, M. J., and S. T. A. Pickett. 1993. Humans as components of ecosystems: the ecology of subtle human effects and populated aeas. Springer Science \& Business Media, New York. 
Mcleod, E., G. L. Chmura, S. Bouillon, R. Salm, M. Björk, C. M. Duarte, C. E. Lovelock, W. H. Schlesinger, and B. R. Silliman. 2011. A blueprint for blue carbon: toward an improved understanding of the role of vegetated coastal habitats in sequestering CO2. Frontiers in Ecology and the Environment 9:552-560.

Mehta, J. N., and S. R. Kellert. 1998. Local attitudes toward community-based conservation policy and programmes in Nepal: a case study in the Makalu-Barun Conservation Area. Environmental Conservation 25:320-333.

Meyerson, L. A., and H. A. Mooney. 2007. Invasive alien species in an era of globalization. Frontiers in Ecology and the Environment 5:199-208.

Meyerson, L. A., and J. K. Reaser. 2003. The Ecological and Socio-Economic Impacts of Invasive Alien Species on Island Ecosystems: Report of an Experts Consultation. The Global Invasive Species Programme (GISP) on behalf of the Convention on Biological Diversity, Washington, DC.

Meynecke, J.-O., and R. G. Richards. 2014. A full life cycle and spatially explicit individual-based model for the giant mud crab (Scylla serrata): a case study from a marine protected area. ICES Journal of Marine Science 71:484-498.

Micheli, F. 1999. Eutrophication, Fisheries, and Consumer-Resource Dynamics in Marine Pelagic Ecosystems. Science 285:1396.

Michener, W. K., E. R. Blood, K. L. Bildstein, M. M. Brinson, and L. R. Gardner. 1997. Climate change, hurricanes and tropical storms, and rising sea level in coastal wetlands. Ecological Applications 7:770-801. 
Milroy, S. P. 2015. Field Methods in Marine Science: From Measurements to Models. Garland Science.

Morgan, S. G., and J. H. Christy. 1995. Adaptive significance of the timing of larval release by crabs. The American Naturalist 145:457-479.

Mouillot, D., D. R. Bellwood, C. Baraloto, J. Chave, R. Galzin, M. Harmelin-Vivien, M. Kulbicki, S. Lavergne, S. Lavorel, N. Mouquet, C. E. T. Paine, J. Renaud, and W. Thuiller. 2013. Rare Species Support Vulnerable Functions in High-Diversity Ecosystems. PLOS Biology 11:e1001569.

Mumby, P. J., A. J. Edwards, J. Ernesto Arias-González, K. C. Lindeman, P. G. Blackwell, A. Gall, M. I. Gorczynska, A. R. Harborne, C. L. Pescod, H. Renken, C. C. C. Wabnitz, and G. Llewellyn. 2004. Mangroves enhance the biomass of coral reef fish communities in the Caribbean. Nature 427:533-536.

Nagelkerken, I., S. J. M. Blaber, S. Bouillon, P. Green, M. Haywood, L. G. Kirton, J.-O. Meynecke, J. Pawlik, H. M. Penrose, A. Sasekumar, and P. J. Somerfield. 2008. The habitat function of mangroves for terrestrial and marine fauna: A review. Mangrove Ecology - Applications in Forestry and Costal Zone Management 89:155-185.

Nagelkerken, I., S. Kleijnen, T. Klop, R. Van Den Brand, E. C. de La Moriniere, and G. Van der Velde. 2001. Dependence of Caribbean reef fishes on mangroves and seagrass beds as nursery habitats: a comparison of fish faunas between bays 
with and without mangroves/seagrass beds. Marine Ecology Progress Series 214:225-235.

Norton, B. G., and B. Hannon. 1997. Environmental values: A place-based theory. Environmental ethics 19:227-245.

Odum, W. E., C. C. Mclvor, and T. J. Smith III. 1982. The ecology of the mangroves of south Florida: a community profile. DTIC Document.

Ogston, A. S., C. D. Storlazzi, M. E. Field, and M. K. Presto. 2004. Sediment resuspension and transport patterns on a fringing reef flat, Molokai, Hawaii. Coral Reefs 23:559-569.

Oksanen, J., F. G. Blanchet, R. Kindt, P. Legendre, P. R. Minchin, R. B. O'Hara, G. L. Simpson, P. Solymos, M. H. H. Stevens, and H. Wagner. 2015. vegan: Community Ecology Package. R package version 2.2-1.

Ostrom, E. 2009. A General Framework for Analyzing Sustainability of Social-Ecological Systems. Science 325:419.

Paerl, H. W. 1988. Nuisance phytoplankton blooms in coastal, estuarine, and inland waters1. Limnology and Oceanography 33:823-843.

Pan, Y., L. Wang, Y. Cao, W. Pang, Q. Wang, Z. Zhu, X. Zhang, and G. Deng. 2016. Variation of benthic algal assemblages among habitats in subalpine Karstic Lakes and implications for bioassessment. Hydrobiologia 777:183-196.

Perry, R. I., H. P. Batchelder, D. L. Mackas, S. Chiba, E. Durbin, W. Greve, and H. M. Verheye. 2004. Identifying global synchronies in marine zooplankton 
populations: issues and opportunities. ICES Journal of Marine Science 61:445456.

Pimentel, D., R. Zuniga, and D. Morrison. 2005a. Update on the environmental and economic costs associated with alien-invasive species in the United States. Ecological Economics:273-288.

Pimentel, D., R. Zuniga, and D. Morrison. 2005b. Update on the environmental and economic costs associated with alien-invasive species in the United States. Integrating Ecology and Economics in Control BioinvasionsIEECB S.I. 52:273-288.

Porter, S. S., G. L. Eckert, C. J. Byron, and J. L. Fisher. 2008. Comparison of Light Traps and Plankton Tows for Sampling Brachyuran Crab Larvae in an Alaskan Fjord. Journal of Crustacean Biology 28:175-179.

Pyšek, P., D. M. Richardson, J. Pergl, V. Jarošík, Z. Sixtová, and E. Weber. 2008. Geographical and taxonomic biases in invasion ecology. Trends in Ecology \& Evolution 23:237-244.

R Core Team. 2016. R: A language and environment for statistical computing. $R$ Foundation for Statistical Computing Vienna, Austria.

Reaser, J. K. 2001. Invasive alien species prevention and control: the art and science of managing people. Pages 89-104 in J. A. McNeely, editor. The great reshuffling: Human dimensions of invasive alien species. IUCN.

Redman, C. L. 1999. Human Dimensions of Ecosystem Studies. Ecosystems 2:296-298. 
Redman, C. L., J. M. Grove, and L. H. Kuby. 2004. Integrating Social Science into the Long-Term Ecological Research (LTER) Network: Social Dimensions of Ecological Change and Ecological Dimensions of Social Change. Ecosystems 7:161-171.

Roberts, L. M. 2000. Historical changes in land use in relation to land erosion and sedimentation on the reefs of South Molokai. Pages 167-176 9th Pacific congress on marine science and technology. Honolulu, Hawaii.

Roberts, L. M., and M. E. Field. 2008. People, land, and the reefs of south Moloka'i. Pages 123-128 in M. E. Field, S. A. Cochran, J. B. Logan, and C. D. Storlazzi, editors. The coral reef of south Moloka'i, Hawai'i: portrait of a sedimentthreatened fringing reef. U.S. Geological Survey Scientific Investigations Report 2007-5101.

Robertson, A. I., and S. J. M. Blaber. 1992. Plankton, Epibenthos and Fish Communities. Pages 173-224 Tropical Mangrove Ecosystems. American Geophysical Union.

Rodewald, A. D. 2012. Spreading messages about invasives. Diversity and Distributions 18:97-99.

Rogers, S. I., and B. Greenaway. 2005. A UK perspective on the development of marine ecosystem indicators. Marine Pollution Bulletin 50:9-19.

Root, T. L., and S. H. Schneider. 2006. Conservation and Climate Change: The Challenges Ahead. Conservation Biology 20:706-708.

Sasekumar, A., V. C. Chong, M. U. Leh, and R. D'Cruz. 1992. Mangroves as a habitat for fish and prawns. Pages 195-207 in V. Jaccarini and E. Martens, editors. The 
Ecology of Mangrove and Related Ecosystems: Proceedings of the International Symposium held at Mombasa, Kenya, 24-30 September 1990. Springer Netherlands, Dordrecht.

Schlaepfer, M. A., D. F. Sax, and J. D. Olden. 2011. The potential conservation value of non-native species. Conservation Biology 25:428-437.

Schultz, P. W., and L. Zelezny. 1999. Values as predictors of environmental attitudes: Evidence for consistency across 14 countries. Journal of environmental psychology 19:255-265.

Schwarz, N., and G. Bohner. 2001. The construction of attitudes. Pages 436-457 Intrapersonal Processes. Blackwell, Oxford.

Selge, S., A. Fischer, and R. van der Wal. 2011. Public and professional views on invasive non-native species-a qualitative social scientific investigation. Biological Conservation 144:3089-3097.

Shackleton, C. M., D. McGarry, S. Fourie, J. Gambiza, S. E. Shackleton, and C. Fabricius. 2007. Assessing the Effects of Invasive Alien Species on Rural Livelihoods: Case Examples and a Framework from South Africa. Human Ecology 35:113-127.

Sharp, R. L., L. R. Larson, and G. T. Green. 2011. Factors influencing public preferences for invasive alien species management. Biological Conservation 144:2097-2104. Sheaves, M., and B. Molony. 2000. Short-circuit in the mangrove food chain. Marine Ecology Progress Series 199:97-109. 
Simberloff, D. 2005. The politics of assessing risk for biological invasions: the USA as a case study. Trends in Ecology \& Evolution 20:216-222.

Slobodkin, L. B. 2001. The good, the bad and the reified. Evolutionary Ecology Research 3:91-105.

Smith, V. H., G. D. Tilman, and J. C. Nekola. 1999. Eutrophication: impacts of excess nutrient inputs on freshwater, marine, and terrestrial ecosystems. Environmental Pollution 100:179-196.

Spalding, M., M. Kainuma, and L. Collins. 2010. World Atlas of Mangroves. Earthcan, New York, NY.

Stenseth, N. C., A. Mysterud, G. Ottersen, J. W. Hurrell, K.-S. Chan, and M. Lima. 2002. Ecological Effects of Climate Fluctuations. Science 297:1292.

Stern, M. J. 2008. Coercion, voluntary compliance and protest: the role of trust and legitimacy in combating local opposition to protected areas. Environmental Conservation 35:200.

Stromberg, J. C., M. K. Chew, P. L. Nagler, and E. P. Glenn. 2009. Changing perceptions of change: the role of scientists in Tamarix and river management. Restoration Ecology 17:177-186.

Summers, C. C. 1971. Molokai; a site survey. Bishop Museum, Pacific Anthropological Records, Honolulu.

Tassin, J., and C. A. Kull. 2015. Facing the broader dimensions of biological invasions. Land Use Policy 42:165-169. 
Tavakol, M., and R. Dennick. 2011. Making sense of Cronbach's alpha. International Journal of Medical Education 2:53-55.

Tittensor, D. P., M. Walpole, S. L. L. Hill, D. G. Boyce, G. L. Britten, N. D. Burgess, S. H. M. Butchart, P. W. Leadley, E. C. Regan, R. Alkemade, R. Baumung, C. Bellard, L. Bouwman, N. J. Bowles-Newark, A. M. Chenery, W. W. L. Cheung, V. Christensen, H. D. Cooper, A. R. Crowther, M. J. R. Dixon, A. Galli, V. Gaveau, R. D. Gregory, N. L. Gutierrez, T. L. Hirsch, R. Höft, S. R. Januchowski-Hartley, M. Karmann, C. B. Krug, F. J. Leverington, J. Loh, R. K. Lojenga, K. Malsch, A. Marques, D. H. W. Morgan, P. J. Mumby, T. Newbold, K. Noonan-Mooney, S. N. Pagad, B. C. Parks, H. M. Pereira, T. Robertson, C. Rondinini, L. Santini, J. P. W. Scharlemann, S. Schindler, U. R. Sumaila, L. S. L. Teh, J. van Kolck, P. Visconti, and Y. Ye. 2014. A mid-term analysis of progress toward international biodiversity targets. Science $346: 241$

Truitt, A. M., E. F. Granek, M. J. Duveneck, K. A. Goldsmith, M. P. Jordan, and K. C. Yazzie. 2015. What is novel about novel ecosystems: managing change in an ever-changing world. Environmental Management 55:1217-1226.

Turner II, B., K. J. Esler, P. Bridgewater, J. Tewksbury, N. Sitas, B. Abrahams, F. S. Chapin III, R. R. Chowdhury, P. Christie, S. Diaz, P. Firth, C. N. Knapp, J. Kramer, R. Leemans, M. Palmer, D. Pietri, J. Pittman, J. Sarukhán, R. Shackleton, R. Seidler, B. van Wilgen, and H. Mooney. 2016. Socio-Environmental Systems (SES) 
Research: what have we learned and how can we use this information in future research programs. Sustainability science 19:160-168.

Turner, J. T., and P. A. Tester. 1997. Toxic marine phytoplankton, zooplankton grazers, and pelagic food webs. Limnology and Oceanography 42:1203-1213.

US EPA, Region 9, W. D. 2003. Project Loko l'a: Restoring Hawai'i's Traditional Fish Ponds.

U.S. Geological Survey. 2012. The StreamStats program.

Vance DJ, Haywood MDE, Heales DS, Kenyon RA, Loneragan NR, and Pendrey RC. 1996. How far do prawns and fish move into mangroves? Distribution of juvenile banana prawns Penaeusmerguiensis and fish in a tropical mangrove forest in northern Australia. Marine Ecology Progress Series 131:115-124.

Vaske, J. J., and K. C. Kobrin. 2001. Place attachment and environmentally responsible behavior. The Journal of Environmental Education 32:16-21.

Vaz, A. S., C. Kueffer, C. A. Kull, D. M. Richardson, J. R. Vicente, I. Kühn, M. Schröter, J. Hauck, A. Bonn, and J. P. Honrado. 2017. Integrating ecosystem services and disservices: insights from plant invasions. Ecosystem Services 23:94-107.

Vitousek, P. M., H. A. Mooney, J. Lubchenco, and J. M. Melillo. 1997. Human Domination of Earth's Ecosystems. Science 277:494.

Vogel, T., and M. Wanke. 2016. Attitudes and attitude change. Taylor \& Francis, New York. 
Wagner, W. L., D. R. Herbst, and S. H. Sohmer. 1990. Manual of the Flowering Plants of Hawai'i. Bishop Museum Special Publications 83. University of Hawaii Press, Bishop Museum Press, Honolulu.

Walther, G.-R., A. Roques, P. E. Hulme, M. T. Sykes, P. Pyšek, I. Kühn, M. Zobel, S. Bacher, Z. Botta-Dukát, H. Bugmann, and others. 2009. Alien species in a warmer world: risks and opportunities. Trends in ecology \& evolution 24:686-693.

Watson, H. C. 1847. Cybele Britannica. Longman, London.

Weisler, M., and P. V. Kirch. 1985. The structure of settlement space in a Polynesian chiefdom: Kawela, Molokai, Hawaiian Islands. New Zealand Journal of Archaeology 7:129-158.

Wester, L. 1981. Introduction and spread of mangroves in the Hawaiian Islands. Yearbook of the Association of Pacific Coast Geographers 43:125-137.

Wilcove, D. S., D. Rothstein, J. Dubow, A. Phillips, and E. Losos. 1998. Quantifying Threats to Imperiled Species in the United States Assessing the relative importance of habitat destruction, alien species, pollution, overexploitation, and disease. BioScience 48:607-615.

Zavaleta, E. S., R. J. Hobbs, and H. A. Mooney. 2001. Viewing invasive species removal in a whole-ecosystem context. Trends in Ecology \& Evolution 16:454-459. 


\section{APPENDIX A: Zooplankton community composition supporting data}

This section is intended to provide additional supporting data regarding zooplankton community composition analysis. Additional analyses and statistics used to explore the data are provided here for reference. Data included provide additional support to help understand patterns and results reported in the text.

Table A1. Permutational multivariate analysis of variance (PERMANOVA) tables showing effects of habitat type on zooplankton community composition.

\begin{tabular}{lrrrrrr}
\hline Source of variation & df & SS & MS & $F$ & $R^{2}$ & $P$ value \\
\hline $\begin{array}{l}\text { A. Light trap samples } \\
\quad \text { Habitat type }\end{array}$ & 3 & 0.30 & 0.10 & 1.12 & 0.17 & 0.31 \\
$\begin{array}{l}\text { Residuals } \\
\quad\end{array}$ & 16 & 1.43 & 0.09 & & & \\
$\begin{array}{l}\text { B. Tow samples } \\
\quad \text { Habitat type }\end{array}$ & 3 & 0.34 & 0.11 & 1.15 & 0.18 & 0.28 \\
$\quad$ Residuals & 16 & 1.58 & 0.10 & & & \\
\hline df degree of freedom, SS sums of squares, MS mean of squares, F pseudo-F ratio
\end{tabular}



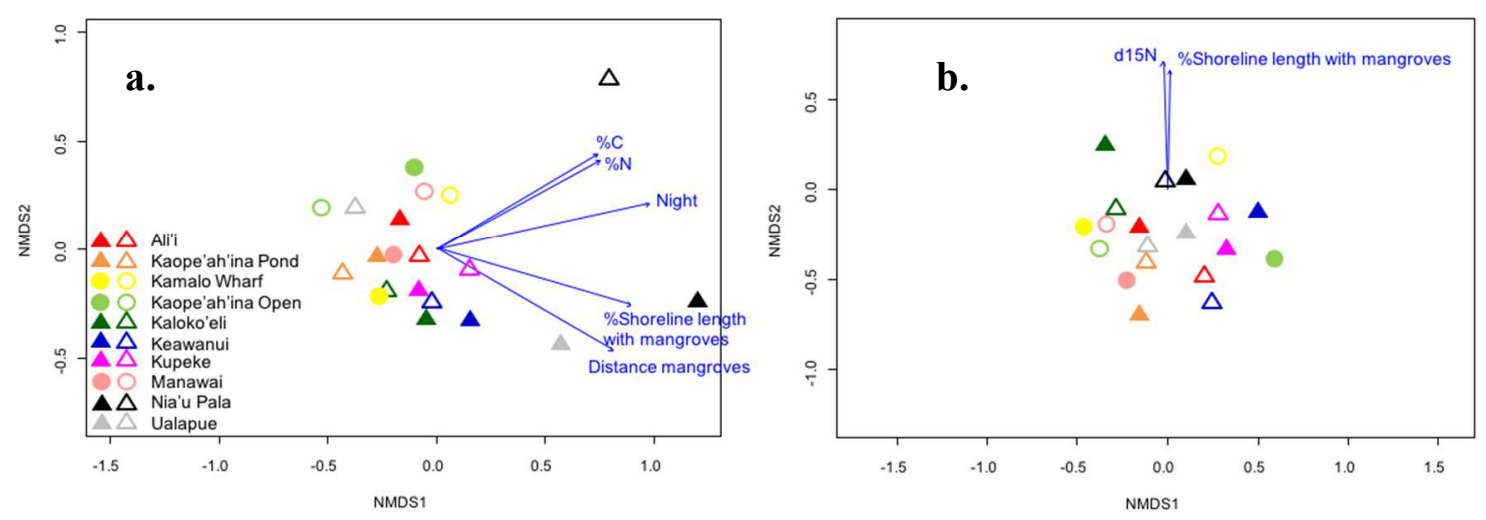

Figure A1. Nonmetric multidimensional scaling (NMDS) comparing zooplankton assemblages across site locations and habitat types collected in light traps separated by a. meroplankton $($ stress $=0.12$ PERMANOVA comparing habitat types: $\mathrm{df}=3, \mathrm{~F}=1.11$, $\mathrm{p}=0.34)$ and $\mathbf{b}$. holoplankton (stress $=0.19$; PERMANOVA comparing habitat types: $\mathrm{df}=$ 3, F=1.07, p=0.40). ( $\mathbf{A}=$ fishpond mangrove, $\Delta$ = fishpond non-mangrove, $\boldsymbol{O}=$ open coast mangrove, $\mathrm{O}=$ open coast non-mangrove) 

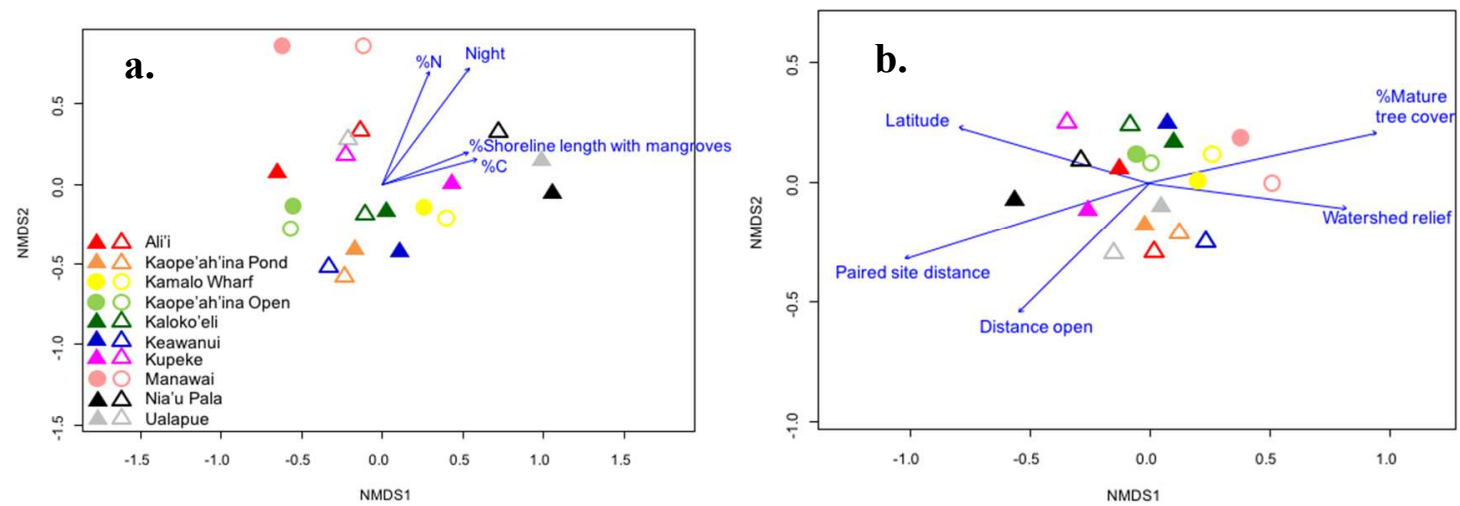

Figure A2. Nonmetric multidimensional scaling (NMDS) comparing zooplankton assemblages across site locations and habitat types collected in plankton tows separated by a. meroplankton (stress $=0.15$; PERMANOVA comparing habitat types: $\mathrm{df}=3$, $\mathrm{F}=0.76, \mathrm{p}=0.71)$ and $\mathbf{b}$. holoplankton ( stress $=0.21 ;$ PERMANOVA comparing habitat types: $\mathrm{df}=3, \mathrm{~F}=1.42, \mathrm{p}=0.12) .(\mathbf{M}=$ fishpond mangrove, $\Delta$ = fishpond non-mangrove = open coast mangrove, $\mathrm{O}=$ open coast non-mangrove) 

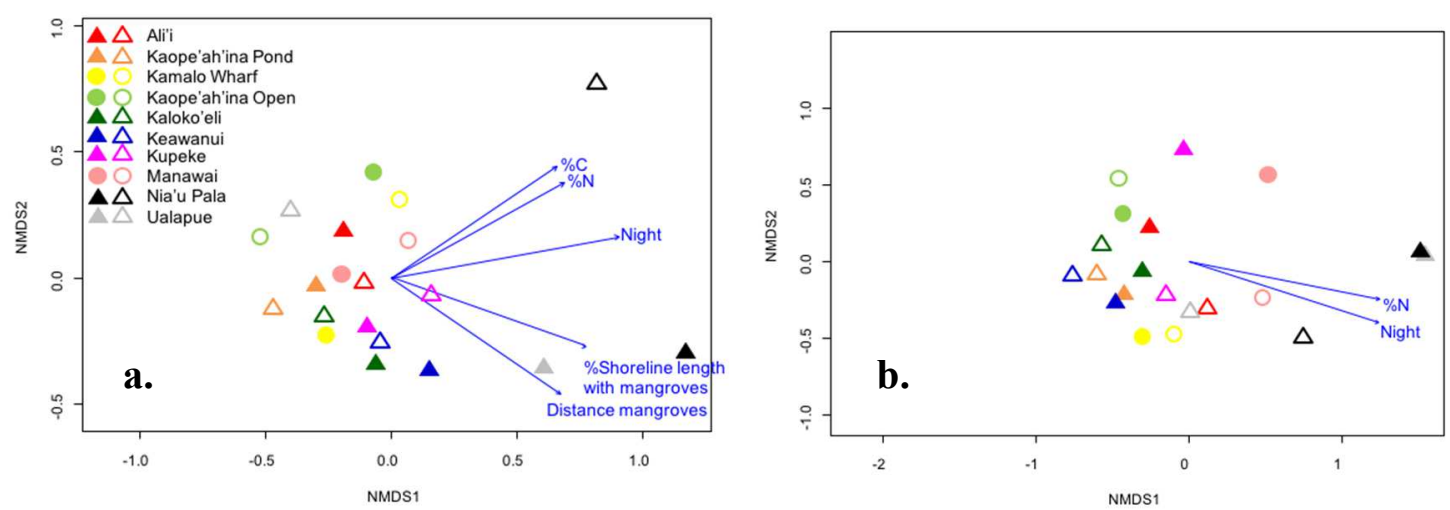

Figure A3. Nonmetric multidimensional scaling (NMDS) comparing zooplankton assemblages of only species relevant to human consumption across site locations and habitat types collected in a. light traps (stress $=0.11$; PERMANOVA comparing habitat types: $\mathrm{df}=3, \mathrm{~F}=1.12, \mathrm{p}=0.34)$ and $\mathbf{b}$. plankton tows (stress $=0.08$; PERMANOVA comparing habitat types: $\mathrm{df}=3, \mathrm{~F}=0.75, \mathrm{p}=0.68)$. $(\mathbf{\Lambda}=$ fishpond mangrove, $\Delta=$ fishpond non-mangrove, $\mathrm{O}$ = open coast mangrove, $\mathrm{O}$ = open coast non-mangrove) 

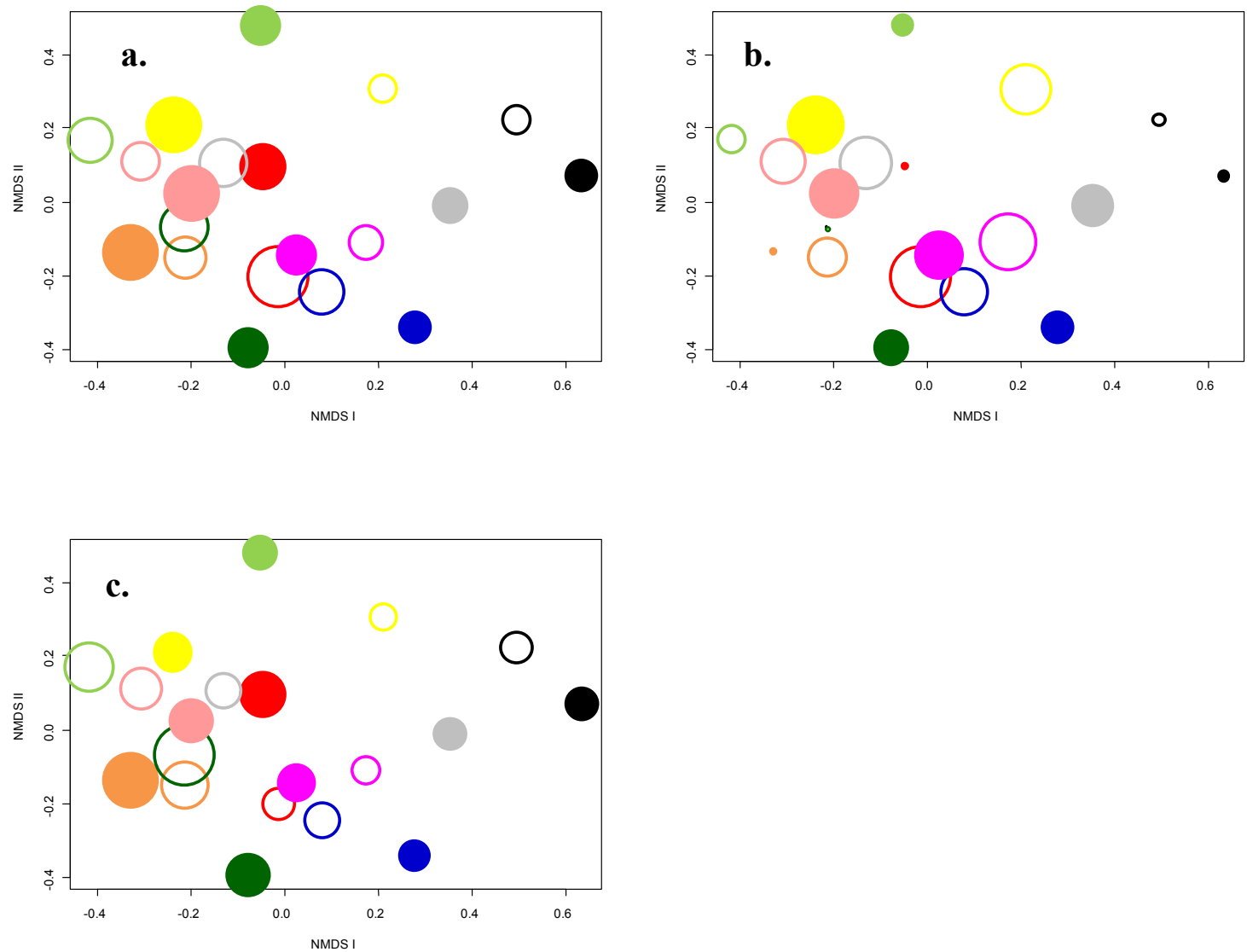

Figure A4. Nonmetric multidimensional scaling (NMDS) comparing zooplankton assemblages collected in light trap samples showing bubble plots of changes in $\mathbf{a}$. richness, b. Shannon diversity, and c. log abundance. Spearman correlation coefficients with $\%$ of shoreline length with mangroves are $-0.411(\mathrm{p}=0.072),-0.082(\mathrm{p}=0.733)$, and $-0.34(\mathrm{p}=0.137)$ respectively. 

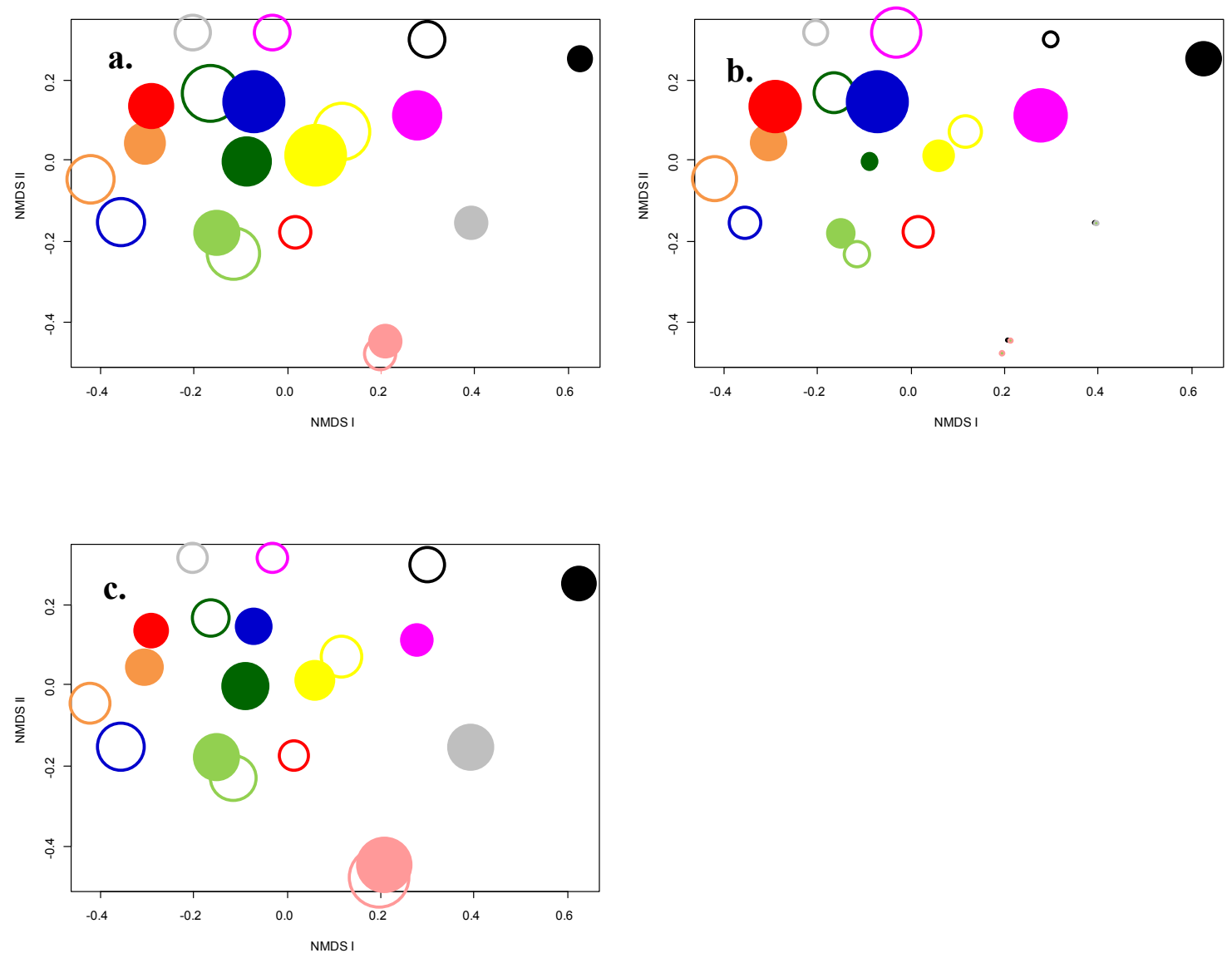

Figure A5. Nonmetric multidimensional scaling (NMDS) comparing zooplankton assemblages collected in plankton tow samples showing bubble plots of changes in $\mathbf{a}$. richness, b. Shannon diversity, and c. $\log$ abundance. Spearman correlation coefficients with $\%$ of shoreline length with mangroves are $0.075(\mathrm{p}=0.754),-0.157(\mathrm{p}=0.509)$, and $-0.033(\mathrm{p}=0.890)$ respectively. 
Table A2. Spearman correlation of meroplankton parameters to $\% \mathrm{~N}$ and $\% \mathrm{C}$ in mangrove leaves

\begin{tabular}{|c|c|c|c|c|}
\hline & \multicolumn{4}{|c|}{ Light traps } \\
\hline & \multicolumn{2}{|l|}{$\% \mathrm{C}$} & \multicolumn{2}{|l|}{$\% \mathrm{~N}$} \\
\hline & $r$ & $p$ & $r$ & $p$ \\
\hline Richness & -0.495 & 0.027 & -0.105 & 0.660 \\
\hline Shannon diversity & 0.205 & 0.385 & -0.142 & 0.551 \\
\hline \multirow[t]{2}{*}{ Abundance } & -0.647 & 0.002 & -0.160 & 0.500 \\
\hline & Tows & & & \\
\hline Richness & -0.092 & 0.701 & -0.698 & 0.001 \\
\hline Shannon diversity & -0.223 & 0.344 & -0.287 & 0.220 \\
\hline Abundance & -0.103 & 0.667 & -0.257 & 0.275 \\
\hline
\end{tabular}


Table A3. Spearman correlation of light trap community parameters to $\%$ mature tree cover in the watershed

\begin{tabular}{|c|c|c|}
\hline & \multicolumn{2}{|c|}{ Light Traps } \\
\hline & $r$ & $p$ \\
\hline Richness & 0.108 & 0.652 \\
\hline Shannon diversity & 0.064 & 0.790 \\
\hline Abundance & 0.129 & 0.586 \\
\hline
\end{tabular}


Table A4. Spearman correlation of \%mangrove shoreline length to watershed variables

\begin{tabular}{lrr}
\hline & $r$ & $p$ \\
\hline$d 13 C$ & -0.430 & 0.218 \\
\%C & 0.418 & 0.232 \\
d15N & $\mathbf{0 . 6 4 8}$ & $\mathbf{0 . 0 4 9}$ \\
$\mathrm{N}$ & 0.418 & 0.232 \\
Drainage area & 0.030 & 0.946 \\
Relief & -0.353 & 0.318 \\
Minbelev & -0.213 & 0.555 \\
\%Low development & 0.383 & 0.275 \\
\%Medium development & -0.017 & 0.962 \\
\%Bare & -0.052 & 0.887 \\
\%Mature tree cover & -0.152 & 0.675 \\
Precip & -0.248 & 0.492 \\
Perm12in & -0.297 & 0.407 \\
Perm24in & -0.200 & 0.584 \\
\%Impervious & 0.236 & 0.514 \\
\%Developed & 0.139 & 0.707 \\
\hline
\end{tabular}


Table A5. Ordinary least squares regression results of \%mangrove shoreline length as a function of d $15 \mathrm{~N}+\% \mathrm{~N}+\%$ developed. ANOVA revealed no significant difference between the full and reduced models. Adjusted $\mathrm{R}^{2}=0.60$

\begin{tabular}{lrllll}
\hline & Estimate & SE & \multicolumn{1}{l}{$\mathrm{T}$} & $\mathrm{p}$ & \\
\cline { 2 - 6 } Intercept & -0.074 & 0.184 & -0.401 & 0.702 & \\
d15N & 0.073 & 0.033 & 2.232 & 0.067 &. \\
\%N & 0.33 & 0.162 & 2.036 & 0.088 &. \\
\%developed & 0.007 & 0.003 & 2.157 & 0.074 &. \\
\hline
\end{tabular}


Table A6. Spearman correlation (positive (+) and negative (-)) between taxon abundance and $\%$ shoreline length with mangroves. Bold indicates significant values; bold italics represent marginally significant values. $\mathrm{RA}=$ mean relative abundance

\begin{tabular}{|c|c|c|c|c|c|c|}
\hline & \multicolumn{3}{|c|}{ Light Traps } & \multicolumn{3}{|l|}{ Tows } \\
\hline & $r$ & $p$ & RA & $r$ & $p$ & RA \\
\hline Copepod & -0.154 & 0.517 & $20.36 \%$ & -0.015 & 0.950 & $25.25 \%$ \\
\hline Shrimp larvae & 0.115 & 0.630 & $12.33 \%$ & -0.343 & 0.138 & $13.31 \%$ \\
\hline Crab zoea & -0.205 & 0.385 & $9.06 \%$ & -0.068 & 0.775 & $7.70 \%$ \\
\hline Amphipod & -0.648 & 0.002 & $9.88 \%$ & -0.026 & 0.914 & $6.45 \%$ \\
\hline Monstrillidae & -0.242 & 0.303 & $5.71 \%$ & -0.355 & 0.125 & $4.91 \%$ \\
\hline Isopod & -0.045 & 0.849 & $7.14 \%$ & -0.070 & 0.770 & $2.13 \%$ \\
\hline Cumacean & -0.393 & 0.086 & $5.54 \%$ & 0.222 & 0.347 & $2.67 \%$ \\
\hline Fish larvae & -0.361 & 0.118 & $2.46 \%$ & -0.127 & 0.594 & $4.56 \%$ \\
\hline Lucifer & -0.164 & 0.490 & $4.26 \%$ & 0.181 & 0.446 & $2.65 \%$ \\
\hline Ostracod & 0.418 & 0.067 & $0.75 \%$ & 0.091 & 0.702 & $6.14 \%$ \\
\hline Bivalve Larvae & -0.120 & 0.615 & $0.06 \%$ & 0.564 & 0.010 & $6.18 \%$ \\
\hline Megalopa (single rostrum) & -0.705 & 0.001 & $5.39 \%$ & -0.589 & 0.006 & $0.76 \%$ \\
\hline Nauplius & -0.359 & 0.120 & $0.18 \%$ & 0.272 & 0.247 & $5.33 \%$ \\
\hline Polycheate & -0.439 & 0.053 & $2.77 \%$ & 0.357 & 0.134 & $2.01 \%$ \\
\hline Gastropod larvae & -0.067 & 0.778 & $0.58 \%$ & -0.037 & 0.879 & $0.76 \%$ \\
\hline Megalopa (double rostrum) & -0.576 & 0.008 & $3.27 \%$ & -0.009 & 0.971 & $0.23 \%$ \\
\hline Mantis & 0.160 & 0.450 & $2.30 \%$ & 0.365 & 0.114 & $1.05 \%$ \\
\hline Mysid & -0.211 & 0.371 & $2.35 \%$ & 0.003 & 0.990 & $0.67 \%$ \\
\hline Lobster larvae & -0.056 & 0.813 & $2.71 \%$ & 0.280 & 0.233 & $0.15 \%$ \\
\hline Barnacle & -0.063 & 0.792 & $0.35 \%$ & -0.227 & 0.336 & $1.46 \%$ \\
\hline Hydropoids & -0.280 & 0.233 & $0.09 \%$ & -0.406 & 0.076 & $1.23 \%$ \\
\hline Megalopa (other) & -0.116 & 0.627 & $0.98 \%$ & 0.280 & 0.233 & $0.15 \%$ \\
\hline Leech & 0.233 & 0.323 & $0.49 \%$ & 0.406 & 0.076 & $0.56 \%$ \\
\hline Nematode & -0.342 & 0.140 & $0.34 \%$ & 0.174 & 0.463 & $0.53 \%$ \\
\hline Parasitic copepod & 0.024 & 0.919 & $0.26 \%$ & -0.120 & 0.615 & $0.10 \%$ \\
\hline Jellies & 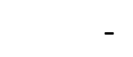 & - & $0.09 \%$ & -0.522 & 0.018 & $0.17 \%$ \\
\hline Post larval crab & -0.510 & 0.021 & $0.19 \%$ & - & - & $0.00 \%$ \\
\hline Cephalopoda & -0.035 & 0.884 & $0.11 \%$ & - & - & $0.00 \%$ \\
\hline
\end{tabular}


Table A7. Spearman correlation (positive (+) and negative (-)) between taxon abundance and night sampled (lunar cycle). Bold indicates significant values; bold italics represent marginally significant values. $\mathrm{RA}=$ mean relative abundance

\begin{tabular}{|c|c|c|c|c|c|c|}
\hline & \multicolumn{3}{|c|}{ Light Traps } & \multicolumn{3}{|l|}{ Tows } \\
\hline & $r$ & $p$ & RA & $r$ & $\mathrm{p}$ & RA \\
\hline Copepod & -0.300 & 0.199 & $20.36 \%$ & -0.113 & 0.635 & $25.25 \%$ \\
\hline Shrimp larvae & -0.274 & 0.243 & $12.33 \%$ & -0.726 & 0.000 & $13.31 \%$ \\
\hline Crab zoea & -0.452 & 0.046 & $9.06 \%$ & -0.445 & 0.050 & $7.70 \%$ \\
\hline Amphipod & -0.224 & 0.343 & $9.88 \%$ & -0.092 & 0.701 & $6.45 \%$ \\
\hline Monstrillidae & -0.006 & 0.980 & $5.71 \%$ & -0.419 & 0.066 & $4.91 \%$ \\
\hline Isopod & 0.058 & 0.808 & $7.14 \%$ & -0.424 & 0.062 & $2.13 \%$ \\
\hline Cumacean & -0.221 & 0.350 & $5.54 \%$ & 0.029 & 0.902 & $2.67 \%$ \\
\hline Fish larvae & -0.336 & 0.148 & $2.46 \%$ & -0.570 & 0.009 & $4.56 \%$ \\
\hline Lucifer & 0.052 & 0.828 & $4.26 \%$ & 0.307 & 0.189 & $2.65 \%$ \\
\hline Ostracod & 0.320 & 0.169 & $0.75 \%$ & -0.209 & 0.376 & $6.14 \%$ \\
\hline Bivalve Larvae & 0.121 & 0.611 & $0.06 \%$ & 0.199 & 0.400 & $6.18 \%$ \\
\hline Megalopa (single rostrum) & -0.466 & 0.038 & $5.39 \%$ & -0.479 & 0.033 & $0.76 \%$ \\
\hline Nauplius & -0.323 & 0.164 & $0.18 \%$ & -0.247 & 0.294 & $5.33 \%$ \\
\hline Polycheate & -0.153 & 0.521 & $2.77 \%$ & 0.329 & 0.157 & $2.01 \%$ \\
\hline Gastropod larvae & -0.165 & 0.487 & $0.58 \%$ & 0.054 & 0.822 & $0.76 \%$ \\
\hline Megalopa (double rostrum) & -0.536 & 0.015 & $3.27 \%$ & 0.092 & 0.699 & $0.23 \%$ \\
\hline Mantis & 0.095 & 0.692 & $2.30 \%$ & -0.093 & 0.695 & $1.05 \%$ \\
\hline Mysid & 0.124 & 0.602 & $2.35 \%$ & 0.352 & 0.128 & $0.67 \%$ \\
\hline Lobster larvae & -0.311 & 0.182 & $2.71 \%$ & -0.162 & 0.496 & $0.15 \%$ \\
\hline Barnacle & 0.074 & 0.757 & $0.35 \%$ & -0.359 & 0.120 & $1.46 \%$ \\
\hline Hydropoids & -0.323 & 0.164 & $0.09 \%$ & -0.469 & 0.037 & $1.23 \%$ \\
\hline Megalopa (other) & -0.302 & 0.195 & $0.98 \%$ & -0.162 & 0.496 & $0.15 \%$ \\
\hline Leech & -0.007 & 0.975 & $0.49 \%$ & -0.235 & 0.320 & $0.56 \%$ \\
\hline Nematode & -0.270 & 0.250 & $0.34 \%$ & 0.176 & 0.457 & $0.53 \%$ \\
\hline Parasitic copepod & 0.173 & 0.467 & $0.26 \%$ & 0.121 & 0.611 & $0.10 \%$ \\
\hline Jellies & - & - & $0.09 \%$ & -0.470 & 0.037 & $0.17 \%$ \\
\hline Post larval crab & -0.497 & 0.026 & $0.19 \%$ & - & - & $0.00 \%$ \\
\hline Cephalopoda & -0.346 & 0.135 & $0.11 \%$ & - & - & $0.00 \%$ \\
\hline
\end{tabular}


Table A8. Spearman correlation of community parameters to mangrove and open shoreline length

\begin{tabular}{|c|c|c|c|c|}
\hline & \multicolumn{4}{|l|}{ Light traps } \\
\hline & \multicolumn{2}{|l|}{ Mangrove length } & \multicolumn{2}{|c|}{ Open length } \\
\hline & $\mathrm{r}$ & $\mathrm{p}$ & $r$ & $\mathrm{p}$ \\
\hline Richness & -0.323 & 0.094 & 0.105 & 0.597 \\
\hline Shannon diversity & -0.163 & 0.408 & -0.114 & 0.564 \\
\hline \multirow[t]{2}{*}{ Abundance } & -0.335 & 0.081 & 0.032 & 0.873 \\
\hline & Tows & & & \\
\hline Richness & 0.163 & 0.407 & -0.091 & 0.645 \\
\hline Shannon diversity & 0.215 & 0.273 & 0.619 & 0.000 \\
\hline Abundance & -0.264 & 0.174 & -0.539 & 0.003 \\
\hline
\end{tabular}




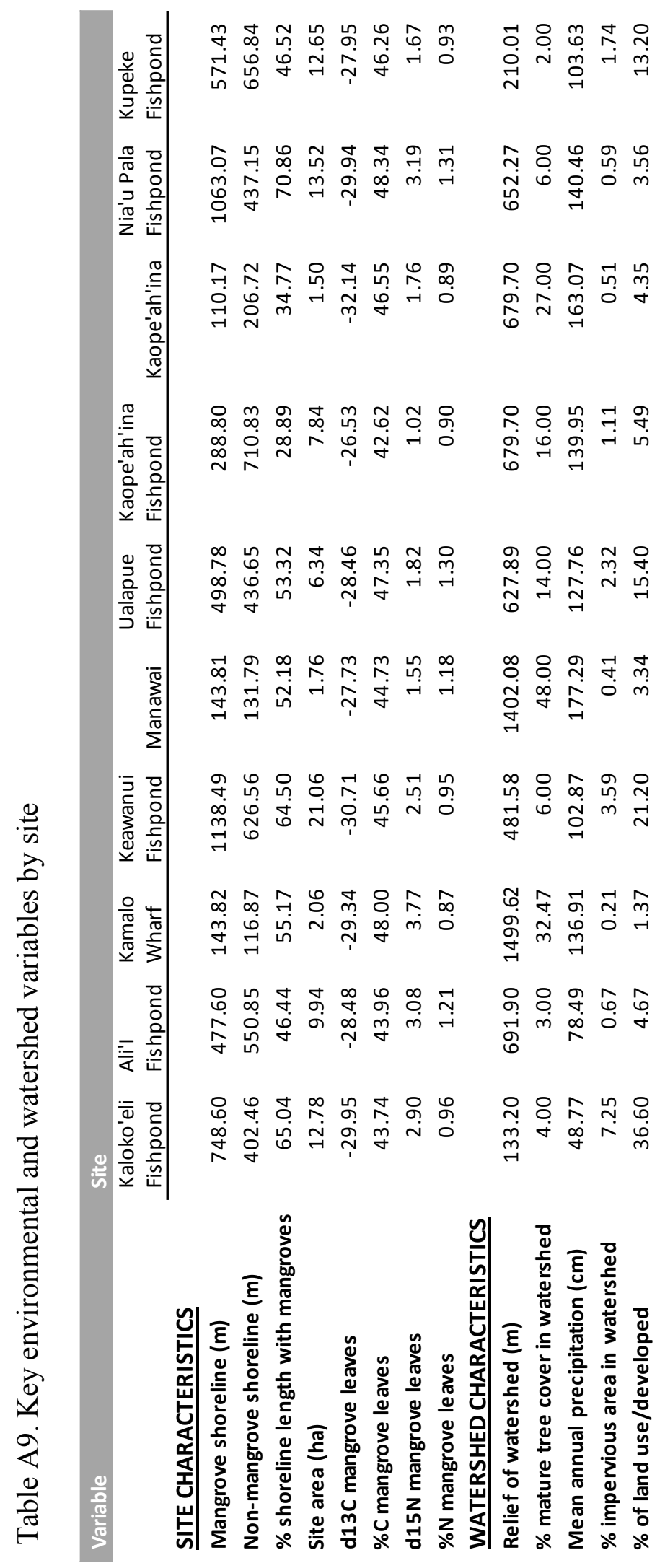


a. NMDS site plot (stress $=0.16)$

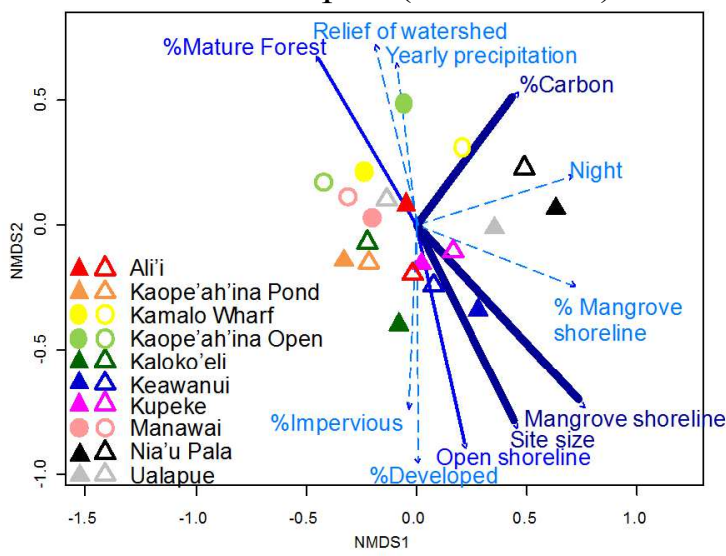

c. Lobster larvae

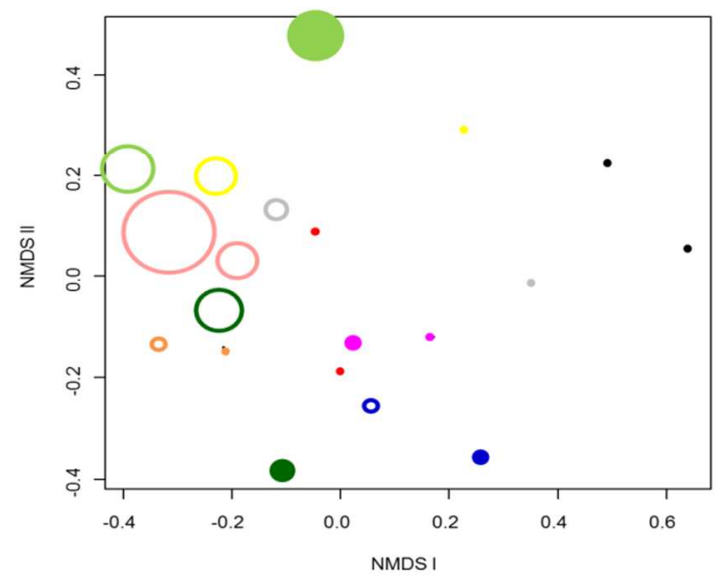

b. Fish larvae

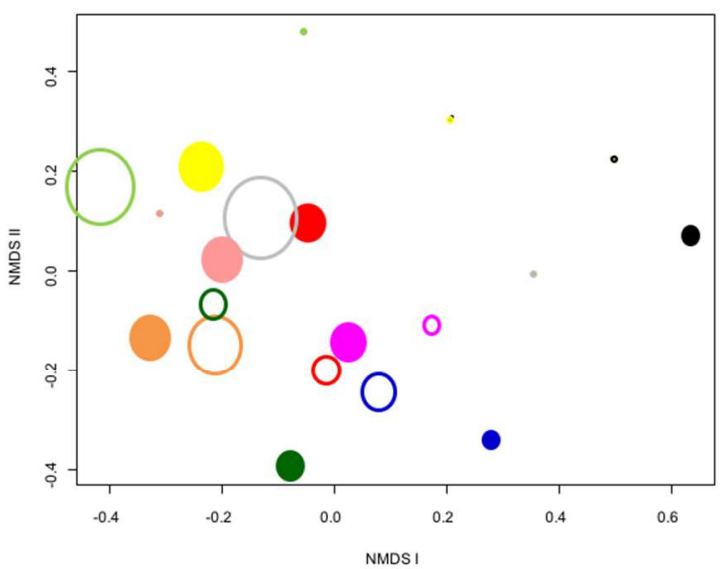

d. Megalopa (single rostrum)

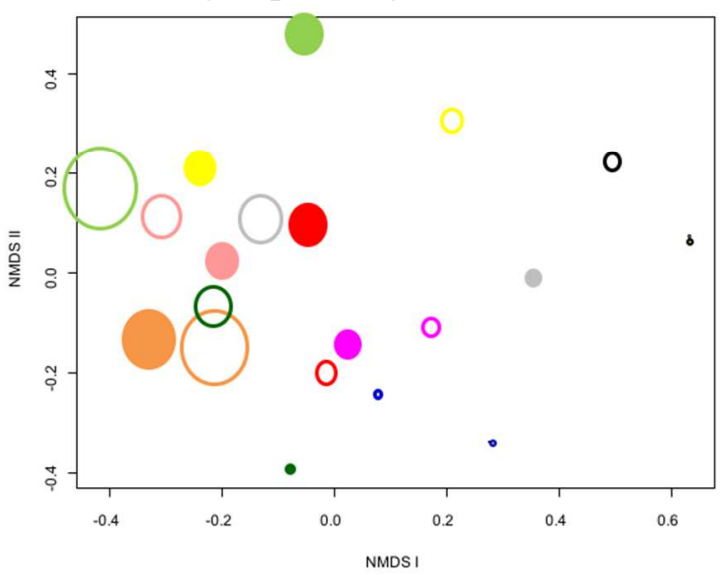

Figure A6. Nonmetric multidimensional scaling (NMDS) comparing zooplankton assemblages collected in light trap samples across site locations and habitat types. a. NMDS plot of study sites and types including environmental vectors driving community assemblages. ( $\mathbf{A}$ = fishpond mangrove, $\Delta$ = fishpond non-mangrove, $\mathbf{D}=$ open coast mangrove, $\mathrm{O}=$ open coast non-mangrove, dark thick line $-\mathrm{p}=0-0.0001$, thin line $p=0.001-0.01$, light dotted line $-p=0.01-0.05)$ b.-d. Bubble plots of changes in relative abundance of three zooplankton taxa (filled circles = mangrove, open circles $=$ nonmangrove). 
a. NMDS site plot ( stress $=0.19)$
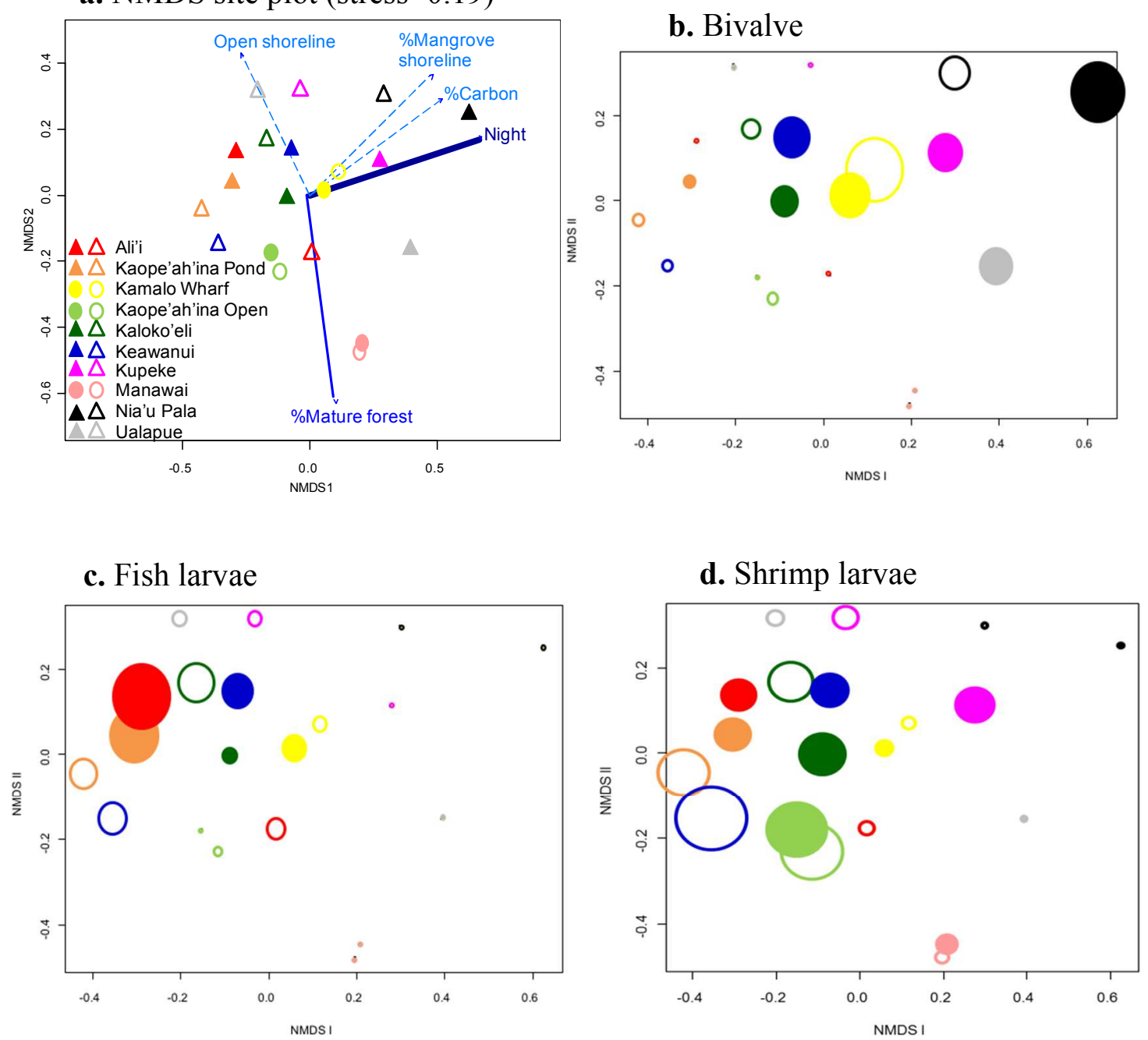

Figure A7. Nonmetric multidimensional scaling (NMDS) comparing zooplankton assemblages collected in plankton tow samples across site locations and habitat types. $\mathbf{a}$. NMDS plot of study sites and types with environmental vectors driving community assemblages. ( $\mathbf{\Delta}$ = fishpond mangrove, $\Delta$ = fishpond non-mangrove, $\boldsymbol{O}$ = open coast mangrove, $\mathrm{O}=$ open coast non-mangrove, dark thick line $-\mathrm{p}=0-0.0001$, thin line $\mathrm{p}=0.001-0.01$, light dotted line $-\mathrm{p}=0.01-0.05)$ b.-d. Bubble plots of changes in relative 
abundance of three zooplankton taxa (filled circles = mangrove, open circles $=$ nonmangrove). 
Table A10. Permutational multivariate analysis of variance (PERMANOVA) tables showing effects of habitat type on zooplankton community composition (excluding rare $\operatorname{taxa})$.

\begin{tabular}{lrrrrrr}
\hline Source of variation & df & SS & MS & $F$ & $R^{2}$ & $P$ value \\
\hline $\begin{array}{lrrrrrr}\text { A. Light trap samples } \\
\text { Habitat type }\end{array}$ & 3 & 0.26 & 0.09 & 1.05 & 0.17 & 0.39 \\
$\begin{array}{l}\text { Residuals } \\
\text { B. Tow samples }\end{array}$ & 16 & 1.33 & 0.08 & 0.83 & & \\
$\begin{array}{l}\text { Habitat type } \\
\text { Residuals }\end{array}$ & 3 & 0.33 & 0.11 & 1.19 & 0.18 & 0.25 \\
\hline df degree of freedom, SS sums of squares, MS mean of squares, F pseudo-F ratio
\end{tabular}


a.

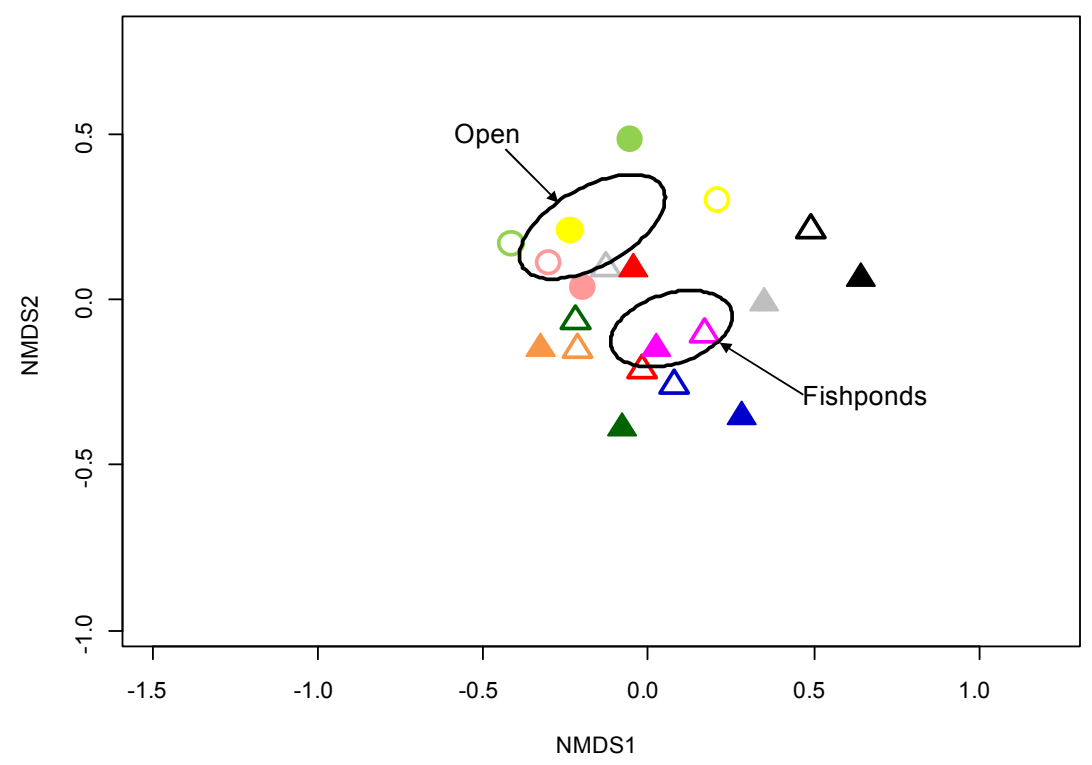

b.

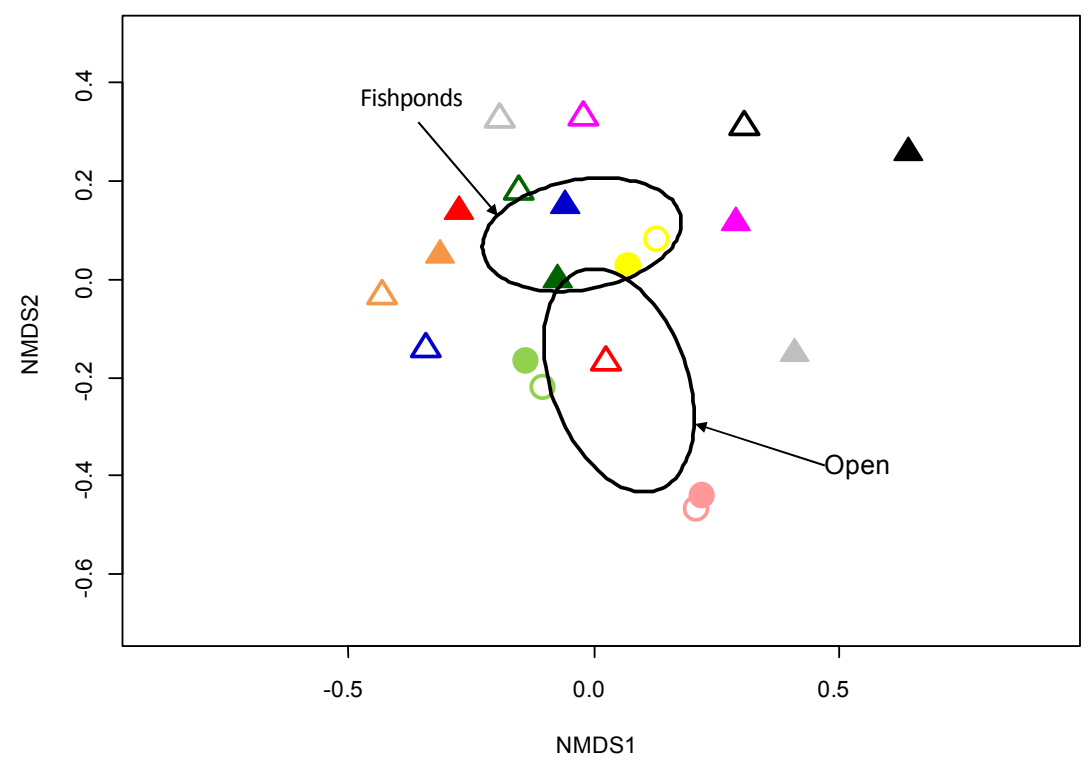

Figure A8. Nonmetric multidimensional scaling (NMDS) comparing zooplankton assemblages between open sites and fishpond sites a. light traps (stress $=0.16$; PERMANOVA comparing habitat types: $\mathrm{df}=1, \mathrm{~F}=2.55, \mathrm{p}=0.01$ ) and $\mathbf{a}$. plankton tows ( stress $=0.195$; PERMANOVA comparing habitat types: $\mathrm{df}=1, \mathrm{~F}=1.70, \mathrm{p}=0.09$ ). Ellipses 
represent $95 \%$ confidence intervals. $(\boldsymbol{\Delta}=$ fishpond mangrove, $\Delta$ = fishpond nonmangrove, $=$ open coast mangrove, $\mathrm{O}=$ open coast non-mangrove) 
a.

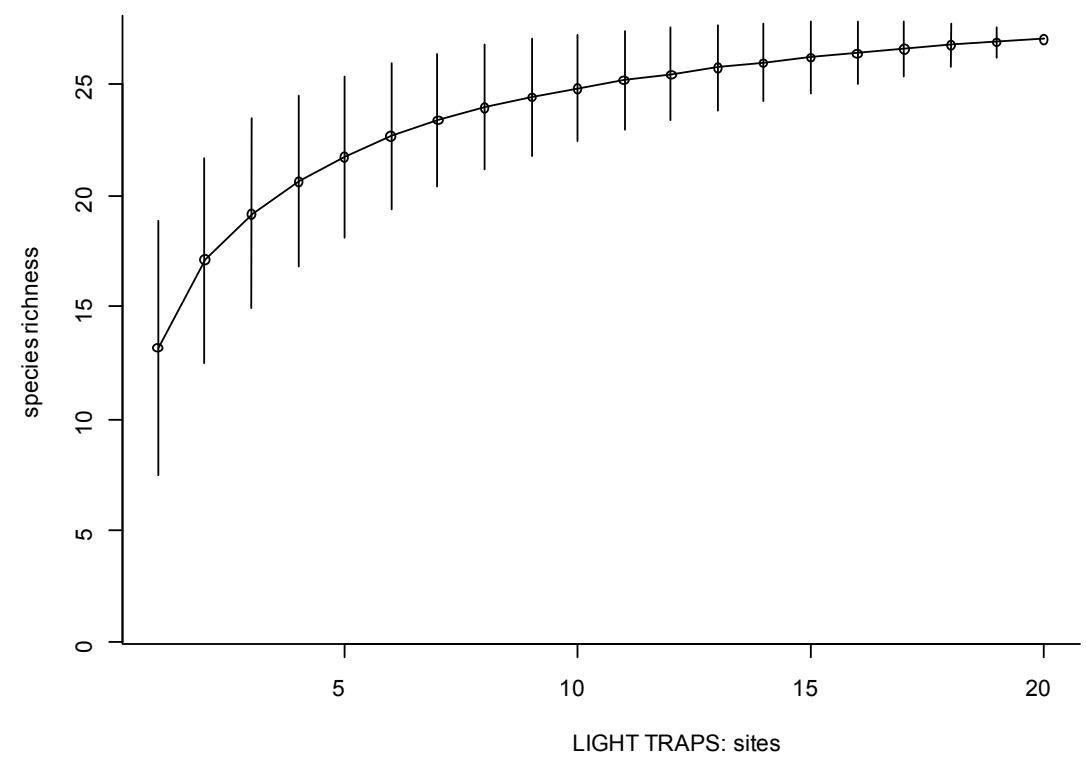

b.

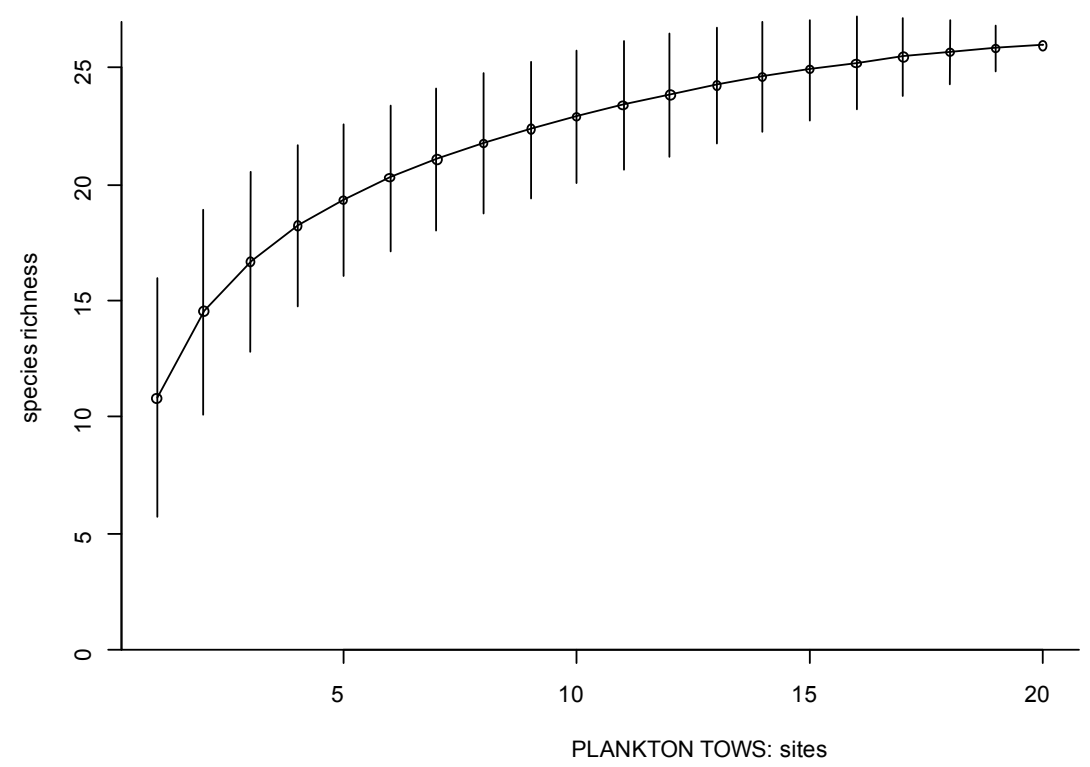

Figure A9. Species accumulation curves for a. light traps and b. plankton tows. 

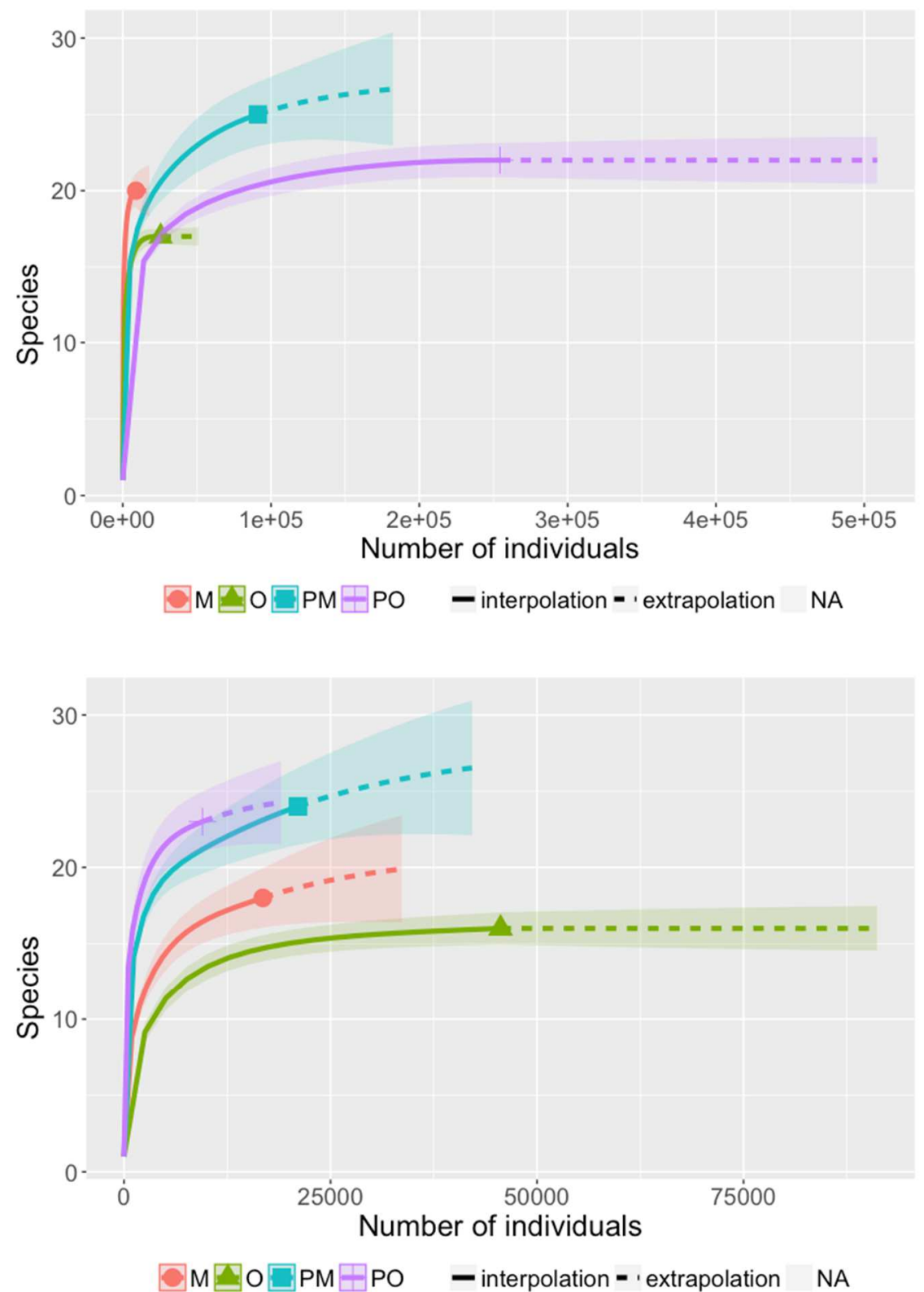

Figure A10. Sample-based species richness (Chao1) rarefaction (solid line) and extrapolation (dotted line) sampling curves by habitat types for A. light traps and B. plankton tows. Shaded areas represent $95 \%$ confidence interval obtained by a bootstrap method. The solid shapes represent the reference samples. ( $M$ open coast mangrove, $O$ open coast non-mangrove, $P M$ fishpond mangrove, $P O$ fishpond non-mangrove) 
Table A11. Spearman correlation of mangrove shoreline length to human disturbance variables

\begin{tabular}{lrr}
\hline & \multicolumn{2}{r}{$p$} \\
\cline { 2 - 3 } \% Mature forest & $-\mathbf{0 . 6 9 3}$ & $\mathbf{0 . 0 0 1}$ \\
Watershed relief & $-\mathbf{0 . 7 4 2}$ & $\mathbf{0 . 0 0 0}$ \\
Yearly precipitation & $-\mathbf{0 . 6 0 0}$ & $\mathbf{0 . 0 0 5}$ \\
& & \\
\% Developed & $\mathbf{0 . 6 2 4}$ & $\mathbf{0 . 0 0 3}$ \\
\% Impervious & $\mathbf{0 . 7 2 1}$ & $\mathbf{0 . 0 0 0}$ \\
\hline
\end{tabular}



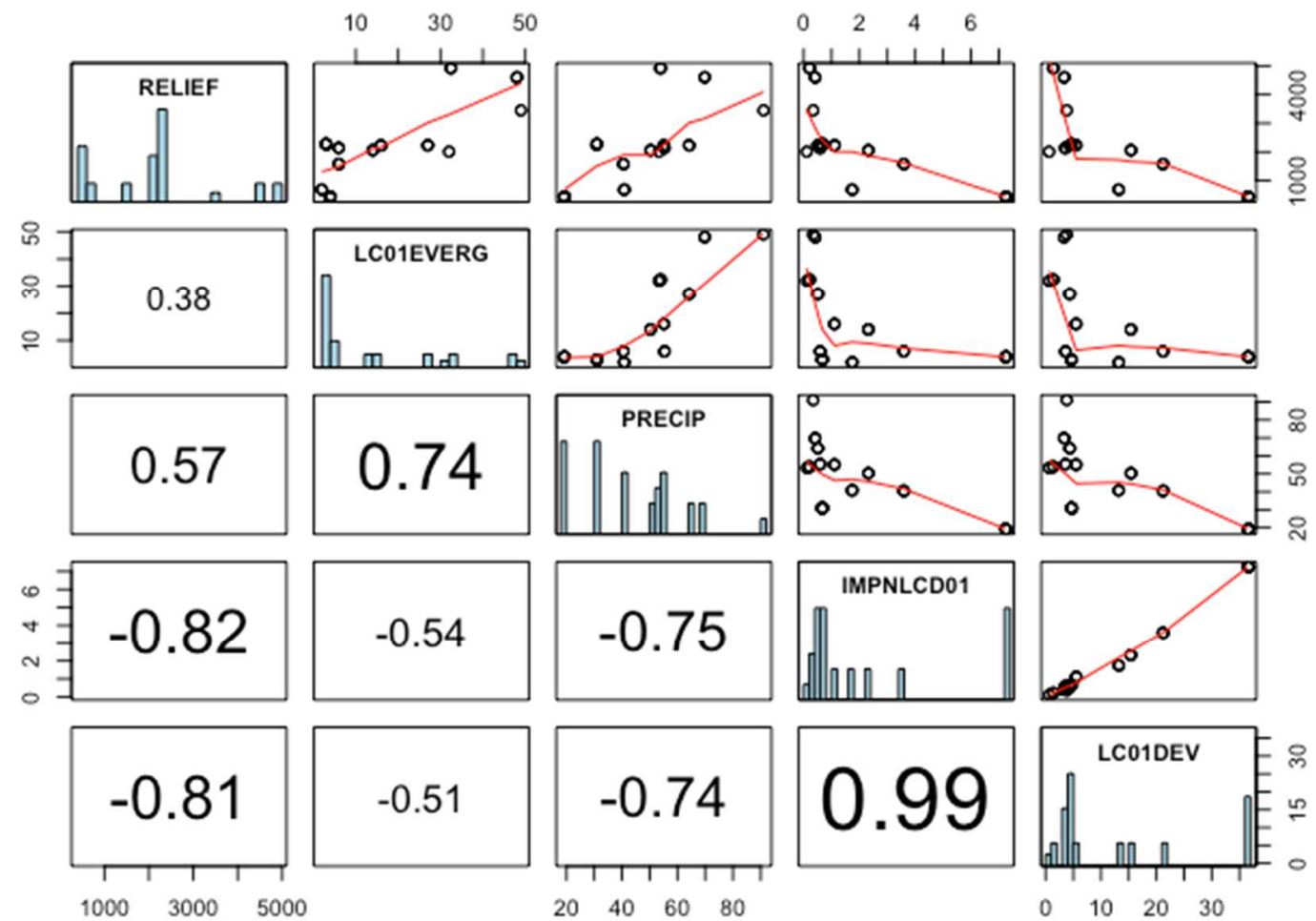

$\begin{array}{llll}20 & 40 \quad 60 \quad 80\end{array}$

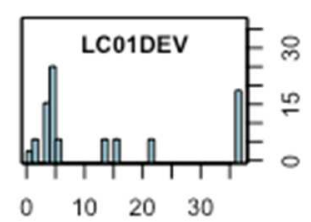

Figure A11. Correlation matrix of variables related to human disturbance. Correlations (r) are represented on the lower left, histograms on the diagonal, and xy plots on the upper right. Relief $=$ relief of watershed, LC01EVERG $=\%$ mature forest, PRECIP $=$ annual precipitation, IMPNLCD01 $=\%$ impervious surface, $\mathrm{LC} 01 \mathrm{DEV}=\%$ developed land 
Table A12. Loadings of variables onto PCA1.

\begin{tabular}{lr}
\hline \hline & PCA1 \\
\cline { 2 - 2 } Relief of watershed & -0.372 \\
\%Mature forest & -0.398 \\
Annual precipitation & -0.194 \\
\%Impervious & 0.605 \\
\%Developed & 0.547 \\
\hline \hline
\end{tabular}




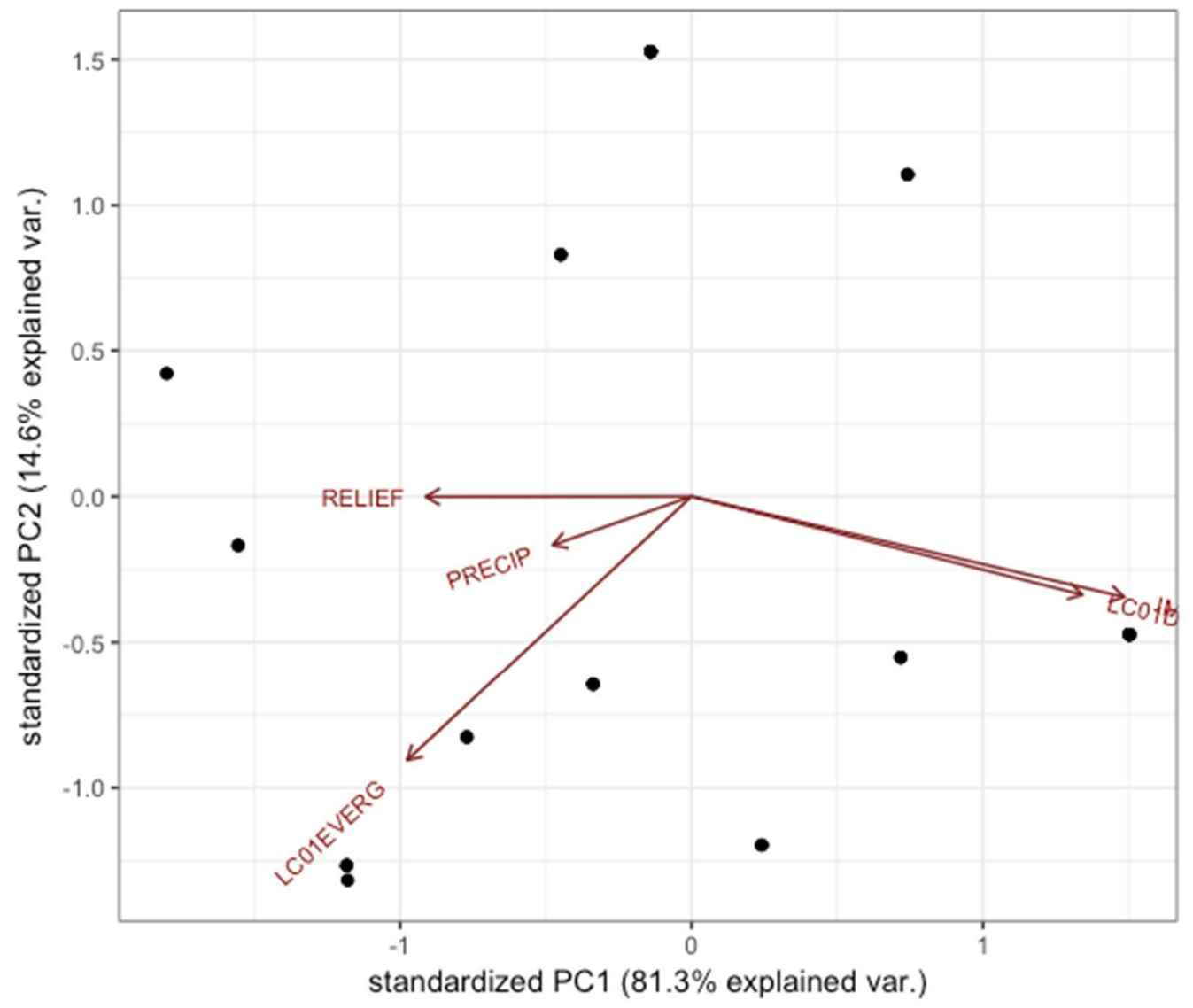

Figure A12. PCA biplot of variables related to human disturbance. PCA1 explains $81.3 \%$ of the variance. 


\section{Section A1: Locomotion}

Many zooplankton are skillful swimmers capable of rapid escape maneuvers and considerable vertical migrations (Johnson and Allen 2012). In tows, bivalves were more abundant at sites with a greater percentage of mangrove shoreline length while fish larvae, for both sampling methods, were more abundant at sites that had lower percentages of mangrove shoreline length (Appendix; Figure A6b, A7b,c). Numerous larger and more mobile zooplankton can detect pressure waves from approaching plankton tows and can often avoid capture (Johnson and Allen 2012). As fish larvae are more mobile than bivalves, they are better able to avoid detection and can utilize red mangrove prop root habitat for protection (Granek and Frasier 2007) and hence may be less likely to be sampled at sites with a greater percentage of mangrove shoreline length. This tactic could, similarly, be employed by many crustaceans, including crab megalopae and shrimp larvae (Luckenbach and Orth 1992).

\section{Section A2: Meroplankton and holoplankton}

While zooplankton are near the bottom of the food chain, many of them grow into species of commercial importance or support healthy coral reef ecosystem dynamics. Zooplankton composition includes both holoplankton, organisms that spend their entire life in the plankton, and meroplankton, organisms that only spend a portion of their life cycle as plankton and then either graduate to the nekton or settle on the benthos (Johnson and Allen 2012). Meroplankton found in our samples included crustaceans that develop into human consumed taxa, some of which utilize mangroves as adults. For example, 
mangrove crabs (Scylla serrata), a prized and sought after commercial species, were intentionally introduced to establish a commercial crab fishery and frequently inhabit mangrove areas (Eldredge and Smith 2001). Interestingly, crab megalopae abundance decreased as mangrove shoreline increased (Table 2.5), though crab megalopae were not to identifiable to Genus. In contrast, crab megalopae abundance increased with increasing mature tree cover in the watershed (Table 2.6). Lower megalopa abundances in mangrove areas is consistent with their life cycle, whereby mangrove crabs in the larval phase are generally offshore and migrate to coastal mangrove habitat as juveniles (Meynecke and Richards 2014). 


\section{APPENDIX B. Survey instrument}

\section{Consent}

We are looking for adult residents of Molokai who have lived here a year or more who would be willing to answer a survey on the mangroves of Molokai. Your participation in this study is voluntary.

The survey is part of a Faculty Enhancement Grant funded project and will be a component of a masters thesis project on the ecosystem services of non-native mangroves in Hawaii. The survey asks questions to assess public perceptions and attitudes about and understanding of mangroves and their management.

We do not anticipate any risks with participating in this survey. No personal information will be stored with your responses. Your participation in the survey is voluntary. We are not offering any compensation for participation. It is completely up to you if you want to participate, and you can skip questions.

The survey will take about 5-10 minutes. No personal information will be collected, and your responses will be kept strictly confidential and individual responses will not be shared with any person or group not directly involved in the survey.

\section{$\underline{\text { A. Demographics }}$}

A1. What is your gender?

_ Male _ Female

A2. Please select your age range? $18-21$

21-25

26-30

31-35

36-40

41-45

46-50

-51-55

-56-60

61-65

66-70

71-75

76-80

over 80 yrs.

A3. What is your ethnicity? 
American Indian or Alaska Native

Asian

Black or African American

Hispanic or Latino

Native Hawaiian or Other Pacific Islander

White

Other

A4. What is the highest degree or level of school you have completed?

Less than high school

High school

Some college

Associated or Vocational degree

Bachelor's degree

Some graduate school

Graduate or professional degree

A5. What is your current employment status?

Employed full time

Employed part time

Unemployed

A homemaker

Student

Retired

A6. What category best describes your household income (before taxes) in 2014 ?

Less than $\$ 25,000$

$\$ 25,000$ - \$49,999

$\$ 50,000-\$ 74,999$

$\$ 75,000$ - \$99,999

$\$ 100,000$ and higher

A7. What is your main source(s) of income?

A7. How long have you lived on Molokai?

A8. How long have you lived in the Hawaiian Islands (in years)? 


\section{B. Molokai Mangroves}

Below are 22 statements about the Molokai mangroves. For each statement, please select the option that matches your assessment. If you Strongly Agree, Agree, or Somewhat Agree with a statement, we invite you to provide additional information below that statement.

B1. Do you rely on mangroves for any benefit? Please mark all that apply.

Fishing

Crabbing

Spiritual/cultural benefits

Tourism

Recreation

Other

None

B2. In what way to you interact with the mangroves (for each of the below, circle a response):

a. Visitation

\begin{tabular}{|c|c|c|c|c|}
\hline Never & Yearly & Monthly & Weekly & Daily \\
\hline
\end{tabular}

b. Fishing in the mangroves

\begin{tabular}{|c|c|c|c|c|}
\hline Never & Yearly & Monthly & Weekly & Daily \\
\hline
\end{tabular}

c. Managing mangroves in fishpond(s)

\begin{tabular}{|c|c|c|c|c|}
\hline Never & Yearly & Monthly & Weekly & Daily \\
\hline
\end{tabular}

d. Managing shoreline mangroves

\begin{tabular}{|c|c|c|c|c|}
\hline Never & Yearly & Monthly & Weekly & Daily \\
\hline
\end{tabular}

e. Other

\begin{tabular}{|l|l|l|l|l|}
\hline Never & Yearly & Monthly & Weekly & Daily \\
\hline
\end{tabular}

B3. How often do you interact with the mangroves?

\begin{tabular}{|c|c|c|c|c|}
\hline Never & Yearly & Monthly & Weekly & Daily \\
\hline
\end{tabular}


B4. What is the condition of Molokai's southern coast?

\begin{tabular}{|c|c|c|c|c|c|c|}
\hline $\begin{array}{c}\text { Very } \\
\text { Healthy }\end{array}$ & Healthy & $\begin{array}{c}\text { Somewhat } \\
\text { Healthy }\end{array}$ & Unsure & $\begin{array}{c}\text { Somewhat } \\
\text { Unhealthy }\end{array}$ & Unhealthy & $\begin{array}{c}\text { Very } \\
\text { Unhealthy }\end{array}$ \\
\hline
\end{tabular}

B5. How would you assess the quality of management of Molokai's southern coast?

\begin{tabular}{|c|c|c|c|c|c|c|}
\hline $\begin{array}{l}\text { Very Well } \\
\text { Managed }\end{array}$ & $\begin{array}{c}\text { Well } \\
\text { Managed }\end{array}$ & $\begin{array}{c}\text { Somewhat } \\
\text { Well } \\
\text { Managed }\end{array}$ & Unsure & $\begin{array}{c}\text { Somewhat } \\
\text { Poorly } \\
\text { Managed }\end{array}$ & $\begin{array}{c}\text { Poorly } \\
\text { Managed }\end{array}$ & $\begin{array}{c}\text { Very } \\
\text { Poorly } \\
\text { Managed }\end{array}$ \\
\hline
\end{tabular}

B6. The mangroves on Molokai should be actively managed.

\begin{tabular}{|c|c|c|c|c|c|c|}
\hline $\begin{array}{c}\text { Strongly } \\
\text { Agree }\end{array}$ & Agree & $\begin{array}{c}\text { Somewhat } \\
\text { Agree }\end{array}$ & $\begin{array}{c}\text { Neither } \\
\text { Agree or } \\
\text { Disagree }\end{array}$ & $\begin{array}{c}\text { Somewhat } \\
\text { Disagree }\end{array}$ & Disagree & $\begin{array}{c}\text { Strongly } \\
\text { Disagree }\end{array}$ \\
\hline
\end{tabular}

If you answered Strongly agree, Agree, or Somewhat agree, please state WHY.

B7. The mangroves on Molokai should be left alone.

\begin{tabular}{|c|c|c|c|c|c|c|}
\hline $\begin{array}{c}\text { Strongly } \\
\text { Agree }\end{array}$ & Agree & $\begin{array}{c}\text { Somewhat } \\
\text { Agree }\end{array}$ & $\begin{array}{c}\text { Neither } \\
\text { Agree or } \\
\text { Disagree }\end{array}$ & $\begin{array}{c}\text { Somewhat } \\
\text { Disagree }\end{array}$ & Disagree & $\begin{array}{c}\text { Strongly } \\
\text { Disagree }\end{array}$ \\
\hline
\end{tabular}

If you answered Strongly agree, Agree, or Somewhat agree, please state WHY.

B8. The mangroves on Molokai should be entirely removed.

\begin{tabular}{|c|c|c|c|c|c|c|}
\hline $\begin{array}{c}\text { Strongly } \\
\text { Agree }\end{array}$ & Agree & $\begin{array}{c}\text { Somewhat } \\
\text { Agree }\end{array}$ & $\begin{array}{c}\text { Neither } \\
\text { Agree or } \\
\text { Disagree }\end{array}$ & $\begin{array}{c}\text { Somewhat } \\
\text { Disagree }\end{array}$ & Disagree & $\begin{array}{c}\text { Strongly } \\
\text { Disagree }\end{array}$ \\
\hline
\end{tabular}

If you answered Strongly agree, Agree, or Somewhat agree, please state WHY. 
B9. Do you consider sedimentation a concern for the coast of Molokai?

\begin{tabular}{|c|c|c|c|c|c|c|}
\hline $\begin{array}{c}\text { Strongly } \\
\text { Agree }\end{array}$ & Agree & $\begin{array}{c}\text { Somewhat } \\
\text { Agree }\end{array}$ & $\begin{array}{c}\text { Neither } \\
\text { Agree or } \\
\text { Disagree }\end{array}$ & $\begin{array}{c}\text { Somewhat } \\
\text { Disagree }\end{array}$ & Disagree & $\begin{array}{c}\text { Strongly } \\
\text { Disagree }\end{array}$ \\
\hline
\end{tabular}

B10. Do you consider chemical runoff a concern for the coast of Molokai?

\begin{tabular}{|c|c|c|c|c|c|c|}
\hline $\begin{array}{c}\text { Strongly } \\
\text { Agree }\end{array}$ & Agree & $\begin{array}{c}\text { Somewhat } \\
\text { Agree }\end{array}$ & $\begin{array}{c}\text { Neither } \\
\text { Agree or } \\
\text { Disagree }\end{array}$ & $\begin{array}{c}\text { Somewhat } \\
\text { Disagree }\end{array}$ & Disagree & $\begin{array}{c}\text { Strongly } \\
\text { Disagree }\end{array}$ \\
\hline
\end{tabular}

B11. Do you consider invasive species a concern for the coast of Molokai?

\begin{tabular}{|c|c|c|c|c|c|c|}
\hline $\begin{array}{c}\text { Strongly } \\
\text { Agree }\end{array}$ & Agree & $\begin{array}{c}\text { Somewhat } \\
\text { Agree }\end{array}$ & $\begin{array}{c}\text { Neither } \\
\text { Agree or } \\
\text { Disagree }\end{array}$ & $\begin{array}{c}\text { Somewhat } \\
\text { Disagree }\end{array}$ & Disagree & $\begin{array}{c}\text { Strongly } \\
\text { Disagree }\end{array}$ \\
\hline
\end{tabular}

B12. The mangroves on Molokai are beneficial.

\begin{tabular}{|c|c|c|c|c|c|c|}
\hline $\begin{array}{c}\text { Strongly } \\
\text { Agree }\end{array}$ & Agree & $\begin{array}{c}\text { Somewhat } \\
\text { Agree }\end{array}$ & $\begin{array}{c}\text { Neither } \\
\text { Agree or } \\
\text { Disagree }\end{array}$ & $\begin{array}{c}\text { Somewhat } \\
\text { Disagree }\end{array}$ & Disagree & $\begin{array}{c}\text { Strongly } \\
\text { Disagree }\end{array}$ \\
\hline
\end{tabular}

If Strongly Agree, Agree, Somewhat Agree, please state in what way(s) they are beneficial

B13. The mangroves on Molokai are harmful.

\begin{tabular}{|c|c|c|c|c|c|c|}
\hline $\begin{array}{c}\text { Strongly } \\
\text { Agree }\end{array}$ & Agree & $\begin{array}{c}\text { Somewhat } \\
\text { Agree }\end{array}$ & $\begin{array}{c}\text { Neither } \\
\text { Agree or } \\
\text { Disagree }\end{array}$ & $\begin{array}{c}\text { Somewhat } \\
\text { Disagree }\end{array}$ & Disagree & $\begin{array}{c}\text { Strongly } \\
\text { Disagree }\end{array}$ \\
\hline
\end{tabular}

If Strongly Agree, Agree, Somewhat Agree, please state in what way(s) they are harmful: 
B14. The mangroves improve the coast on Molokai.

\begin{tabular}{|c|c|c|c|c|c|c|}
\hline $\begin{array}{c}\text { Strongly } \\
\text { Agree }\end{array}$ & Agree & $\begin{array}{c}\text { Somewhat } \\
\text { Agree }\end{array}$ & $\begin{array}{c}\text { Neither } \\
\text { Agree or } \\
\text { Disagree }\end{array}$ & $\begin{array}{c}\text { Somewhat } \\
\text { Disagree }\end{array}$ & Disagree & $\begin{array}{c}\text { Strongly } \\
\text { Disagree }\end{array}$ \\
\hline
\end{tabular}

If you answered Strongly agree, Agree, or Somewhat agree, please state How.

B15. The mangroves hurt industry on Molokai.

\begin{tabular}{|c|c|c|c|c|c|c|}
\hline $\begin{array}{c}\text { Strongly } \\
\text { Agree }\end{array}$ & Agree & $\begin{array}{c}\text { Somewhat } \\
\text { Agree }\end{array}$ & $\begin{array}{c}\text { Neither } \\
\text { Agree or } \\
\text { Disagree }\end{array}$ & $\begin{array}{c}\text { Somewhat } \\
\text { Disagree }\end{array}$ & Disagree & $\begin{array}{c}\text { Strongly } \\
\text { Disagree }\end{array}$ \\
\hline
\end{tabular}

If you answered Strongly agree, Agree, or Somewhat agree, please state How.

B16. The mangroves hurt cultural sites on Molokai.

\begin{tabular}{|c|c|c|c|c|c|c|}
\hline $\begin{array}{c}\text { Strongly } \\
\text { Agree }\end{array}$ & Agree & $\begin{array}{c}\text { Somewhat } \\
\text { Agree }\end{array}$ & $\begin{array}{c}\text { Neither } \\
\text { Agree or } \\
\text { Disagree }\end{array}$ & $\begin{array}{c}\text { Somewhat } \\
\text { Disagree }\end{array}$ & Disagree & $\begin{array}{c}\text { Strongly } \\
\text { Disagree }\end{array}$ \\
\hline
\end{tabular}

If you answered Strongly agree, Agree, or Somewhat agree, please state How.

B17. I feel like management decisions about the mangroves are made with consideration of public input.

\begin{tabular}{|c|c|c|c|c|c|c|}
\hline $\begin{array}{c}\text { Strongly } \\
\text { Agree }\end{array}$ & Agree & $\begin{array}{c}\text { Somewhat } \\
\text { Agree }\end{array}$ & $\begin{array}{c}\text { Neither } \\
\text { Agree or } \\
\text { Disagree }\end{array}$ & $\begin{array}{c}\text { Somewhat } \\
\text { Disagree }\end{array}$ & Disagree & $\begin{array}{c}\text { Strongly } \\
\text { Disagree }\end{array}$ \\
\hline
\end{tabular}

B18. I feel like management decisions about the mangroves are made with consideration of all interest and values.

\begin{tabular}{|c|c|c|c|c|c|c|}
\hline $\begin{array}{c}\text { Strongly } \\
\text { Agree }\end{array}$ & Agree & $\begin{array}{c}\text { Somewhat } \\
\text { Agree }\end{array}$ & $\begin{array}{c}\text { Neither } \\
\text { Agree or } \\
\text { Disagree }\end{array}$ & $\begin{array}{c}\text { Somewhat } \\
\text { Disagree }\end{array}$ & Disagree & $\begin{array}{c}\text { Strongly } \\
\text { Disagree }\end{array}$ \\
\hline
\end{tabular}


B19. How well informed would you consider yourself to be concerning the pros and cons of the mangroves?

\begin{tabular}{|c|c|c|c|c|c|c|}
\hline $\begin{array}{c}\text { Very Well } \\
\text { Informed }\end{array}$ & $\begin{array}{c}\text { Well } \\
\text { Informed }\end{array}$ & $\begin{array}{c}\text { Somewhat } \\
\text { Well } \\
\text { Informed }\end{array}$ & Unsure & $\begin{array}{c}\text { Somewhat } \\
\text { Uninformed }\end{array}$ & Uniformed & $\begin{array}{c}\text { Very } \\
\text { Uninformed }\end{array}$ \\
\hline
\end{tabular}

B20. Have you visited the mangroves in person?

\begin{tabular}{|c|c|}
\hline Yes & No \\
\hline
\end{tabular}

B21. When did you first become aware of the mangrove issue?

B22. Are you aware of issues that we have not asked about? If yes, please list:

B23. Whose responsibility should it be to manage the mangroves?

List all that apply: 


\title{
APPENDIX C. Human subjects' approval
}

\section{蛋 Portland $\underset{\text { SNIVERSITY }}{\text { State }}$}

\begin{abstract}
Post Office Box $751 \quad 503-725-2227$ tel
Portland, Oregon 97207-0751 503-725-8170 fax

Human Subjects Research Review Committee
\end{abstract}

hsrrc@lists.pdx.edu

Date: May 28,2015

To: $\quad$ Elise Granek / Casey Lewis

From: Karen Cellarius, HSRRC Chair

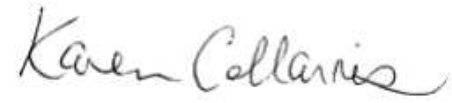

Re: HSRRC approval for your project titled, "Hawai'i Mangroves Project" HSRRC Proposal \# 153446

Review Type: Exempt, Category 2

In accordance with your request, the Human Subjects Research Review Committee has reviewed your proposal referenced above for compliance with PSU and DHHS policies and regulations covering the protection of human subjects. The Committee is satisfied that your provisions for protecting the rights and welfare of all subjects participating in the research are adequate, and your project is approved. Please note the following requirements:

Approval: You are approved to conduct this research study after receipt of this approval letter, and the research must be conducted according to the plans and protocol submitted (approved copy enclosed).

Consent: Signed consent is waived from all participants in this study. A written consent statement is required.

Changes to Protocol: Any changes in the proposed study, whether to procedures, survey instruments, consent forms or cover letters, must be outlined and submitted to the Committee immediately. The proposed changes cannot be implemented before they have been reviewed and approved by the Committee.

Adverse Reactions and/or Unanticipated Problems: If any adverse reactions or unanticipated problems occur as a result of this study, you are required to notify the Committee immediately. If the issue is serious, approval may be withdrawn pending an investigation by the Committee.

Completion of Study: Please notify the Committee as soon as your research has been completed. Study records, including protocols and signed consent forms for each participant, must be kept by the investigator in a secure location for three years following completion of the study (or per any requirements specified by the project's funding agency).

If you have questions or concerns, please contact the Office of Research Integrity in the PSU RSP at 503-725-2227, 1600 SW $4^{\text {th }}$ Ave., Market Center Building, Suite 620. 


\section{APPENDIX D. Social analysis supporting material}

\section{Methods: Multinomial Logistic Regression}

For the second question, multinomial logistic regression was used to model the relationship between attitude toward mangroves and predictor variables (Chatterjee and Simonoff 2013). Some predictor variables were indexed due to high correlations and conceptual consistency, and Cronbach's alpha was used to measure internal consistency. The response variable (attitude toward mangroves) was divided into three categories according to the valence of the attitude index: Positive, Neutral, and Negative. As mangrove management planning is ongoing, multinomial logistic regression provides important information on the influential predictors of both Positive and Negative attitudes and their differences. Models were assessed for Independence of Irrelevant Alternatives (IIA; Chatterjee \& Simonoff 2013).

\section{Results: Multinomial Regression}

Believing that sedimentation, runoff, and invasive species threaten Moloka'i's coast (measured through the coastal threat index) differentiated respondents with Negative or Positive attitudes towards mangroves from those with Neutral attitudes (Table 3.3). Some respondents view mangroves as providing sediment retention and runoff filtration. Other respondents who agreed that Moloka'i's coast was threatened had negative attitudes about mangroves suggesting that mangroves are part of the problem faced by the coastline. In addition, years lived on Moloka'i and perceived familiarity with costs and benefits of mangroves were significant predictors of individuals who held Negative, relative to Neutral attitudes. Longer term residents were more likely to have 
Neutral than Negative attitudes, and greater perceived familiarity with costs and benefits of mangroves increased the likelihood of having a Negative attitude. Positive attitudes were associated with the use of mangroves for benefits, whereas believing that mangroves hurt industry decreased the likelihood of having a Positive attitude.

Table D1. Multinomial logistic regression predicting general attitude towards non-native mangroves organized by category: Positive [ $\mathrm{n}=50]$, Neutral $[\mathrm{n}=38]$, and Negative $[\mathrm{n}=76]$, where Neutral is the reference category. Standard error in parentheses. $\mathrm{N}=164$. McFadden $\mathrm{R}^{2}=0.31$. $\mathrm{Chi}^{2}: \mathrm{p}<0.001$

\begin{tabular}{|c|c|c|c|c|c|c|}
\hline \multirow[b]{2}{*}{ Variables } & \multicolumn{3}{|c|}{ Neutral vs. Negative } & \multicolumn{3}{|c|}{ Neutral vs. Positive } \\
\hline & $\beta(S E)$ & & Odds & $\beta(\mathrm{SE})$ & & Odds \\
\hline Intercept & $-1.76(0.76)$ & & 0.17 & $-0.89(0.71)$ & & 0.41 \\
\hline \multicolumn{7}{|l|}{ PLACE CONNECTION } \\
\hline Lived on Moloka'i (Years) & $-0.04(0.02)$ & $*$ & 0.96 & $-0.03(0.03)$ & & 0.97 \\
\hline Lived in Hawai'i (Years) & $0.04(0.02)$ & & 1.04 & $0.01(0.02)$ & & 1.02 \\
\hline \multicolumn{7}{|l|}{ VALUES \& EXPERIENCE \& AWARENESS } \\
\hline Rely on mangroves for benefit & $-0.49(0.53)$ & & 0.61 & $1.24(0.55)$ & $*$ & 3.47 \\
\hline $\begin{array}{l}\text { Mangrove cost/benefit familiarity } \\
\text { COAST CONCERNS }\end{array}$ & $0.43(0.18)$ & $*$ & 1.54 & $0.29(0.19)$ & & 1.34 \\
\hline Condition of Moloka'i's southern coast & $-0.12(0.20)$ & & 0.89 & $0.28(0.21)$ & & 1.32 \\
\hline Coastal threat index & $1.30(0.31)$ & $* * *$ & 3.66 & $0.54(0.29)$ & $*$ & 1.71 \\
\hline Mangroves hurt industry & $-0.10(0.24)$ & & 0.90 & $-0.68(0.28)$ & $*$ & 0.50 \\
\hline Mangroves hurt cultural sites & $0.28(0.21)$ & & 1.32 & $-0.09(0.23)$ & & 0.91 \\
\hline
\end{tabular}

Significance levels: $*(<0.10),{ }^{* *}(<0.01),{ }^{* * *}(<0.001)$

\section{Discussion: Building blocks of attitude: Influential components}

Determining what variables are influencing attitudes is important as strong attitudes are known to be resistant to change, persist over time, lead to selective 
information processing, and predict behavior (Eagly \& Chaiken 1998). Both positive and negative attitudes towards mangroves were significantly influenced by perceived coastal threats such that respondents who agreed that sedimentation, invasive species, and chemical runoff posed threats to the Moloka'i coastline were more likely to have an opinion. Conflicting beliefs of whether mangroves are reducing coastal threats or contributing to them may provide an opportunity to improve knowledge gaps concerning the ecosystem services provided by Moloka'i's mangroves.

How long respondents have lived on Moloka'i and how well informed they consider themselves about mangroves' costs and benefits were influential in determining negative attitudes towards mangroves. Respondents that had lived on Moloka'i for a shorter duration were more likely to have a negative attitude towards mangroves perhaps indicating that individuals who spend more time on Moloka'i begin to perceive benefits of mangroves or become more normalized to their presence. Since time in an area can lead to a stronger connection to place (Gieryn 2000, Lewicka 2005) and place connection is a fundamental reason why people partake in action to protect natural areas (Norton and Hannon 1997, Vaske and Kobrin 2001, Lokocz et al. 2011), this connection may facilitate support for certain management actions.

Respondents who considered themselves well informed on costs and benefits of Moloka'i's mangroves were more likely to have a negative attitude towards mangroves. Whether those with negative attitudes had greater knowledge or whether negative perception or information had greater weight and a stronger impact on attitudes (Fiske 
and Taylor 1991, Cacioppo et al. 1997) is unclear and future research may clarify participants' actual level of knowledge and understanding.

Though previous studies have noted economic costs of aquatic invasive or nonnative species (Lovell et al. 2006), relatively few have quantified economic benefits (Schlaepfer et al. 2011).Positive attitudes towards Moloka'i's mangroves were more common among respondents who use mangroves for their benefit. Value is a demonstrated component of general environmental attitudes and can manifest in management support or opposition (Balram and Dragićević 2005, Selge et al. 2011). With $46 \%$ of respondents relying on mangroves for some benefit, a large proportion of residents have learned to utilize this non-native plant to their advantage. In addition to benefits, perceiving that mangroves did not impact industry led to a more positive view of mangroves. 